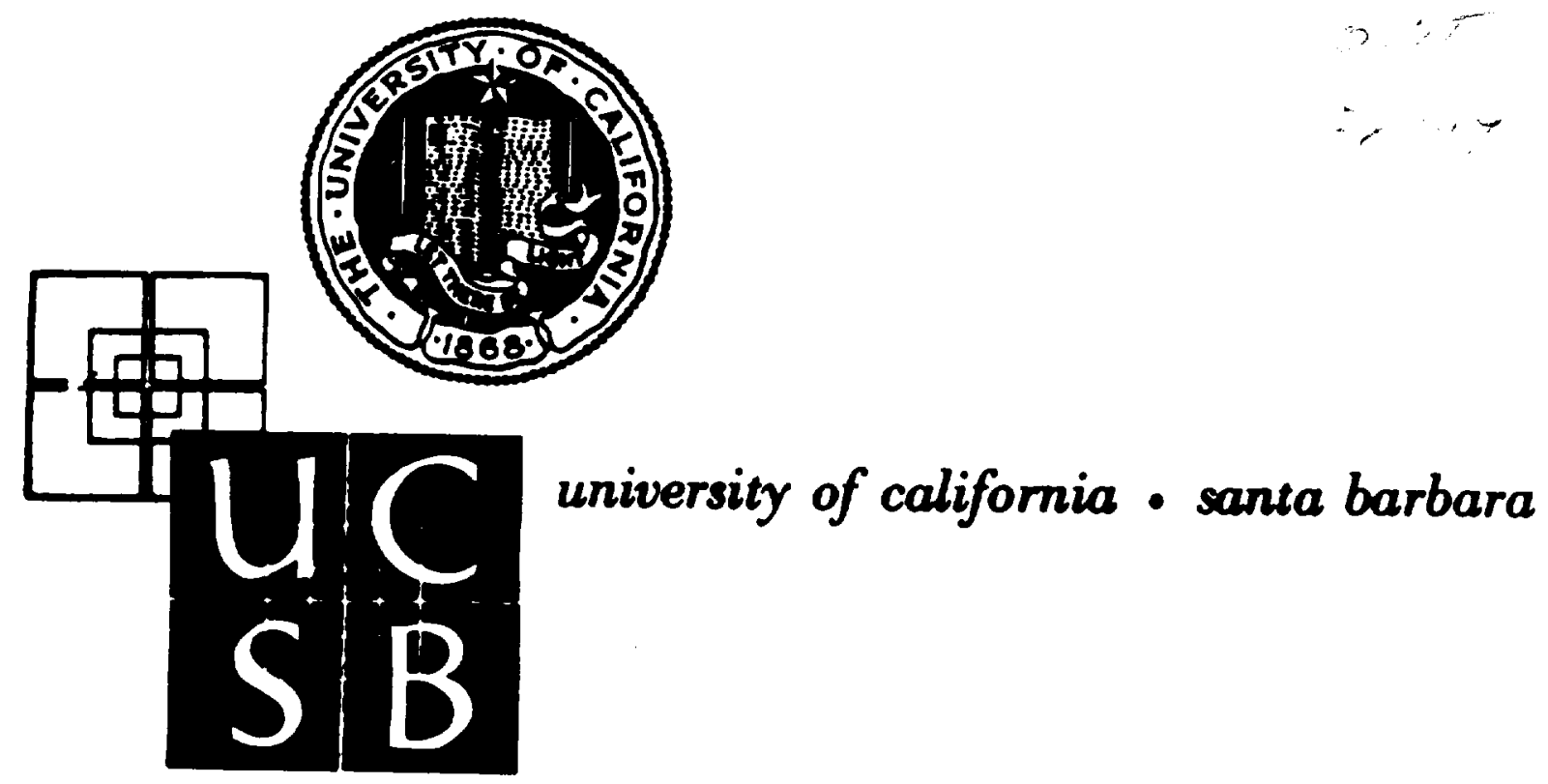

MECHANICAL PROPERTIES OF AEROGELS

Kelly E. Parmenter and Frederick Milstein

Department of Mechanical Engineering

University of California

Santa Barbara, CA 93106

National Aeronautics and Space Administration

Research Grant Number: NAG 2-930

FINAV FEB 271930

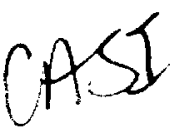




\section{MECHANICAL PROPERTIES OF AEROGELS}

Kelly E. Parmenter and Frederick Milstein

Department of Mechanical Engineering

University of California

Santa Barbara, CA 93106

National Aeronautics and Space Administration

Research Grant Number: NAG 2-930 


\section{ABSTRACT}

Aerogels are extremely low density solids that are characterized by a high porosity and pore sizes on the order of nanometers. Their low thermal conductivity and sometimes transparent appearance make them desirable for applications such as insulation in cryogenic vessels and between double paned glass in solar architecture. An understanding of the mechanical properties of aerogels is necessary before aerogels can be used in load bearing applications. In the present study, the mechanical behavior of various types of fiber-reinforced silica aerogels was investigated with hardness, compression, tension and shear tests. Particular attention was paid to the effects of processing parameters, testing conditions, storage environment, and age on the aerogels' mechanical response. The results indicate that the addition of fibers to the aerogel matrix generally resulted in softer, weaker materials with smaller elastic moduli. Furthermore, the testing environment significantly affected compression results. Tests in ethanol show an appreciable amount of scatter, and are not consistent with results for tests in air. In fact, the compression specimens appeared to crack and begin to dissolve upon exposure to the ethanol solution. This is consistent with the inherent hydrophobic nature of these aerogels. In addition, the aging process affected the aerogels' mechanical behavior by increasing their compressive strength and elastic moduli, while decreasing their strain at fracture. However, desiccation of the specimens did not appreciably affect the mechanical properties, even though it reduced the aerogel density by removing trapped moisture. Finally, tension and shear test results indicate that the shear strength of the aerogels exceeds the tensile strength. This is consistent with the response of brittle materials. Future work should concentrate on mechanical testing at cryogenic temperatures, and should involve more extensive tensile tests. Moreover, before the mechanical response of reinforced aerogels can be fully understood, more tests of unreinforced aerogels are necessary. Unreinforced aerogels are of particular use because their birefringent nature allows for visual determination of stress fields during mechanical testing. The success of any future tests depends on the availability of a large supply of quality specimens with well-documented preparation and storage histories. 


\section{TABLE OF CONTENTS}

ABSTRACT

TABLE OF CONTENTS

NOMENCLATURE iv

1. INTRODUCTION 1

2. TESTING PROCEDURES 4

2.1 Hardness Tests 4

2.2 Compression Tests $\quad 8$

2.3 Tensile Tests 9

$\begin{array}{lll}2.4 & \text { Shear Tests } & 10\end{array}$

2.5 Special Handling 11

3. RESULTS 12

$\begin{array}{lll}3.1 & \text { Hardness Tests } & 12\end{array}$

3.2 Compression Tests $\quad 22$

3.3 Correlation of Compressive Strength and Hardness 34

3.4 Tensile Tests 35

3.5 Shear Tests 38

4. SUMMARY \& CONCLUSIONS 39

$\begin{array}{ll}\text { REFERENCES } & 41\end{array}$

APPENDIX A - Specimen Dimensions A.1

APPENDIX B - Hardness Results $\quad$ B.1

APPENDDX C - Hardness Trend Data $\quad$ C. 1

APPENDIX D - Compression Results: Tests in Air D.

APPENDIX E - Compression Results: Tests in Ethanol E.1

APPENDDX F - Compression Results: Specimens Aged in Air F.1

APPENDIX G - Compression Results: Specimens Aged in Air and Desiccated G.1 


\section{NOMENCLATURE}
A indent surface area $\left(\mathrm{mm}^{2}\right)$
a,b dimensions (mm)
D indenter diameter (mm)
E elastic modulus (MPa)
F $\operatorname{load}(\mathrm{N})$
$\mathrm{H}$ hardness (MPa)
L maximum load (N)
S compressive strength $(\mathrm{MPa})$
$\mathrm{V}$ shear force (N)

\section{Greek Symbols}

$\delta \quad$ indent depth ( $\mathrm{mm})$

$\varepsilon_{\mathrm{f}}$ strain at fracture $(\mathrm{mm} / \mathrm{mm})$

$\sigma$ standard deviation of data 


\section{INTRODUCTION}

Silica aerogels are high porosity, extremely low density solids composed of interconnected particles that form an "open" microstructure. As a result of the low solid thermal conductivity of silica, and pore sizes on the order of nanometers, the thermal conductivity of silica aerogel is very low. The low thermal conductivity along with a sometimes transparent appearance make silica aerogels desirable for a wide variety of insulating applications, including cover layers for windows and solar collectors, and as replacements for hazardous CFC insulating foams in cryo-vessels [Fricke, 1992]. However, the same properties of aerogels that make them such good insulators (high porosity and low solid thermal conductivity) also make them inherently fragile and brittle. Thus, their use in load-bearing applications is challenging. Currently, attention is being placed on improving the mechanical properties of aerogels without sacrificing their other unique properties.

Relatively few experiments to determine the mechanical properties of aerogels have been carried out to date. The experiments that are most applicable to the present work include the following tests done with unreinforced silica aerogels. No results for fiberreinforced silica aerogels have been found in the literature. In earlier work, Gronauer et al. [1986] measured the Young's modulus of unreinforced silica aerogels using sound velocity measurement techniques. Subsequently, Woignier and Phalippou measured the Young's modulus and fracture strength with a three point flexural technique, and the toughness with a single edge notched beam in three point bending technique. More recently, ultrasonic and static compression experiments have been undertaken to determine the elastic modulus [Cross et al., 1989; Gross and Fricke, 1992; Gross et al., 1992].

The present work investigates the mechanical behavior of fiber-reinforced and unreinforced silica aerogels. Silica aerogel is manufactured by first dissolving an alcoholate (silicon methylate (1)) in an organic solvent (methanol (1), 5-30\% by volume). The mixture is then hydrolyzed at room temperature by adding between 2 and 20 moles of water, and silica is produced. After the $\mathrm{pH}$ is adjusted as desired, the mixture is put into an autoclave and heated to above the solvent's critical temperature to dry the solvent while 
eliminating its saturated vapor phase. (If not supercritically dried, the porous structure is destroyed by surface tension forces between the vapor-liquid interface.) The vapor is then evacuated, and the product is cooled with dry nitrogen gas [Teichner et al., 1976].

Two processing parameters--the mass percentage of fiber reinforcements and the target density--were altered to obtain aerogels with differing physical characteristics. The target density is a rough prediction of the final aerogel density based on the mass of the original ingredients and the volume of the aerogel mold. It is useful for comparing the properties of aerogels manufactured with the same target density, but it does not reflect the final aerogel density. The final aerogel densities are significantly larger than the target densities. The mass percentage of reinforcements was varied from $0 \%$ to $25 \%$, and the target density was varied from $40 \mathrm{~kg} / \mathrm{m}^{3}$ to $80 \mathrm{~kg} / \mathrm{m}^{3}$. The reinforced aerogels contained a mixture of $68 \%$ silica, $20 \%$ alumina, and $12 \%$ aluminaborosilicate fibers, with diameters of $3 \mu \mathrm{m}, 2-4 \mu \mathrm{m}$, and $8 \mu \mathrm{m}$, respectively. All fibers had lengths of $1.27 \mathrm{~cm}$. Table 1.1 is a summary of the materials received and tested.

The mechanical behavior of the aerogels was studied by traditional techniques of mechanical testing (including hardness, compression, and tension tests), and modifications thereof. Particular attention was paid to the effects of processing parameters, testing conditions, storage environment, and age on the aerogels' mechanical behavior. The following paragraphs summarize the procedures and findings of this study. 
Table 1.1

Summary of Materials

\begin{tabular}{|c|c|c|c|c|c|c|}
\hline $\begin{array}{c}\text { NASA } \\
\text { Batch } \\
\text { Number }\end{array}$ & $\begin{array}{l}\text { Specimen } \\
\text { Name }\end{array}$ & $\begin{array}{c}\text { Number } \\
\text { of } \\
\text { Specimens }\end{array}$ & $\begin{array}{c}\text { Fiber } \\
\text { Percentage } \\
(\%) \\
\end{array}$ & $\begin{array}{l}\text { Target } \\
\text { Density } \\
\left(\mathbf{k g} / \mathbf{m}^{3}\right)\end{array}$ & $\begin{array}{c}\text { Final } \\
\text { Density } \\
\left(\mathbf{k g} / \mathbf{m}^{3}\right)\end{array}$ & Types of Tests \\
\hline 1,2 & $\cdot$ & $\sim 6$ & unreinforced & - & - & $\begin{array}{c}\text { Vickers, Knoop, Photoelasticity, } \\
\text { Hardness }\end{array}$ \\
\hline 1,2 & - & $\sim 6$ & reinforced & - & - & Vickers, Knoop, Hardness \\
\hline 3 & $1^{*}$ & 1 & reinforced & - & 250 & Hardness (time at max displacement) \\
\hline 3 & $2 *$ & 1 & reinforced & - & 300 & Hardness (load dependence) \\
\hline 3 & $4^{*}$ & 1 & reinforced & - & 210 & Hardness (rate dependence) \\
\hline 3 & $5^{*}$ & 1 & reinforced & - & 240 & Hardness \\
\hline 3 & $A^{*}$ & 1 & 25 & 50 & 200 & Hardness \\
\hline 3 & $\mathrm{~B}^{*}$ & 1 & 10 & 50 & 220 & Hardness \\
\hline 4 & $1^{*}$ & 11 & 25 & 80 & 240 & Compression (Air) \\
\hline 4 & $2^{*}$ & 15 & 25 & 80 & 240 & $\begin{array}{c}\text { Hardness, Compression (Air, } \\
\text { Ethanol) }\end{array}$ \\
\hline$\overline{4}$ & $3^{*}$ & 15 & 25 & 80 & 240 & $\begin{array}{c}\text { Hardness, Compression (Air. } \\
\text { Ethanol, Desiccated) }\end{array}$ \\
\hline 4 & $1^{*}$ & 5 & 10 & 50 & 230 & Compression (Air, Ethanol) \\
\hline 4 & $2 *$ & 15 & 10 & 50 & 230 & Hardness, Compression (Air) \\
\hline 5 & $4^{* *}$ & 2 & unreinforced & - & 240 & Hardness \\
\hline 5 & $5^{* *}$ & 2 & unreinforced & - & 240 & Compression (Air) \\
\hline 5 & $6 *$ & 2 & unreinforced & - & 240 & Compression (Air) \\
\hline 6 & $9 * *$ & 5 & 5 & 40 & 260 & Compression (Air) \\
\hline 6 & $12^{* *}$ & 2 & 5 & 40 & 260 & Hardness \\
\hline 6 & $14^{* *}$ & 2 & 10 & 40 & 190 & Hardness \\
\hline 6 & $15^{* *}$ & 6 & 10 & 40 & 190 & Compression (Air) \\
\hline 7 & $5^{* *}$ & 7 & 25 & 40 & 190 & Hardness, Compression (Air) \\
\hline 7 & $6^{* *}$ & 7 & 25 & 40 & 190 & Hardness, Compression (Air) \\
\hline 7 & $7 * *$ & 6 & 25 & 40 & 190 & Hardness, Compression (Air) \\
\hline 7 & $14^{* *}$ & 1 & 10 & 80 & 330 & Hardness \\
\hline 7 & $16^{* *}$ & 10 & 10 & 80 & 330 & Hardness, Compression (Air) \\
\hline 7 & $17^{* *}$ & 7 & 10 & 80 & 330 & Hardness, Compression (Air) \\
\hline 7 & $35^{* *}$ & 6 & 5 & 80 & 320 & Hardness, Compression (Air) \\
\hline 7 & $2 * *$ & 1 & 25 & 40 & 190 & Tension \\
\hline 7 & $24^{* *}$ & 2 & 10 & 80 & 330 & Tension \\
\hline 7 & $27 * *$ & 2 & 10 & 80 & 330 & Tension \\
\hline 7 & $33^{* *}$ & 2 & 25 & 80 & 240 & Tension \\
\hline 7 & $34^{* *}$ & 1 & 25 & 80 & 240 & Tension \\
\hline 7 & $38 * *$ & $1 \cdot$ & 5 & 80 & 320 & Tension \\
\hline 7 & $18 * *$ & 1 & 10 & 80 & 330 & Shear \\
\hline 7 & $19^{* *}$ & 1 & 10 & 80 & 330 & Shear \\
\hline 7 & $21^{* *}$ & 1 & 10 & 80 & 330 & Shear \\
\hline 7 & $28^{* *}$ & 1 & 10 & 80 & 330 & Shear \\
\hline 7 & $29^{* *}$ & 1 & 10 & 80 & 330 & Shear \\
\hline 7 & $31^{* *}$ & 1 & 25 & 80 & 240 & Shear \\
\hline
\end{tabular}

* Parmenter \& Milstein Numbering System

** NASA Numbering System 


\section{TESTING PROCEDURES}

\subsection{Hardness Tests}

Hardness tests were the first type of material testing technique initiated because of the non-destructive nature and, for many materials, the ease of application of such tests. Generally hardness tests yield pertinent information about the response of a material at the expense of only a few indents on the material's surface, compared with the complete destruction of specimens often associated with tensile and compression tests.

\section{Traditional Methods of Indentation}

Initially, traditional indentation methods such as Vickers and Knoop were employed for hardness determination. Unfortunately, these methods failed to work on the silica aerogel specimens. At even very small loads $(\leq 0.245 \mathrm{~N})$, the indentation pressure was too large for these fragile materials, and resulted in cracks and surface cave-ins. In addition, because the aerogels absorb and transmit light more readily than they reflect it, it was difficult to obtain enough contrast in the magnified images of the indents to make accurate measurements of indent size. This was particularly true for very low loads, and for the more opaque (fiber-reinforced) aerogels. Attempts to use dyes to improve the contrast of the magnified images were unsuccessful because the dyes caused cracks on the surfaces of the aerogels (see Section 2.5). Examples of indents made in semi-transparent (unreinforced) aerogels are provided in the following two figures. Figure 2.1 is a photograph of an indent made with a Vickers microindenter at a load of $0.981 \mathrm{~N}$. Figure 2.2 is a series of photographs of an indent made with a Knoop microindenter at a load of $1.961 \mathrm{~N}$.

\section{Alternative Indentation Approach}

Results of experiments with Vickers and Knoop hardness tests demonstrated the need to substantially reduce indentation pressure in order to deform the aerogels plastically without creating cracks. In an alternative approach, the indents were made with a 19.05 
$\mathrm{mm}$ diameter steel ball, at loads of $18.2 \mathrm{~N}$ and smaller. The ball and socket fixture was secured to the crosshead of a displacement-controlled Instron 1123 testing machine. The load was measured with a compression load cell (range $=0$ to $981 \mathrm{~N}$ ), and the crosshead displacement was measured with a linear variable differential transformer (LVDT) (range $= \pm 1.27 \mathrm{~mm}$ ). All tests were conducted under ambient conditions. An initial preload of $2.02 \mathrm{~N}$ was applied to minimize surface effects. The load was subsequently applied to the "full-loading" value and then reduced to the preload value where the net indentation value, $\delta$, was determined. The indent surface area, $\mathrm{A}$, was approximated from the indent depth and ball diameter, $\mathrm{D}$, with the following relation:

$$
\mathrm{A}=\pi \mathrm{D} \delta .
$$

The hardness, $\mathrm{H}$, was defined as the maximum load, $\mathrm{L}$, divided by the indent surface area:

$$
H=\frac{L}{A} .
$$

\section{Test Parameters}

The influences of three testing parameters on the hardness were investigated. First, the duration of time at maximum displacement was varied to see if the aerogels were prone to stress relaxation, or creep. During these tests, specimens were loaded at a rate of $0.102 \mathrm{~mm} / \mathrm{min}$ until a force of approximately $14 \mathrm{~N}$ was reached, and then the displacement was held constant for a specified period of time before the load was reduced. The time at maximum displacement ranged from 0 to 60 minutes. Second, the maximum load was varied to see how load sensitive the hardness tests were. The peak loads ranged from 10.2 to $18.3 \mathrm{~N}$. Loads higher than $18.3 \mathrm{~N}$ tended to crack the specimens and loads smaller than $10.2 \mathrm{~N}$ tended to yield indecernible results. Third, the rate dependence of the hardness was studied by varying the crosshead speed from 0.025 to $0.203 \mathrm{~mm} / \mathrm{min}$. 


\section{Photoelasticity}

Tests were performed to determine whether the transparent, unreinforced, aerogels would exhibit birefringence (photoelasticity) when indented; this is of interest because such birefringence could be used as a means of characterizing internal stresses in the material. For these tests, a polarizing lens was placed behind the specimen, an analyzing lens was placed in front of the specimen, and a fiber-optic white light source was used for illumination. The aerogels were then viewed and filmed with a video camera while being indented with the steel ball.

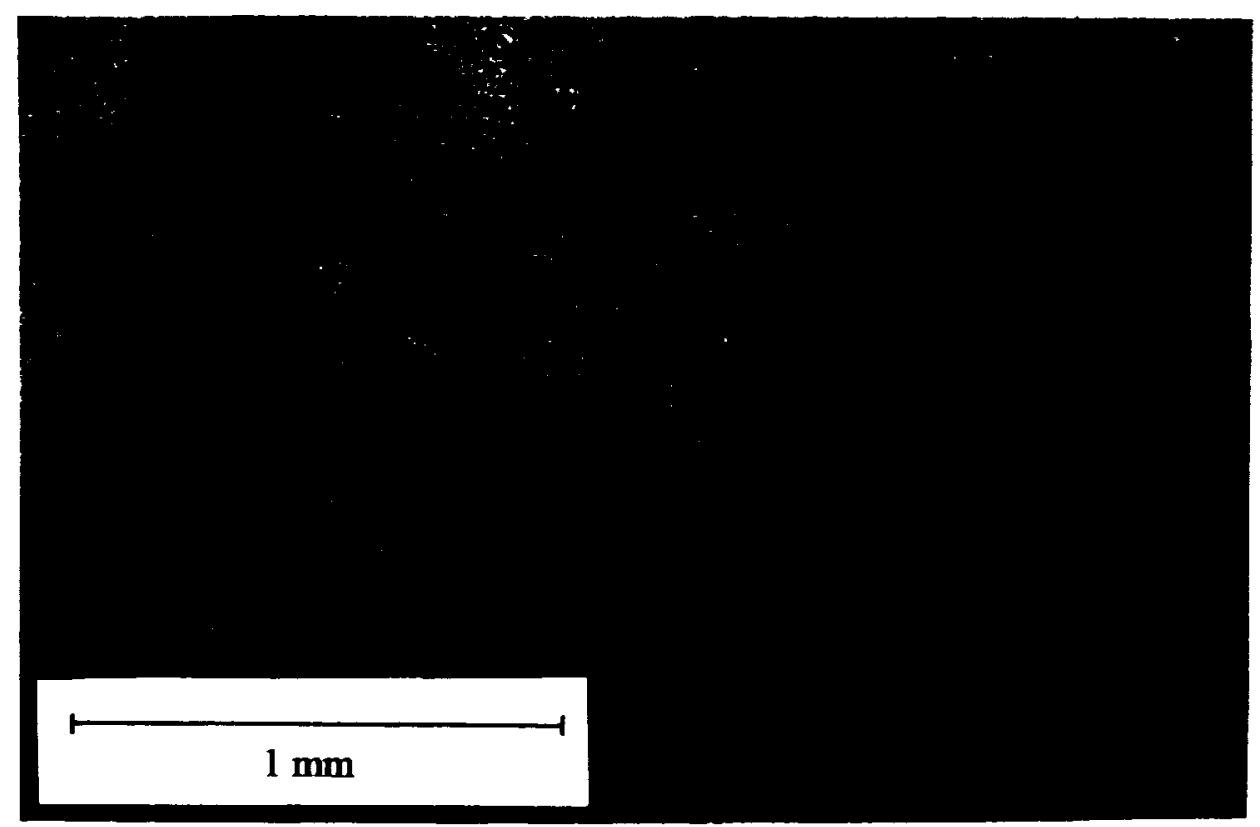

Figure 2.1

Vickers Indentation at $0.981 \mathrm{~N}$ Load 


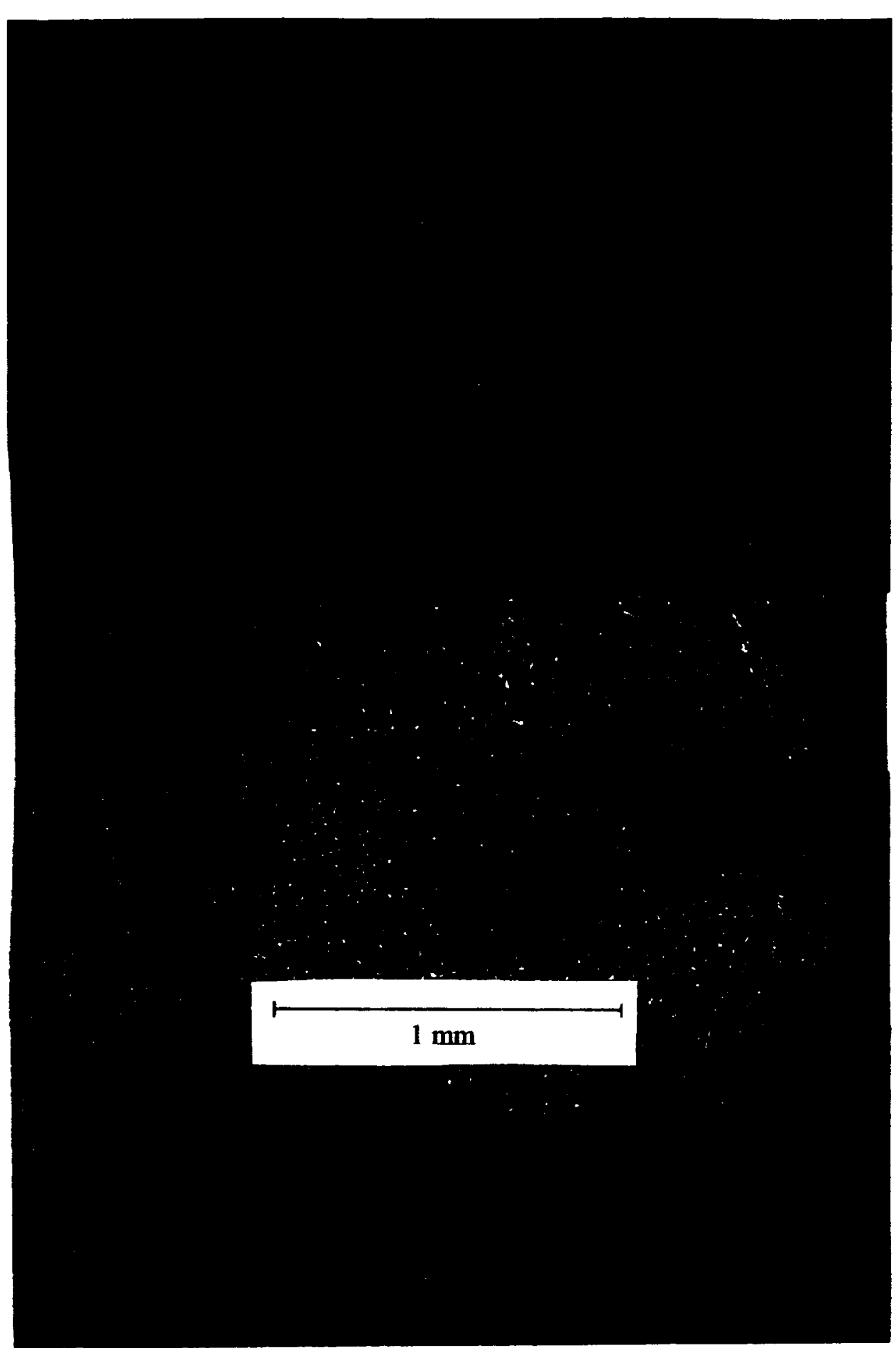

Figure 2.2

Knoop Indentation at 1.961 N Load 


\subsection{Compression Tests}

Compression tests were performed with the same displacement-controlled Instron 1123 testing machine used for hardness tests. Compression specimens were machined from raw material into rectangular blocks. The blocks had square cross sections and heights equal to twice the length of a side (see Appendix $A$ for dimensions). The specimens were placed, one at a time, between the top and bottom portions of a compression fixture, and were loaded at a rate of $0.102 \mathrm{~mm} / \mathrm{min}$ by lowering the top portion of the fixture (which was secured to the crosshead) until they fractured macroscopically. The bottom portion of the compression fixture was a stationary flat plate whereas the top portion consisted of a "frictionless" hemisphere secured into a socket with vacuum grease. The top portion was thus self-aligning. The load was measured with a compression load cell (range $=0$ to $981 \mathrm{~N}$ ), and the crosshead displacement was measured with a LVDT (range $= \pm 6.35 \mathrm{~mm}$ ). The majority of tests were conducted under ambient conditions.

The Load-Displacement curves were converted to Stress-Strain curves by dividing the loads by the original cross-sectional areas of the specimens, and the displacements by the original heights of the specimens. The compressive strength, the strain at fracture, and two secant moduli were determined from the Stress-Strain data.

\section{Tests in Ethanol}

Tests were conducted in a liquid ethanol environment at ambient temperatures to determine ethanol's applicability for use in future cryogenic experiments. If compression results in ethanol matched compression results in air, then ethanol would be a potential medium in which to cool specimens to cryogenic temperatures. For these tests, the specimens were submerged in a petri dish full of ethanol, and tested with the procedure for compression tests described above. 


\section{Effects of Age and Storage Environment}

The influences of age and storage environment on aerogel compression results were quantified by comparing Stress-Strain curves for aerogels that had different storage histories. Two types of aerogels were investigated. The first type of aerogel was manufactured with a target density of $50 \mathrm{~kg} / \mathrm{m}^{3}$ and a fiber percentage of $10 \%$. Tests were performed on compression specimens machined from two different batches of bulk material. Specimens from one batch were tested within one week of being machined, and specimens from the other batch were stored in an air environment, under ambient conditions, for 2 months before being tested. The second type of aerogel studied was manufactured with a target density of $80 \mathrm{~kg} / \mathrm{m}^{3}$ and a fiber percentage of $25 \%$. For this type of aerogel, all tests were done on specimens machined from the same batch of bulk material. Some compression specimens were tested within a week of being machined, some were tested after being stored in an air environment, under ambient conditions, for approximately 2 months, and the remaining were tested after being stored in the same air environment for two months and then in a desiccator at ambient temperature for 10 days. The dessicator's purpose was to remove any absorbed moisture from the specimens.

\subsection{Tensile Tests}

Tensile tests were performed with the displacement-controlled Instron 1123 testing machine described previously. The aerogel specimens were machined from bulk material into "dog-bone" shapes with the dimensions provided in Appendix A. The specimens were inserted and held with pins between the top and bottom portions of a tension fixture, and were then loaded by raising the top portion at a rate of $0.102 \mathrm{~mm} / \mathrm{min}$ until they fractured macroscopically. The bottom portion was stationary, while the top portion was secured to the load cell with a universal coupling. The load cell's range was 0 to $981 \mathrm{~N}$. The crosshead displacement was determined from the Instron's internal displacement gage. Strain gages were not used to measure the actual strain within the gage length of the specimens because of the extreme difficulty in adhering gages without damaging or altering the mechanical properties of the aerogels. All tensile tests were conducted under ambient conditions. 


\subsection{Shear Tests}

Tests were conducted on the Instron 1123 with notched beam specimens (commonly referred to as Iosipescu specimens) in antisymmetric four point bending. Figure 2.3 shows a diagram of the loading arrangement. The dimensions of an Iosipescu specimen are provided in Appendix A.

Under the appropriate conditions, a specimen tested in this way will have virtually pure shear within the section of the notch-root axis [Iosipescu, 1963]. Since brittle materials fail in tension before they fail in shear, this type of test will yield the lower bound of the shear strength (i.e., the actual shear strength will be greater than the indicated shear strength at failure) rather than the ultimate shear strength if the specimens tested behave as truly brittle materials. The load was measured with a compression load cell (range $=0$ to $981 \mathrm{~N}$ ), and the displacement was determined from the Instron's internal displacement gage. The crosshead speed was set at $0.102 \mathrm{~mm} / \mathrm{min}$, and all experiments were conducted under ambient conditions.

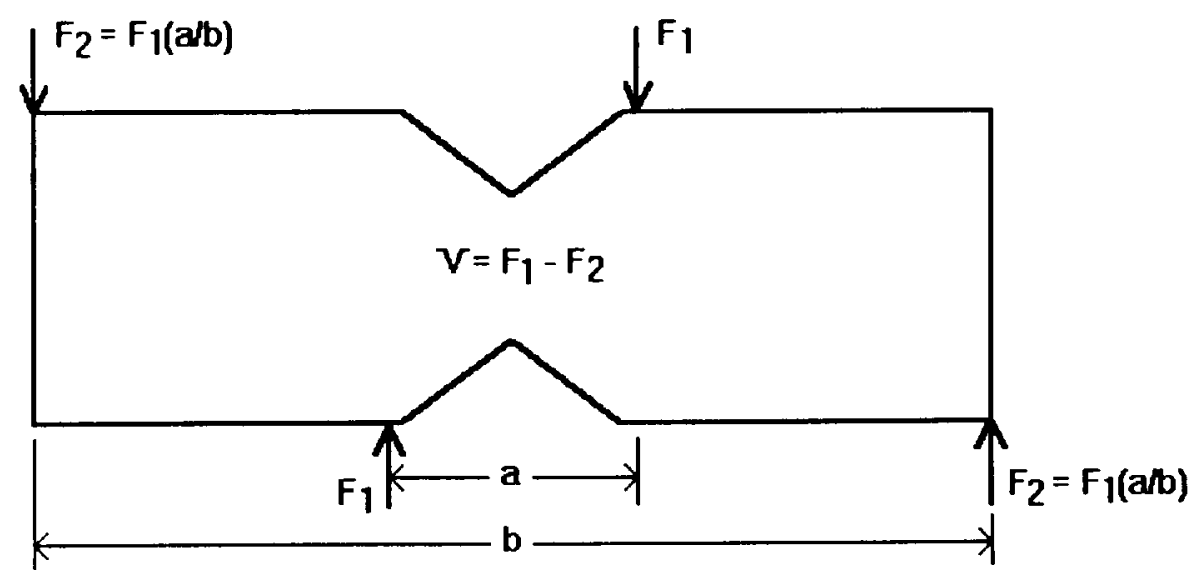

Figure 2.3

Antisymmetric Four Point Bending Arrangement 


\subsection{Special Handling}

It was observed that the aerogels are soluble in water (hydrophobic) and other liquids. In addition, perspiration from fingers and hands can cause micro-cracks to form on surfaces that have been handled without gloves. To prevent this from occurring, all test specimens were handled with gloves. Moreover, special care was taken to degrease and dry all equipment that came in contact with the specimens. 


\section{RESULTS}

\subsection{Hardness Tests}

A summary of the hardness results for each different type of aerogel tested is provided in Table 3.1. In addition, plots depicting the relationships between target density and hardness and target density and final density, as well as a representative LoadDisplacement curve are shown in Figures 3.1 through 3.3, respectively. The LoadDisplacement curve is from an experiment with an unreinforced aerogel specimen. The bulk of the hardness tests were carried out with a maximum load of approximately $14 \mathrm{~N}$, a crosshead speed of $0.102 \mathrm{~mm} / \mathrm{min}$, and no time delay at maximum load. For the aerogel manufactured with a target density of $40 \mathrm{~kg} / \mathrm{m}^{3}$ and a fiber percentage of $10 \%$, the maximum load was lowered to approximately $10 \mathrm{~N}$ because of the extreme softness of the material. Appendix B contains detailed hardness results and representative LoadDisplacement curves for each type of specimen tested.

The results in Table 3.1 and Figures 3.1 and 3.2 indicate that the hardness is a strong function of fiber percentage and target density. The hardness tends to increase with an increase in target density for a given fiber percentage, and decrease with an increase of fiber percentage for a given target density. However, an exception to the second trend is found with specimens of target density equal to $40 \mathrm{~kg} / \mathrm{m}^{3}$. For these specimens, the hardness of the $10 \%$ fiber-reinforced material is smaller than the hardness of the $25 \%$ fiber-reinforced material.

Results of the three investigations of the influence of testing parameters are depicted graphically in Figures 3.4 through 3.6. Detailed hardness results are provided in Appendix C. Figure 3.4 shows the variation of hardness with time at maximum displacement. Each datum point reflects a separate indentation. The displacement was held constant for time periods ranging from 0 to 60 minutes. The results indicate that the load relaxed, the indentation depth increased, and therefore, the hardness decreased, with an increase in time at maximum displacement. The amount of relaxation was rapid at first, and then gradually leveled off. These results are indicative of a creeping material. Figure 3.5 
shows the influence of maximum applied load upon hardness. The important result here is that hardness is not sensitive to load, within the scatter due to material inhomogeneities found in many of the materials. Figure 3.6 depicts the influence of cross-head speed (or loading rate) on the measured hardness. Again, the important conclusion is that crosshead speed is not a significant variable in the range of $\sim 0.05$ to $0.2 \mathrm{~mm} / \mathrm{min}$.

Table 3.1

Summary of Hardness Results

\begin{tabular}{|c|c|c|c|c|c|}
\hline $\begin{array}{c}\text { Fiber } \\
\text { Percentage } \\
(\%)\end{array}$ & $\begin{array}{l}\text { Target } \\
\text { Density } \\
\left(\mathrm{kg} / \mathrm{m}^{3}\right)\end{array}$ & $\begin{array}{c}\text { Final } \\
\text { Density } \\
\left(\mathbf{k g} / \mathrm{m}^{3}\right)\end{array}$ & $\begin{array}{c}\text { Number of } \\
\text { Indents }\end{array}$ & $\begin{array}{c}\text { Mean } \\
\text { Hardness } \\
\left(\text { MPa }^{\star}\right)\end{array}$ & $\begin{array}{c}\text { Standard } \\
\text { Deviation, } \sigma \\
(\mathrm{MPa})\end{array}$ \\
\hline 0 & - & 240 & 12 & 5.37 & 0.47 \\
\hline 5 & 40 & 260 & 10 & 2.20 & 0.26 \\
\hline 5 & 80 & 320 & 6 & 5.67 & 1.84 \\
\hline 10 & 40 & 190 & 7 & 0.97 & 0.04 \\
\hline 10 & 50 & 230 & 6 & 3.71 & 0.55 \\
\hline 10 & 80 & 330 & 12 & 5.37 & 2.71 \\
\hline 25 & 40 & 190 & 14 & 1.54 & 0.06 \\
\hline 25 & 50 & 200 & 24 & 2.02 & 0.24 \\
\hline 25 & 80 & 240 & 10 & 2.11 & 0.21 \\
\hline
\end{tabular}




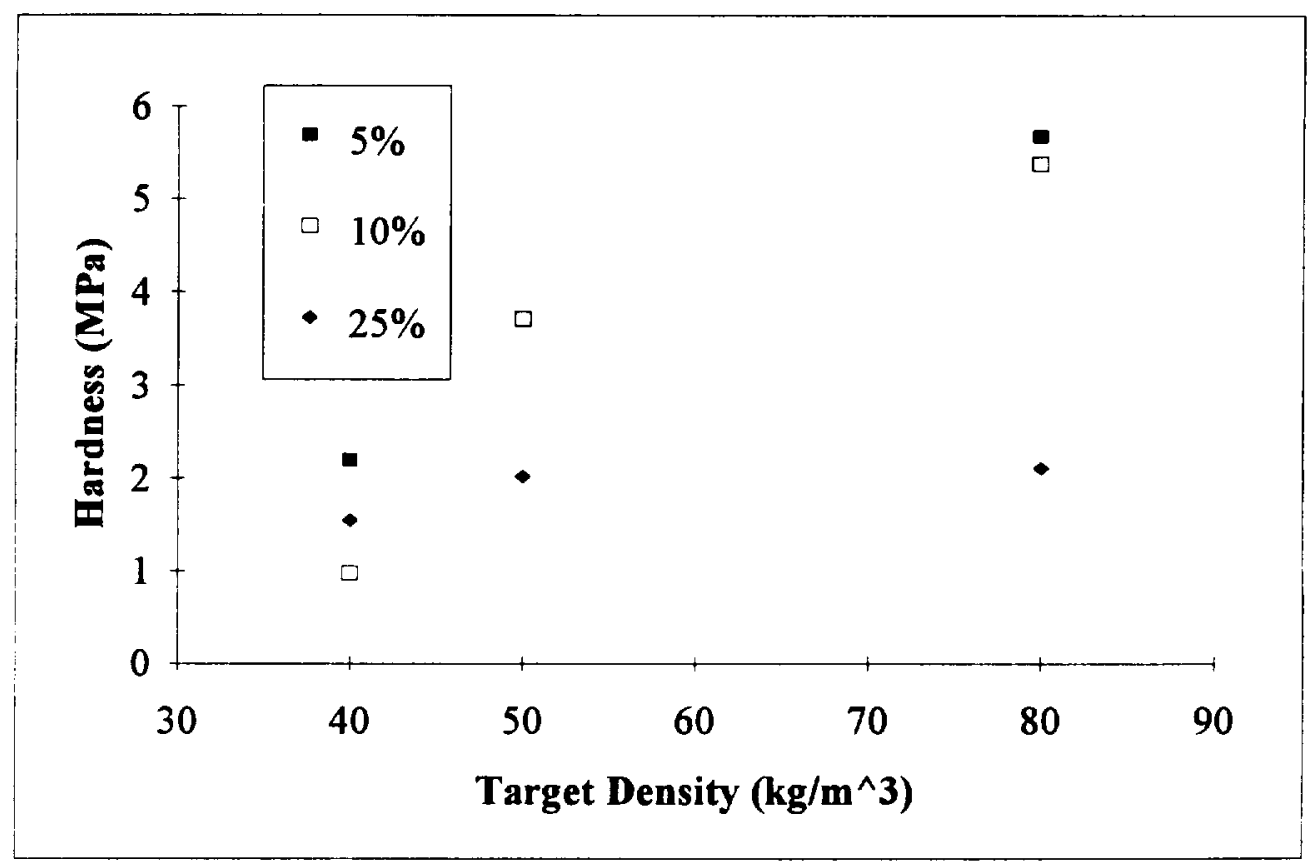

Figure 3.1

Hardness vs. Target Density

with Fiber Percentage as a Parameter 


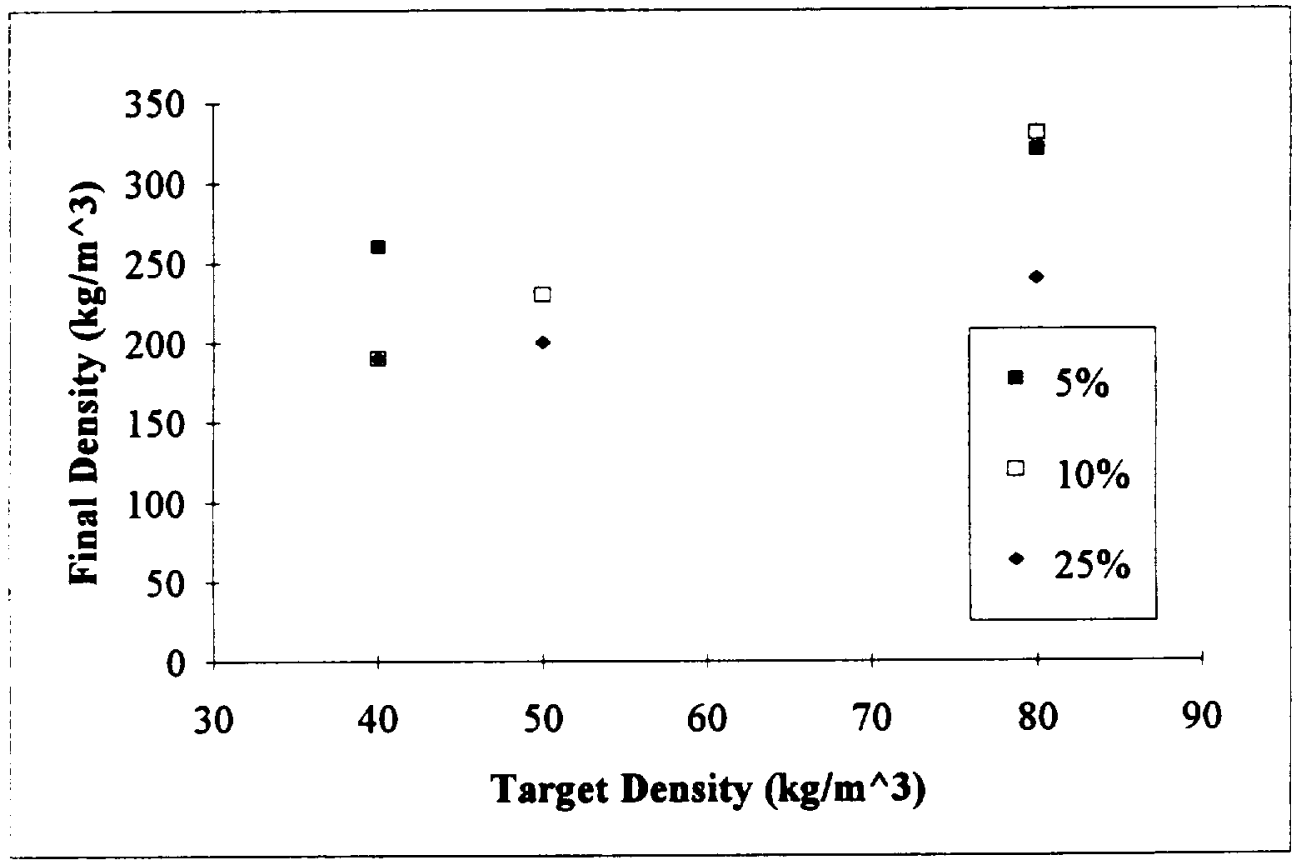

Figure 3.2

Final Density vs. Target Density

with Fiber Percentage as a Parameter 


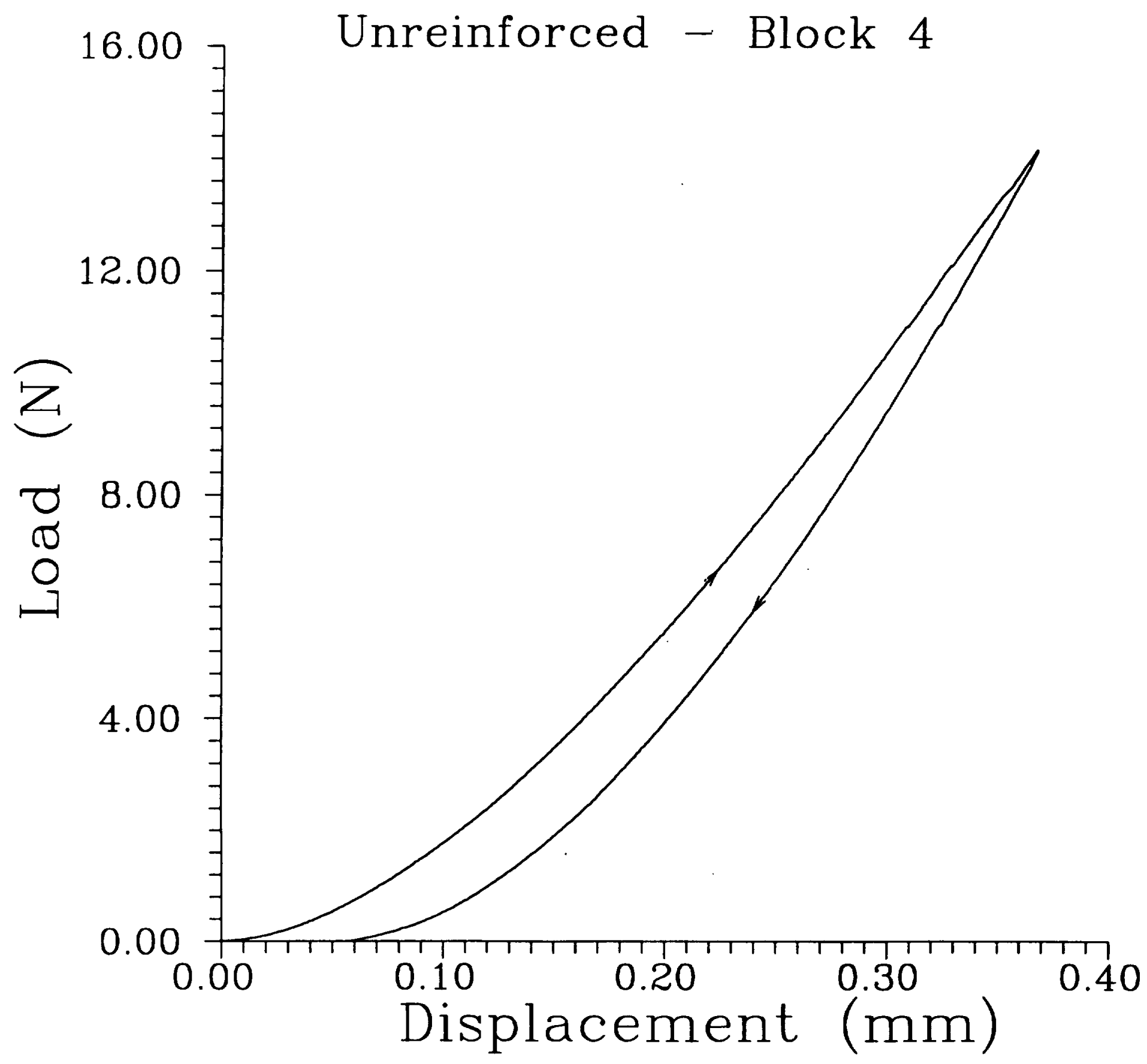

Figure 3.3

Load vs. Displacement Curve for Unreinforced Silica Aerogel using Hardness Measurement 


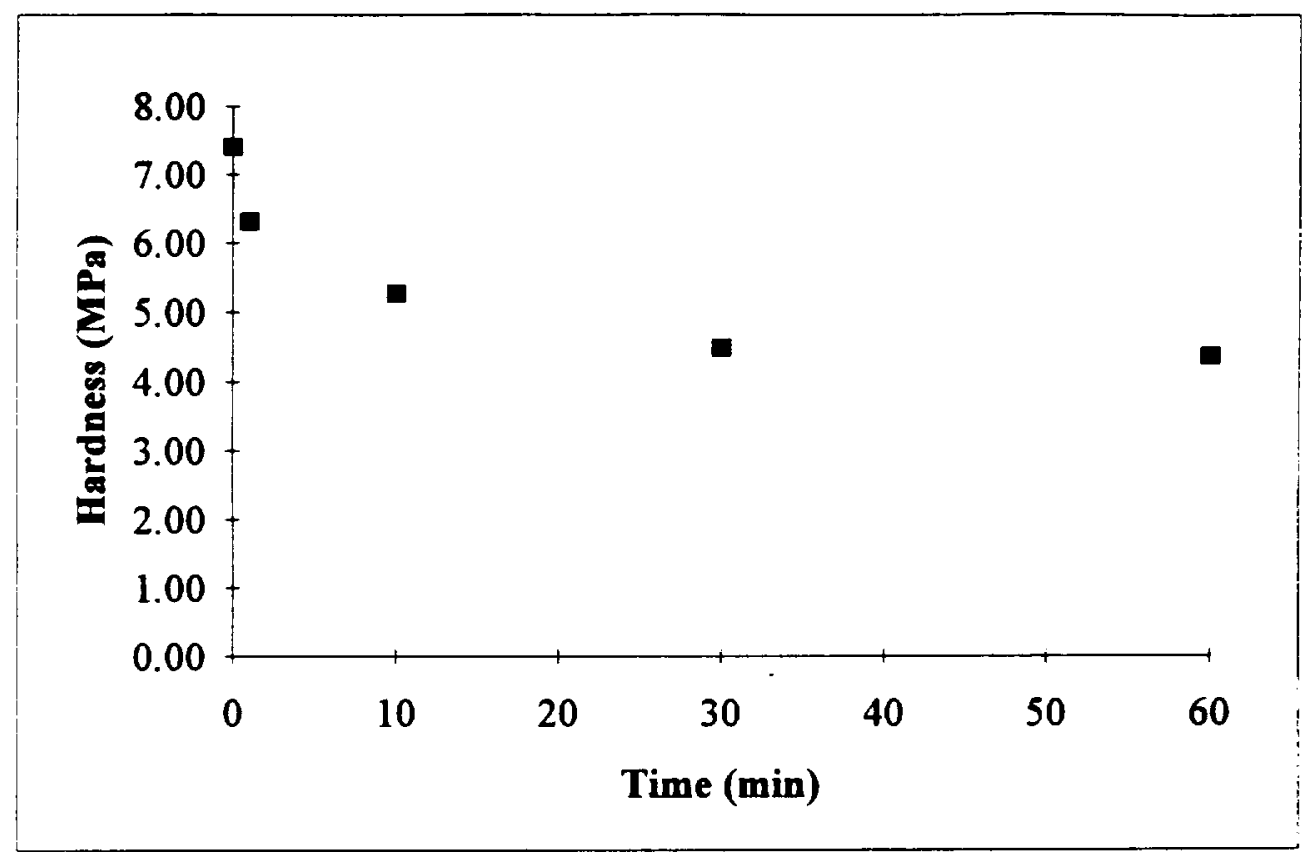

Figure 3.4 - Relaxation Test

Hardness vs. Time at Maximum Displacement 


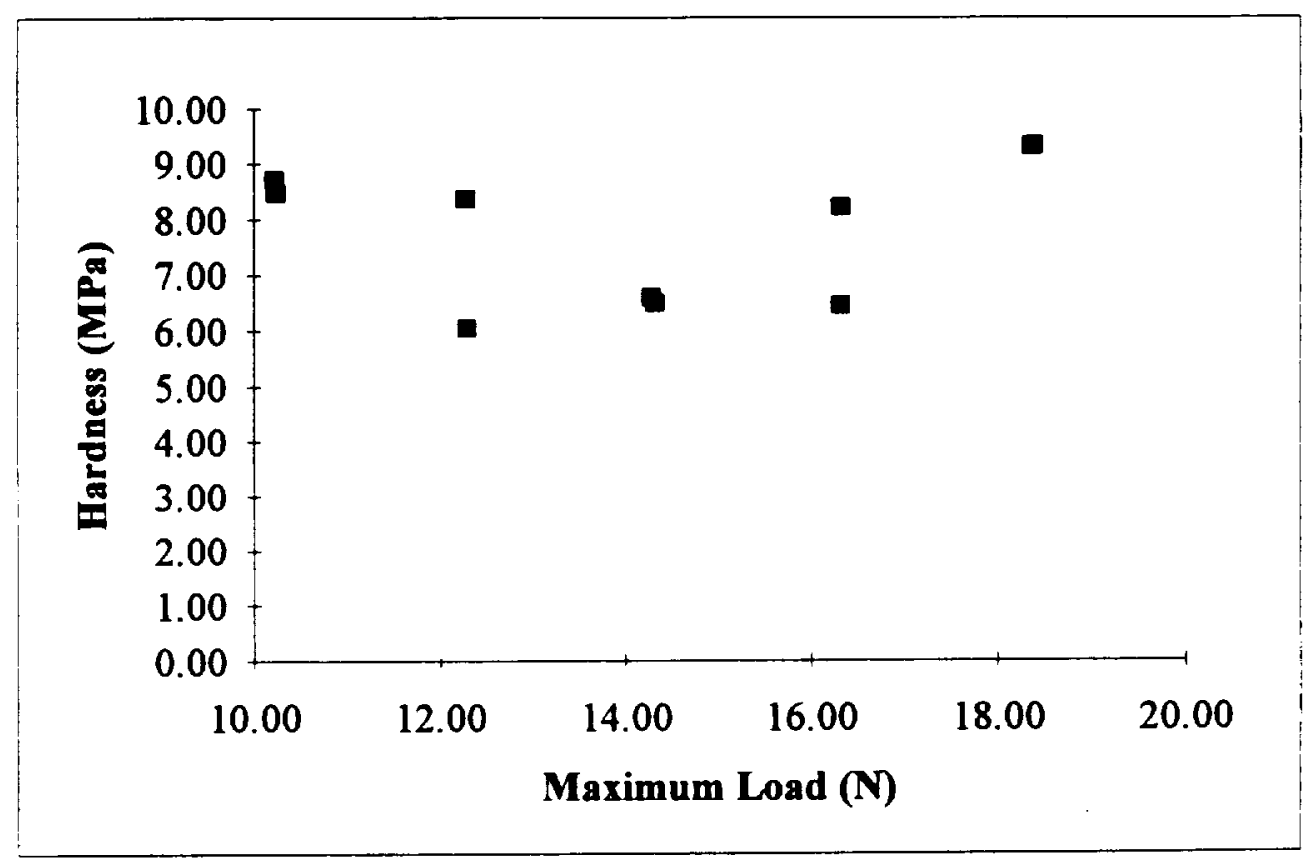

Figure 3.5 - Load Variation Test

Hardness vs. Maximum Load 


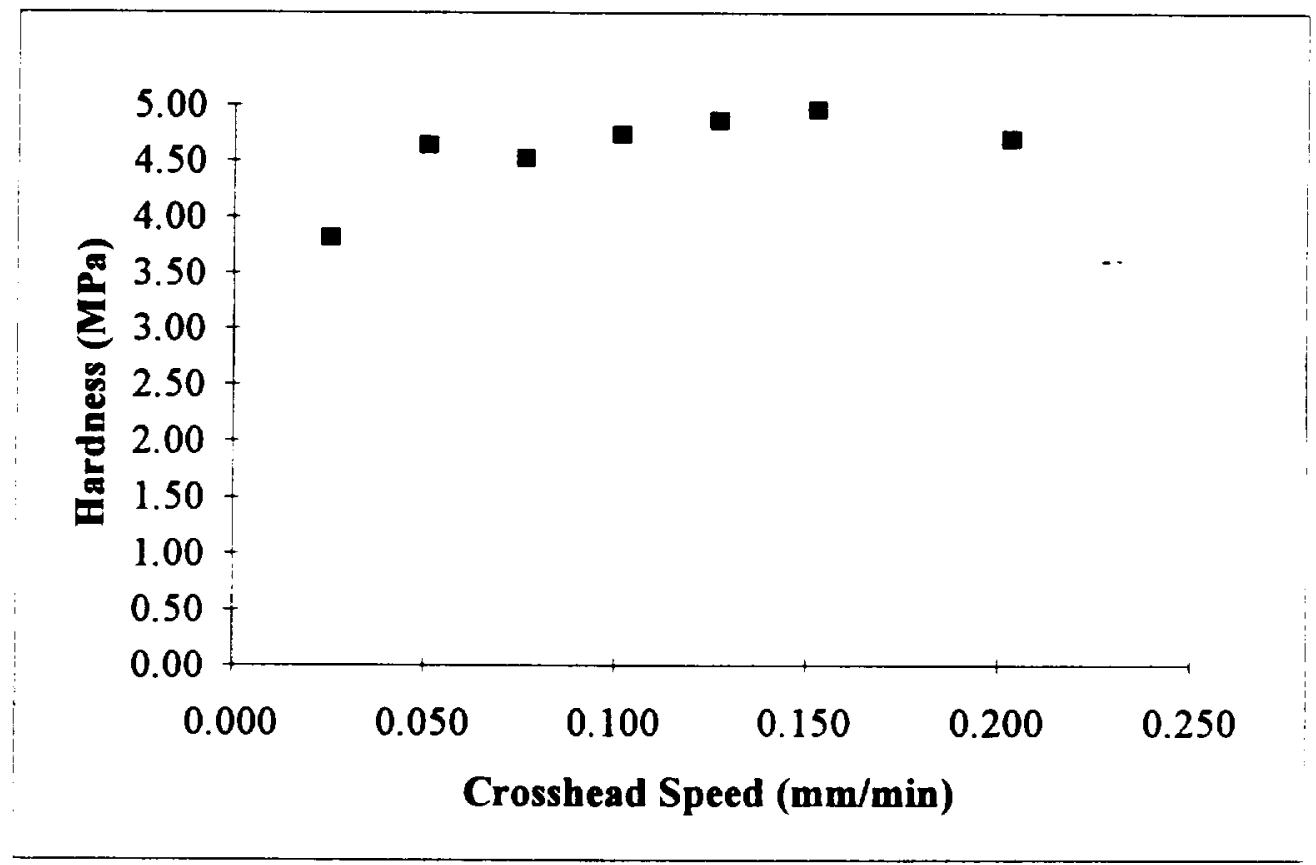

Figure 3.6 - Rate Test

Hardness vs. Crosshead Speed 


\section{Photoelasticity}

Photographs depicting the state of stress of unreinforced aerogel during indentation are provided in Figures 3.7a,b,c. The applied load increases from Figure 3.7a to Figure 3.7c. Although the images lack clarity because of the poor quality of the transparent specimens provided for testing, birefringence is clearly present. Thus photoelasticity techniques may indeed be used to study internal stresses in transparent aerogel specimens. The scratches on the surface of the present specimen, through which the fringe patterns were observed, resulted in scattering of incoming light and, therefore, reduced clarity. More tests are anticipated if transparent samples of reasonable quality are made available.

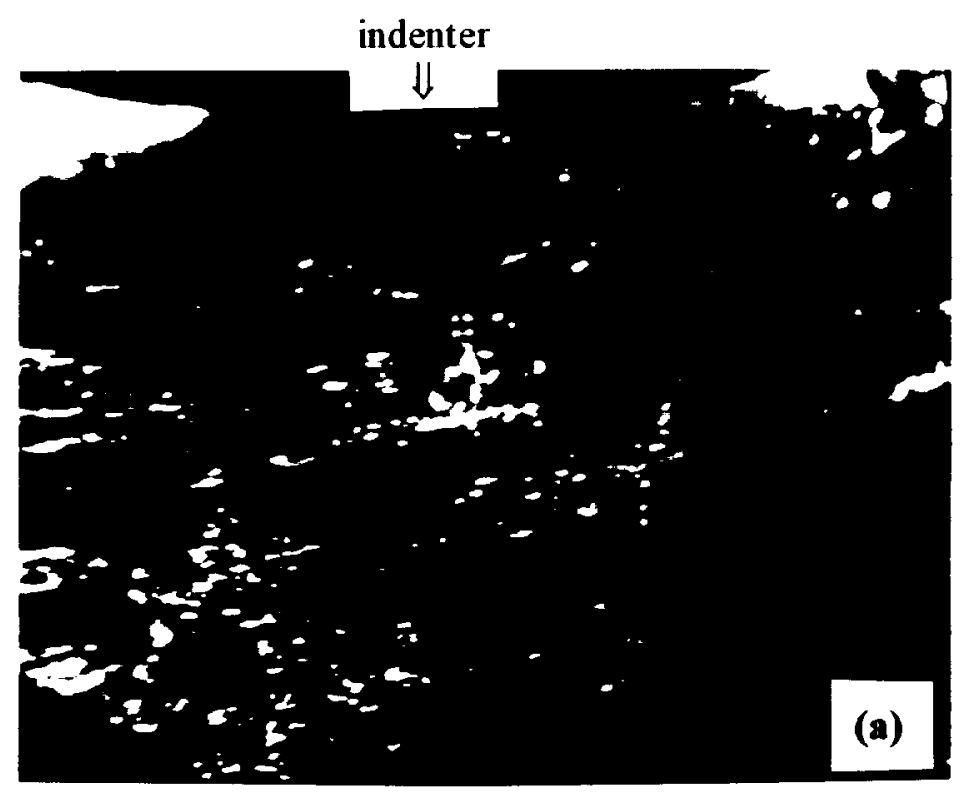

Figure 3.7

Stress Distributions in a Photoelastic Specimen During Indentation. Load Increases from Fig. 3.7a to Fig.'3.7c. 

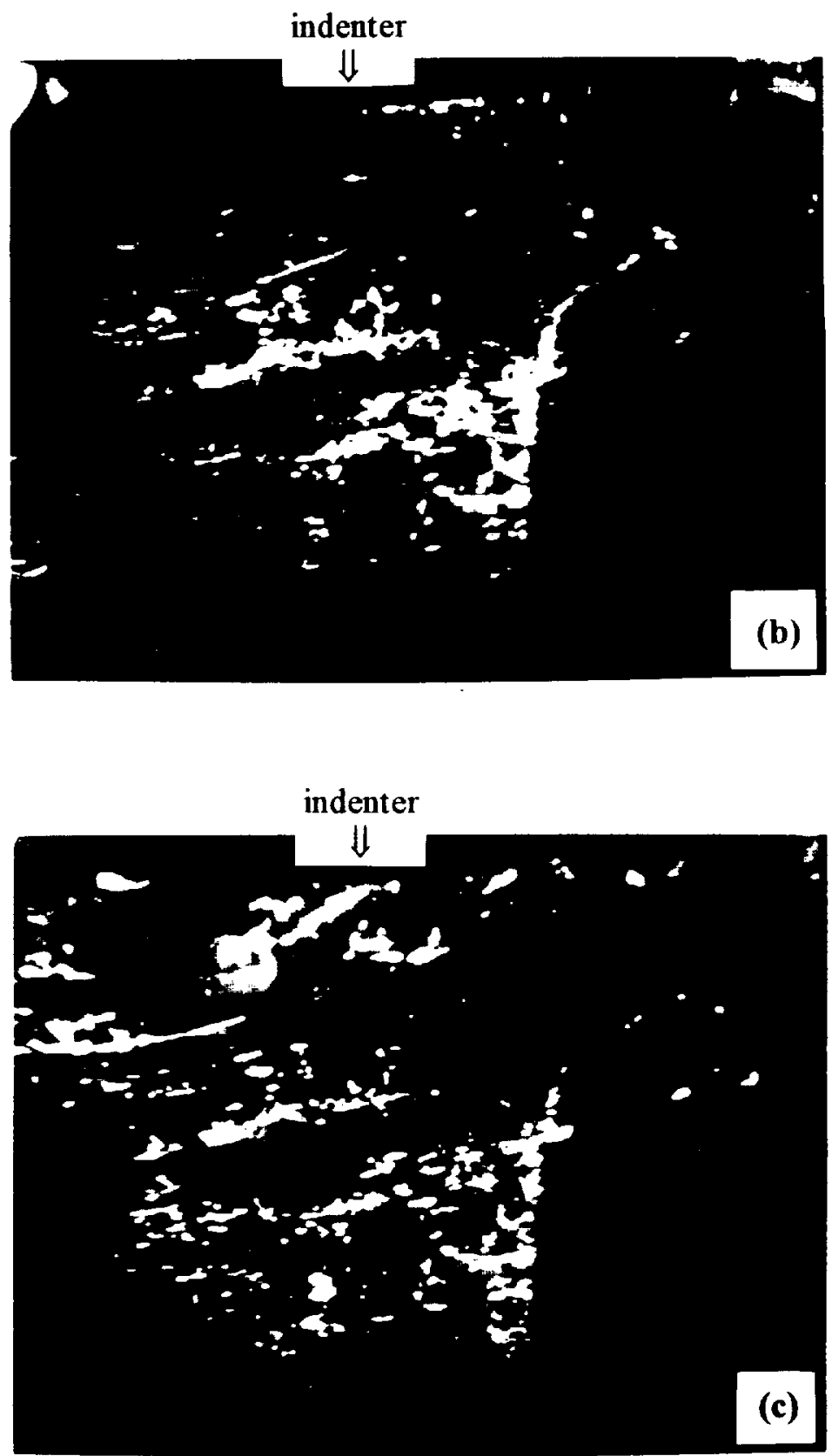

Figure 3.7, continued

Stress Distributions in a Photoelastic Specimen During Indentation. Load Increases from Fig. 3.7a to Fig. 3.7c. 


\subsection{Compression Tests}

A summary of compression results for the various aerogels tested is provided in Table 3.2. The compressive strength is defined as the maximum stress carried by the specimens during a test, and the strain at fracture is the strain at which macroscopic failure of the specimen occurred. Each secant modulus is determined by measuring the slope between two points on the Stress-Strain curves. For $\mathrm{E}_{50 \%}$, the slope is calculated between the point of stress equal to $0.040 \mathrm{MPa}$ and the point where the stress is $50 \%$ of the compressive strength. For $\mathrm{E}_{90 \%}$, the slope is calculated between the point of stress equal to $0.040 \mathrm{MPa}$ and the point where the stress is $90 \%$ of the compressive strength. The slopes are referenced to the $0.040 \mathrm{MPa}$ value to eliminate effects of any surface irregularities. Representative stress-strain curves for each type of material tested are shown in Figure 3.8, and the relationship between compressive strength and target density is depicted in Figure 3.9. Appendix D contains detailed compression results and StressStrain curves for every experiment conducted.

The data in Table 3.2 and Figures 3.8 and 3.9 indicate that the compressive strength, the strain at fracture, and the secant moduli are all dependent on target density and fiber percentage. The compressive strength increased with an increase in target density for a given fiber percentage, and decreased with an increase in fiber percentage for a given target density. There was one exception to the second trend: the compressive strength of the aerogel manufactured with $25 \%$ fibers and a target density of $40 \mathrm{~kg} / \mathrm{m}^{3}$ exceeded that of the aerogel manufactured with $10 \%$ fibers and a target density of $40 \mathrm{~kg} / \mathrm{m}^{3}$. This result is consistent with the results from hardness experiments. Furthermore, the strain at fracture tended to decrease with an increase in target density for a given fiber percentage, but did not follow a discemible trend with fiber percentage. Finally, the secant moduli increased with an increase in target density for a given fiber percentage, and decreased (for the most part) with an increase in fiber percentage for a given target density. Again, the exception to this was found for the specimens of target density equal to $40 \mathrm{~kg} / \mathrm{m}^{3}$, and fiber percentages of $10 \%$ and $25 \%$. 
It is possible that the exceptions mentioned above are the result of inconsistant production and storage histories of the specimens before shipment to our labs. It has been found that age and storage environment have appreciable influences on the compression results of aerogel specimens, as is demonstrated in subsequent paragraphs.

Table 3.2

Summary of Compression Results

\begin{tabular}{|c|c|c|c|c|c|c|c|}
\hline $\begin{array}{c}\text { Fiber } \\
\text { Percentage } \\
(\%)\end{array}$ & $\begin{array}{l}\text { Target } \\
\text { Density } \\
\left(\mathrm{kg} / \mathrm{m}^{3}\right)\end{array}$ & $\begin{array}{c}\text { Final } \\
\text { Density } \\
\left(\mathrm{kg} / \mathrm{m}^{3}\right)\end{array}$ & $\begin{array}{l}\text { Number } \\
\text { of Spec- } \\
\text { imens }\end{array}$ & $\begin{array}{c}\text { Compressive } \\
\text { Strength, } S \\
(\mathbf{M P a})\end{array}$ & $\begin{array}{l}\text { Strain at } \\
\text { Fracture, } \varepsilon_{\mathrm{q}} \\
(\mathbf{m m} / \mathbf{m m})\end{array}$ & $\begin{array}{c}\text { Secant Modulus } \\
@ \mathbf{5 0 \%} \text { of } \mathrm{S} \\
(\mathrm{MPa})\end{array}$ & $\begin{array}{c}\text { Secant Modulus } \\
\text { @ } 90 \% \text { of S } \\
(\mathrm{MPa})\end{array}$ \\
\hline 0 & - & 204 & 3 & $\begin{array}{l}S=1.01 \\
\sigma=0.03\end{array}$ & $\begin{array}{l}\varepsilon_{f}=0.100 \\
\sigma=0.009\end{array}$ & $\begin{array}{c}\mathrm{E}_{50 \%}=16.4 \\
\sigma=1.8\end{array}$ & $\begin{array}{c}\mathrm{E}_{90 \%}=14.1 \\
\sigma=0.6\end{array}$ \\
\hline 5 & 40 & 260 & 3 & $\begin{array}{l}S=1.00 \\
\sigma=0.08\end{array}$ & $\begin{array}{l}\varepsilon_{\mathrm{f}}=0.071 \\
\sigma=0.010\end{array}$ & $\begin{array}{c}E_{50 \%}=20.4 \\
\sigma=3.2\end{array}$ & $\begin{array}{c}E_{90 \%}=18.3 \\
\sigma=3.2\end{array}$ \\
\hline 5 & 80 & 320 & 4 & $\begin{array}{l}S=1.45 \\
\sigma=0.18\end{array}$ & $\begin{array}{l}\varepsilon_{\mathrm{f}}=0.053 \\
\sigma=0.004\end{array}$ & $\begin{array}{c}E_{50 \%}=36.0 \\
\sigma=3.4\end{array}$ & $\begin{array}{c}E_{90 \%}=33.9 \\
\sigma=2.5\end{array}$ \\
\hline 10 & 40 & 190 & 6 & $\begin{array}{l}S=0.34 \\
\sigma=0.03\end{array}$ & $\begin{array}{l}\varepsilon_{\mathrm{f}}=0.069 \\
\sigma=0.007\end{array}$ & $\begin{array}{c}E_{50 \%}=8.1 \\
\sigma=1.6\end{array}$ & $\begin{array}{c}E_{90 \%}=6.1 \\
\sigma=0.9\end{array}$ \\
\hline 10 & 50 & 230 & 9 & $\begin{array}{l}S=1.01 \\
\sigma=0.05\end{array}$ & $\begin{array}{l}\varepsilon_{\mathrm{f}}=0.067 \\
\sigma=0.004\end{array}$ & $\begin{array}{c}E_{50 \%}=23.4 \\
\sigma=1.4\end{array}$ & $\begin{array}{c}E_{90 \%}=18.0 \\
\sigma=0.7\end{array}$ \\
\hline 10 & 80 & 330 & 15 & $\begin{array}{l}S=1.27 \\
\sigma=0.14\end{array}$ & $\begin{array}{l}\varepsilon_{f}=0.051 \\
\sigma=0.003\end{array}$ & $\begin{array}{c}E_{50 \%}=30.4 \\
\sigma=4.4\end{array}$ & $\begin{array}{c}E_{90 \%}=31.8 \\
\sigma=3.2\end{array}$ \\
\hline 25 & 40 & 190 & 16 & $\begin{array}{l}S=0.55 \\
\sigma=0.03\end{array}$ & $\begin{array}{l}\varepsilon_{\mathrm{f}}=0.142 \\
\sigma=0.015\end{array}$ & $\begin{array}{c}E_{50 \%}=8.6 \\
\sigma=0.7\end{array}$ & $\begin{array}{c}E_{90 \%}=5.3 \\
\sigma=0.5\end{array}$ \\
\hline 25 & 80 & 240 & 15 & $\begin{array}{l}S=0.79 \\
\sigma=0.02\end{array}$ & $\begin{array}{l}\varepsilon_{\mathrm{f}}=0.077 \\
\sigma=0.010\end{array}$ & $\begin{array}{c}E_{50 \%}=22.3 \\
\sigma=3.1\end{array}$ & $\begin{array}{c}E_{90 \%}=15.0 \\
\sigma=2.1\end{array}$ \\
\hline
\end{tabular}




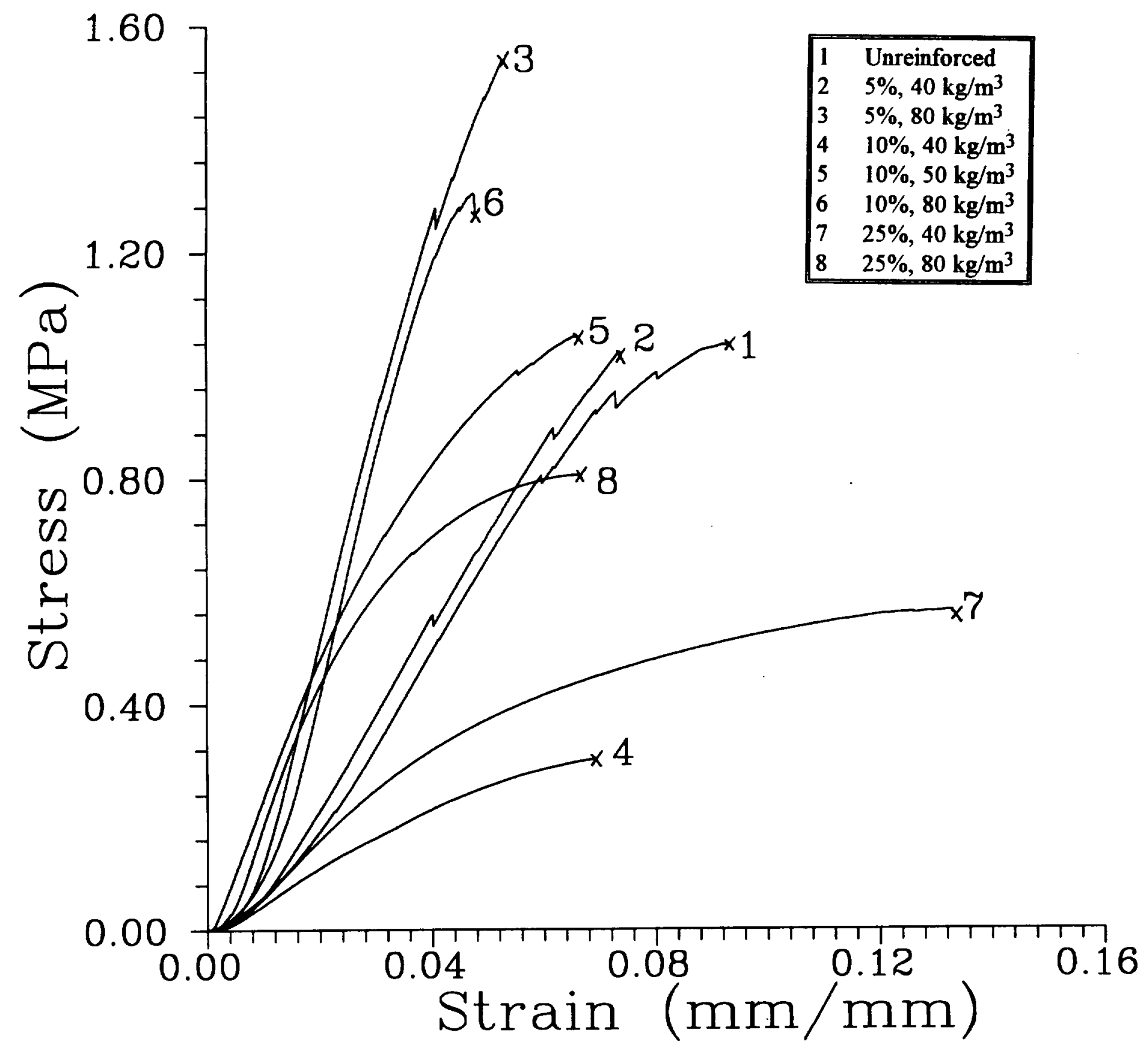

Figure 3.8

Representative Stress-Strain Data 


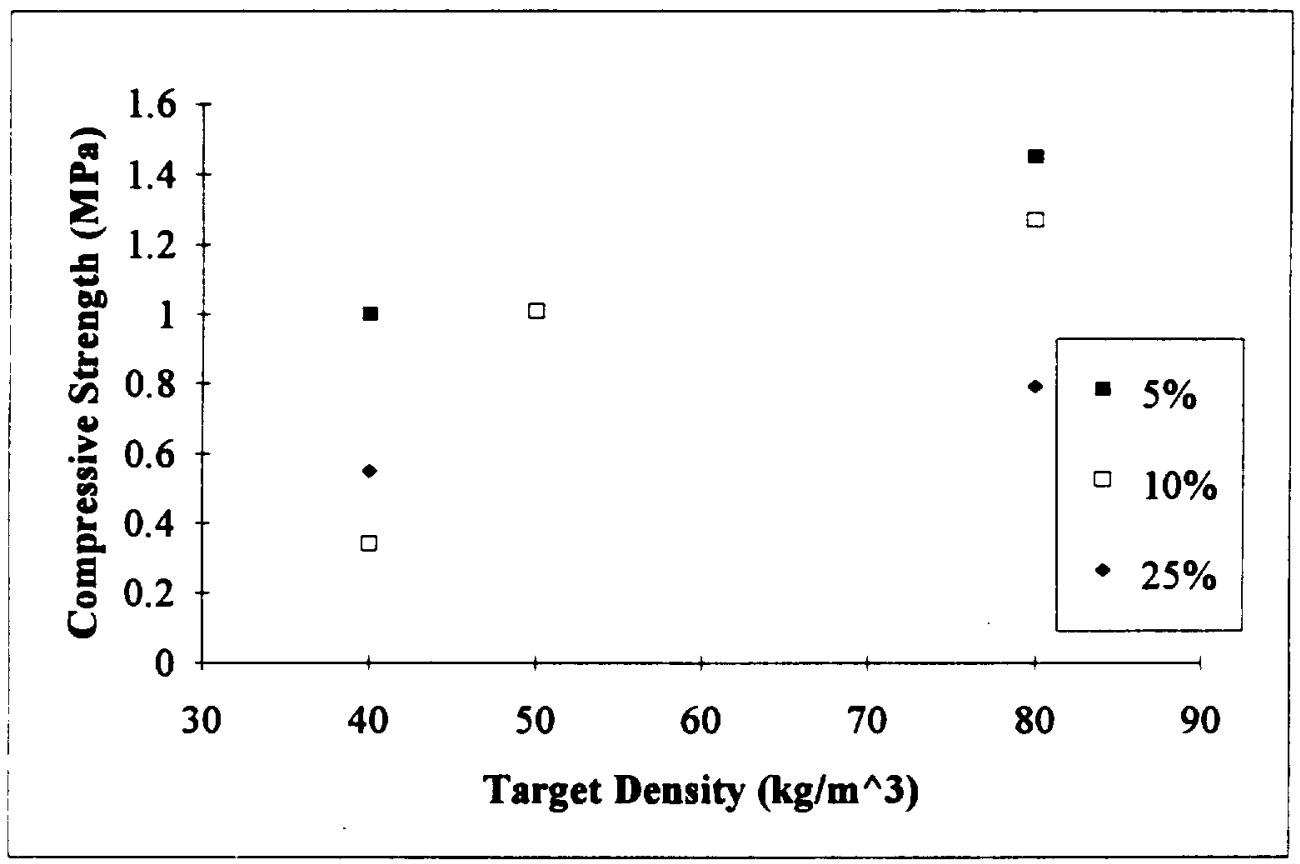

Figure 3.9

Compressive Strength vs. Target Density with Fiber Percentage as a Parameter 


\section{Tests in Ethanol}

The compressive results of experiments in ethanol are compared with results of experiments in air in Table 3.3 and in Figures 3.10 through 3.12. All specimens were stored in air, under ambient conditions, for approximately two months before being tested. For both types of material, the compression results for tests in ethanol are not consistent, and show a considerably greater amount of scatter (larger $\sigma$ values in Table 3.3), than results for tests in air. The average compressive strength is smaller in ethanol than in air by $43 \%$ for the $10 \%$ fibers case, and by $16 \%$ for the $25 \%$ fibers case. The calculated moduli are also higher in air than in ethanol. In addition, the compression specimens appeared to crack and begin to dissolve upon exposure to the ethanol solution. Therefore, ethanol is not a desirable medium in which to conduct cryogenic tests. Detailed compression results and stress-strain curves are provided in Appendices $E$ and F, for tests done in ethanol and air, respectively.

Table 3.3

Summary of Compression Results for Tests in Air and Ethanol

\begin{tabular}{|c|c|c|c|c|c|c|c|}
\hline $\begin{array}{c}\text { Fiber } \\
\text { Percentage } \\
(\%) \\
\end{array}$ & $\begin{array}{l}\text { Target } \\
\text { Density } \\
\left(\mathrm{k} g / \mathrm{m}^{\mathbf{3}}\right)\end{array}$ & $\begin{array}{c}\text { Final } \\
\text { Density } \\
\left(\mathbf{k g} / \mathbf{m}^{3}\right)\end{array}$ & $\begin{array}{c}\text { Environ- } \\
\text { ment }\end{array}$ & $\begin{array}{l}\text { Number } \\
\text { of Spec- } \\
\text { imens }\end{array}$ & $\begin{array}{c}\text { Compressive } \\
\text { Strength, } \mathbf{S} \\
\text { (MPa) } \\
\end{array}$ & $\begin{array}{c}\text { Secant Modulus } \\
\text { @ } 50 \% \text { of } \mathrm{S} \\
(\mathrm{MPa}) \\
\end{array}$ & $\begin{array}{c}\text { Secant Modulus } \\
@ 90 \% \text { of S } \\
(\mathrm{MPa}) \\
\end{array}$ \\
\hline 10 & 50 & 250 & Air & 2 & $\begin{array}{l}S=1.07 \\
\sigma=0.05\end{array}$ & $\begin{array}{c}E_{50 \%}=34.2 \\
\sigma=0.2\end{array}$ & $\begin{array}{c}E_{90 \%}=28.4 \\
\sigma=0.1\end{array}$ \\
\hline 10 & 50 & 250 & Ethanol & 3 & $\begin{array}{l}S=0.61 \\
\sigma=0.21\end{array}$ & $\begin{array}{c}E_{50 \%}=20.5 \\
\sigma=6.4\end{array}$ & $\begin{array}{c}E_{90 \%}=18.1 \\
\sigma=6.9\end{array}$ \\
\hline 25 & 80 & 250 & Air & 3 & $\begin{array}{l}S=0.78 \\
\sigma=0.05\end{array}$ & $\begin{array}{c}E_{50 \%}=29.5 \\
\sigma=3.0\end{array}$ & $\begin{array}{c}E_{90 \%}=23.9 \\
\sigma=1.4\end{array}$ \\
\hline 25 & 80 & 250 & Ethanol & 4 & $\begin{array}{l}S=0.65 \\
\sigma=0.08\end{array}$ & $\begin{array}{c}\mathrm{E}_{50 \%}=24.3 \\
\sigma=5.1\end{array}$ & $\begin{array}{c}E_{90 \%}=20.9 \\
\sigma=4.1\end{array}$ \\
\hline
\end{tabular}




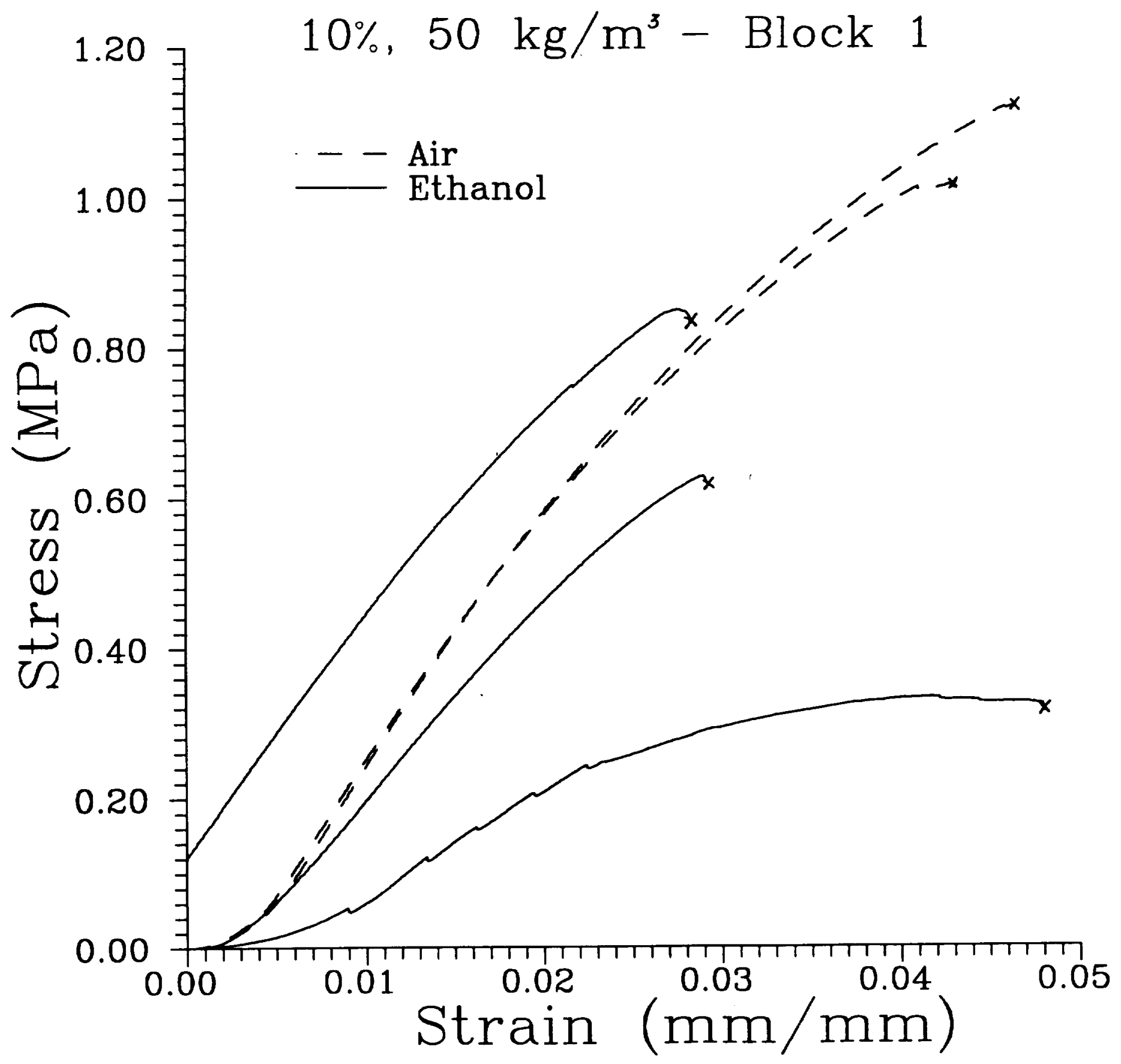

Figure 3.10

Comparison of Stress-Strain Curves for Tests in Ethanol and Air.

Target Density $=50 \mathrm{~kg} / \mathrm{m}^{3}$, Fiber Percentage $=10 \%$. 


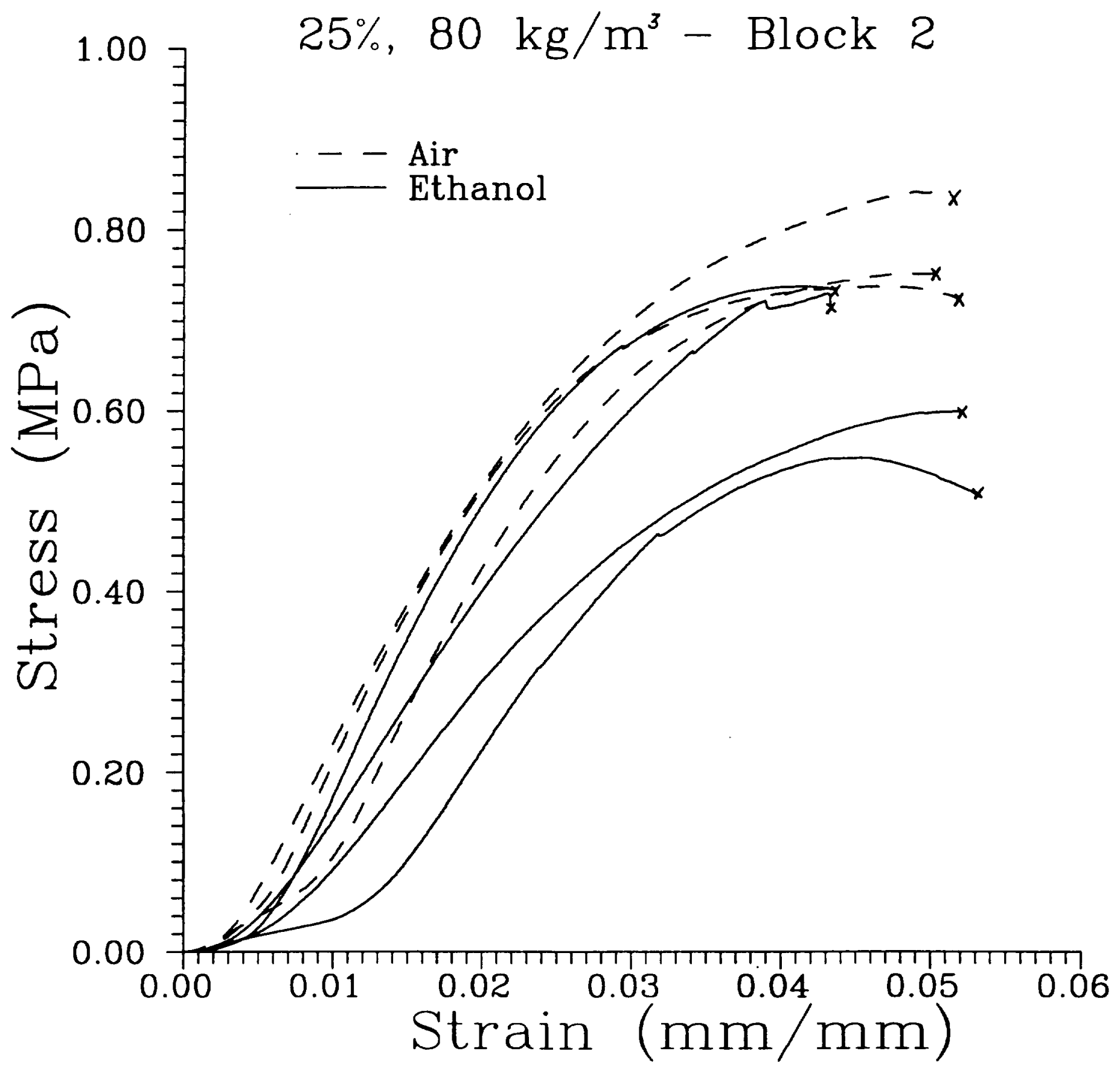

Figure 3.11

Comparison of Stress-Strain Curves for Tests in Ethanol and Air.

Target Density $=80 \mathrm{~kg} / \mathrm{m}^{3}$, Fiber Percentage $=25 \%$. 


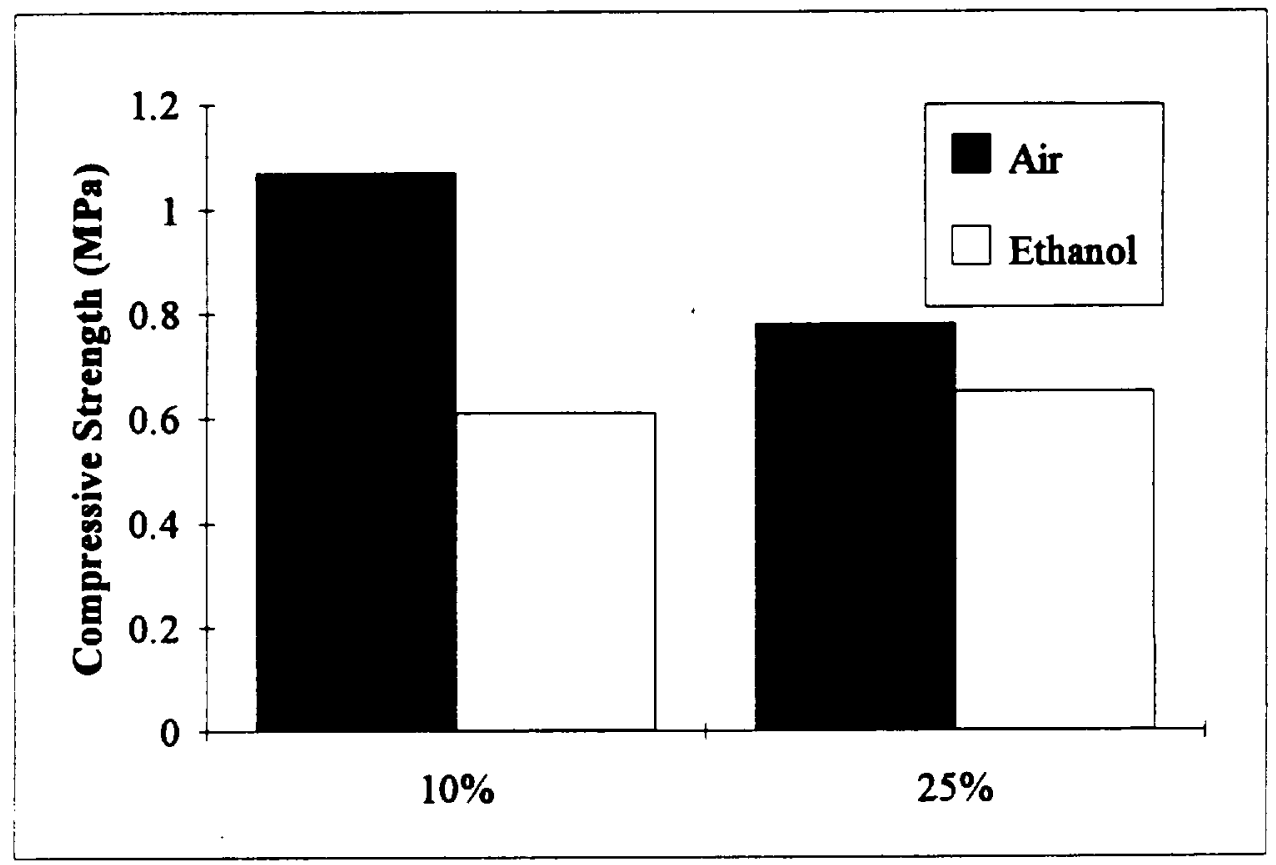

Figure 3.12

Comparison of Compressive Strengths for Tests in Ethanol and Air for $10 \%$ and $25 \%$ Fiber Reinforced Specimens

\section{Effects of Age and Storage Environment}

The influences of age and storage environment are tabulated in Table 3.4 and depicted in Figures 3.13 through 3.15. Figure 3.13 is a comparison of the compressive responses of specimens ( $10 \%$ fibers, target density $\left.=50 \mathrm{~kg} / \mathrm{m}^{3}\right)$ aged for 2 months in air with specimens tested within a week of being machined. Figure 3.14 is a comparison of the compressive responses of specimens ( $25 \%$ fibers, target density $=80 \mathrm{~kg} / \mathrm{m}^{3}$ ) aged for 2 months in air, with specimens aged for 2 months in air and then stored in a desiccator for ten days, and with specimens tested within a week of being machined. Figure 3.15 is a comparison of the strains at fracture for the various materials tested. The results indicate 
that the aging process tends to increase the compressive strength and secant moduli, while decreasing the strain at fracture for both types of materials. Therefore, the toughness decreases and the specimens seem to become more brittle with age. Furthermore, although the density decreases noticeably after desiccation, the compressive results for desiccated specimens agree well with the results for specimens aged in air alone. The results may also indicate a slight increase in strength occurring during desiccation, but since the increase is of the same order as experimental scatter, a solid conclusion cannot be drawn. Detailed compression results and Stress-Strain curves are included in Appendix D for freshly machined specimens, Appendix $F$ for specimens aged in air, and Appendix $G$ for specimens aged in air and then desiccated.

Table 3.4

Summary of Compression Results for Specimens Freshly Machined, Aged in Air, and Aged in Air and Desiccated

\begin{tabular}{|c|c|c|c|c|c|c|c|c|}
\hline $\begin{array}{c}\text { Fiber } \\
\text { Percent } \\
(\%) \\
\end{array}$ & $\begin{array}{l}\text { Target } \\
\text { Density } \\
\left(\mathrm{kg} / \mathrm{m}^{3}\right) \\
\end{array}$ & $\begin{array}{c}\text { Final } \\
\text { Density } \\
\left(\mathbf{k g} / \mathrm{m}^{3}\right)\end{array}$ & Storage & $\begin{array}{c}\begin{array}{c}\text { Number } \\
\text { of Spec- } \\
\text { Imens }\end{array} \\
\end{array}$ & $\begin{array}{c}\text { Compressive } \\
\text { Strength, S } \\
\text { (MPa) }\end{array}$ & $\begin{array}{c}\text { Strain at } \\
\text { Fracture, } \varepsilon_{r} \\
(\mathbf{m m} / \mathbf{m m})\end{array}$ & $\begin{array}{c}\text { Modulus } \\
\text { @ } 50 \% \text { of } \mathrm{S} \\
(\mathrm{MPa}) \\
\end{array}$ & $\begin{array}{c}\text { Modulus } \\
\text { @ } 90 \% \text { of S } \\
(\mathrm{MPa}) \\
\end{array}$ \\
\hline 10 & 50 & 230 & Fresh & 9 & $\begin{array}{l}S=1.01 \\
\sigma=0.05\end{array}$ & $\begin{array}{l}\varepsilon_{\mathrm{f}}=0.067 \\
\sigma=0.004\end{array}$ & $\begin{array}{c}E_{50 \%}=23.4 \\
\sigma=1.4\end{array}$ & $\begin{array}{c}E_{90 \%}=18.0 \\
\sigma=0.7\end{array}$ \\
\hline 10 & 50 & 250 & Aged & 2 & $\begin{array}{l}S=1.07 \\
\sigma=0.05\end{array}$ & $\begin{array}{l}\varepsilon_{\mathrm{f}}=0.045 \\
\sigma=0.002\end{array}$ & $\begin{array}{c}E_{50 \%}=34.2 \\
\sigma=0.2\end{array}$ & $\begin{array}{c}E_{90 \%}=28.4 \\
\sigma=0.1\end{array}$ \\
\hline 25 & 80 & 240 & Fresh & 3 & $\begin{array}{l}S=0.77 \\
\sigma=0.02\end{array}$ & $\begin{array}{l}\varepsilon_{\mathrm{f}}=0.073 \\
\sigma=0.007\end{array}$ & $\begin{array}{c}E_{50 \%}=23.9 \\
\sigma=1.4\end{array}$ & $\begin{array}{c}E_{90 \%}=16.1 \\
\sigma=0.8\end{array}$ \\
\hline 25 & 80 & 250 & Aged & 3 & $\begin{array}{l}S=0.77 \\
\sigma=0.09\end{array}$ & $\begin{array}{l}\varepsilon_{\mathrm{f}}=0.045 \\
\sigma=0.004\end{array}$ & $\begin{array}{c}E_{50 \%}=28.9 \\
\sigma=5.9\end{array}$ & $\begin{array}{c}E_{90 \%}=25.1 \\
\sigma=3.8\end{array}$ \\
\hline 25 & 80 & 240 & $\begin{array}{c}\text { Des- } \\
\text { iccated }\end{array}$ & 4 & $\begin{array}{l}S=0.90 \\
\sigma=0.05\end{array}$ & $\begin{array}{l}\varepsilon_{\mathrm{f}}=0.047 \\
\sigma=0.004\end{array}$ & $\begin{array}{c}E_{50 \%}=30.6 \\
\sigma=2.1\end{array}$ & $\begin{array}{c}\mathrm{E}_{90 \%}=26.9 \\
\sigma=1.5\end{array}$ \\
\hline
\end{tabular}




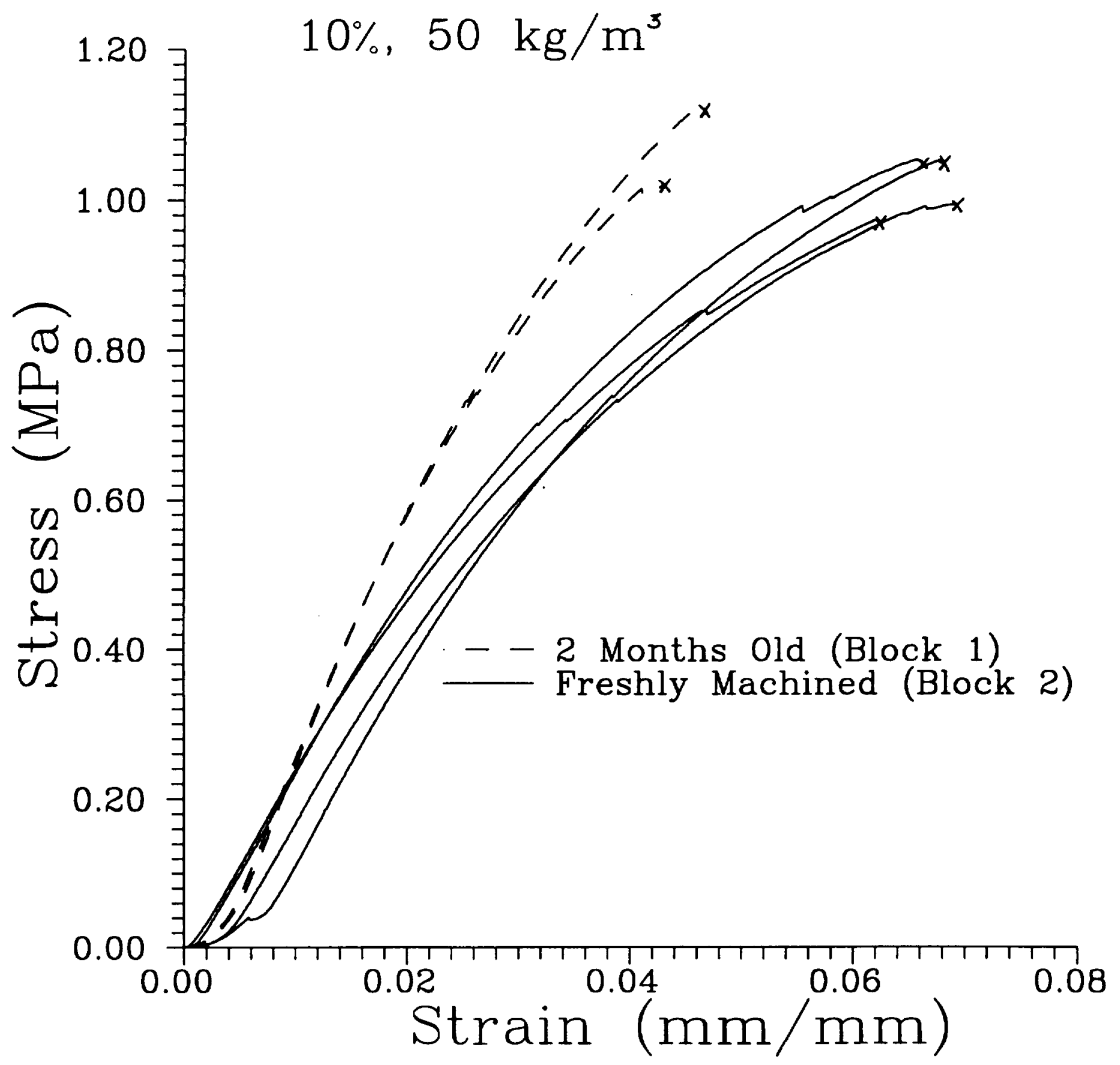

Figure 3.13

Comparison of Stress-Strain Curves for Freshly Machined Specimens and Specimens Aged in Air for 2 Months.

Target Density $=50 \mathrm{~kg} / \mathrm{m}^{3}$, Fiber Percentage $=10 \%$. 


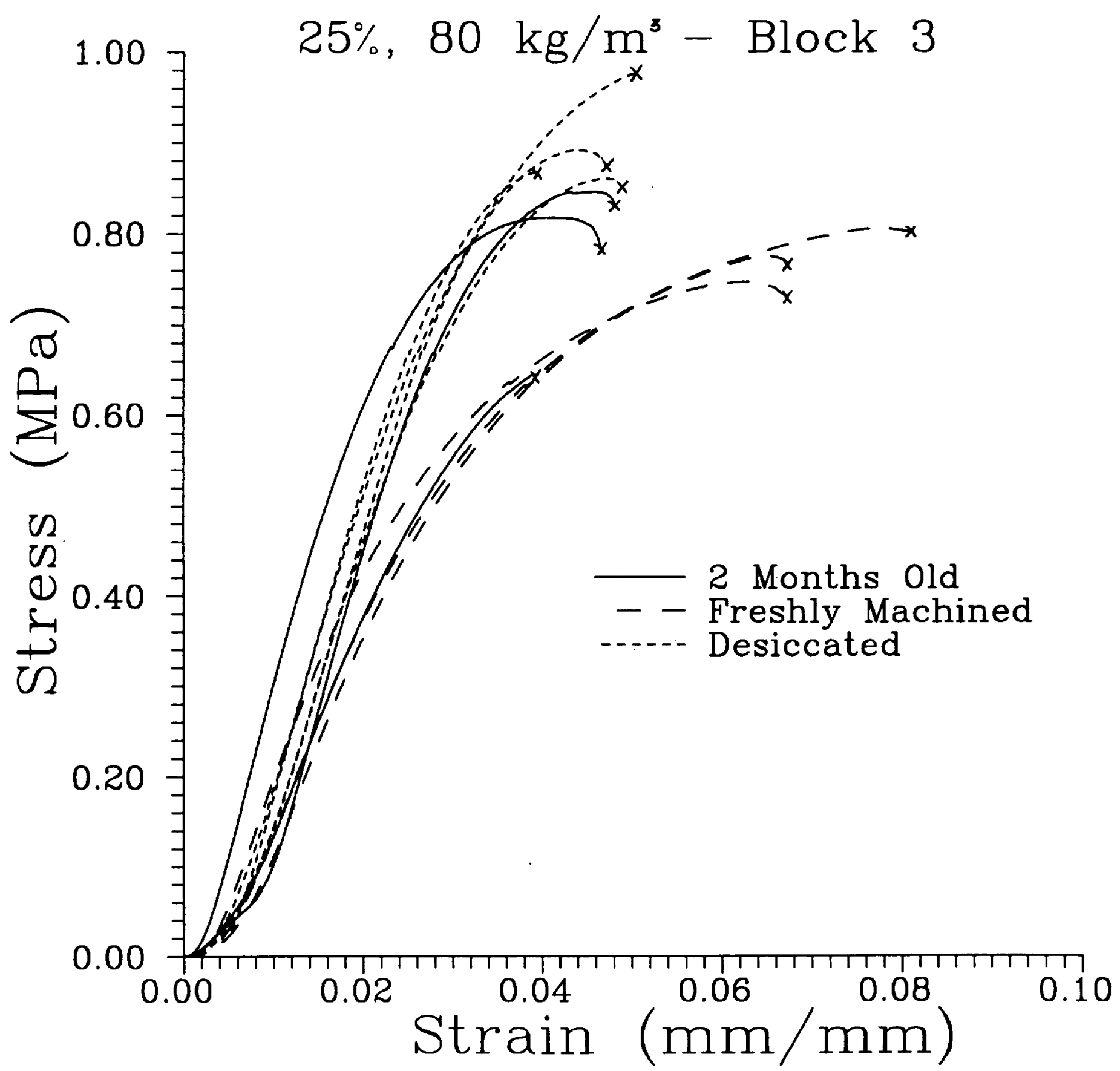

Figure 3.14

Comparison of Stress-Strain Curves for Freshly Machined Specimens, Specimens Aged in Air for 2 Months, and Specimens Aged in Air for Two Months and Desiccated for 10 Days. Target Density $=80 \mathrm{~kg} / \mathrm{m}^{3}$, Fiber Percentage $=25 \%$. 


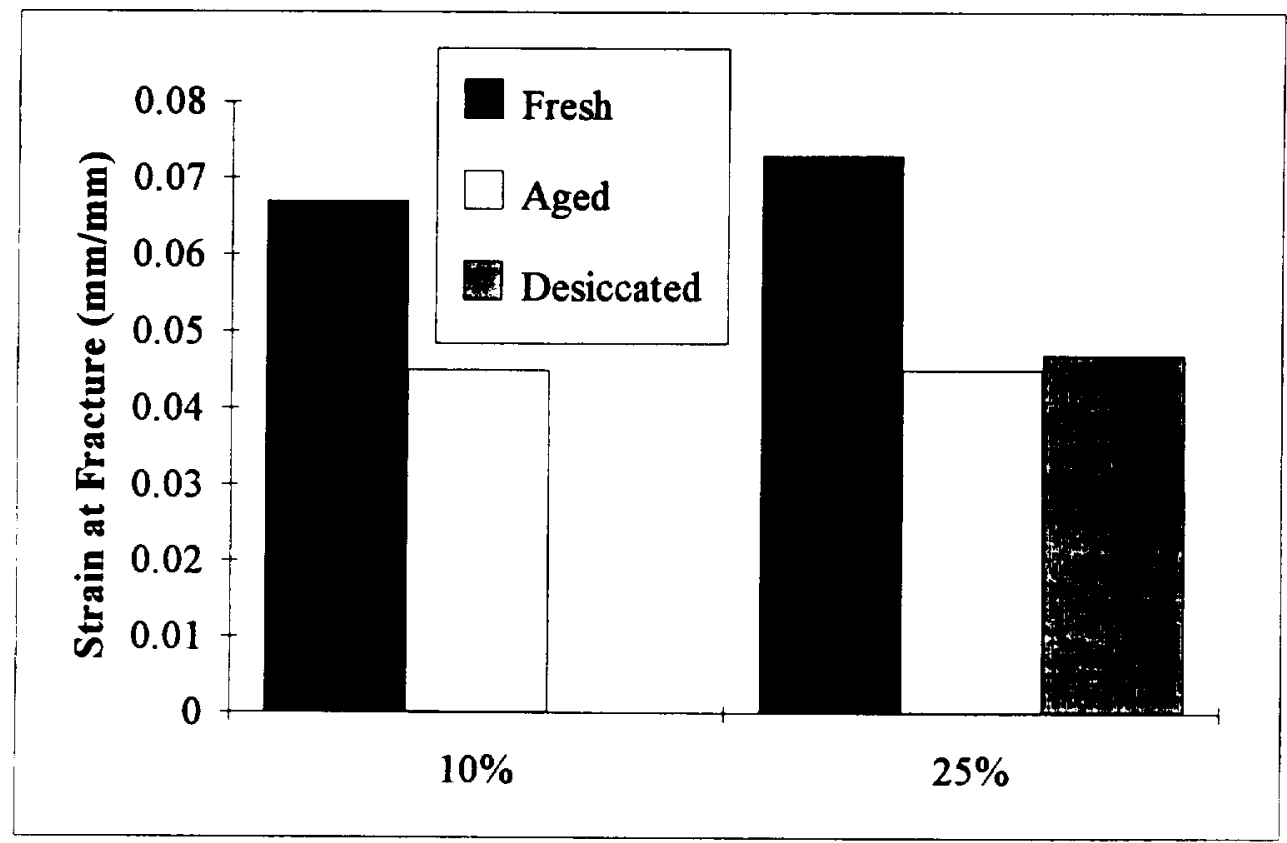

Figure 3.15

Comparison of Strains at Fracture for Fresh, Aged, and Desiccated Specimens 


\subsection{Correlation of Compressive Strength and Hardness}

The relationship between hardness, $H$, and compressive strength, $S$, is plotted in Figure 3.16. It is worthwhile to relate hardness to compressive strength, since the former is a measure of the resistance to the local compressive strength in the neighborhood of the indenter, but is less destructive than traditional compression tests. Considering the wide range of processing parameters investigated, there is reasonably good correlation between the compressive strength and the hardness.

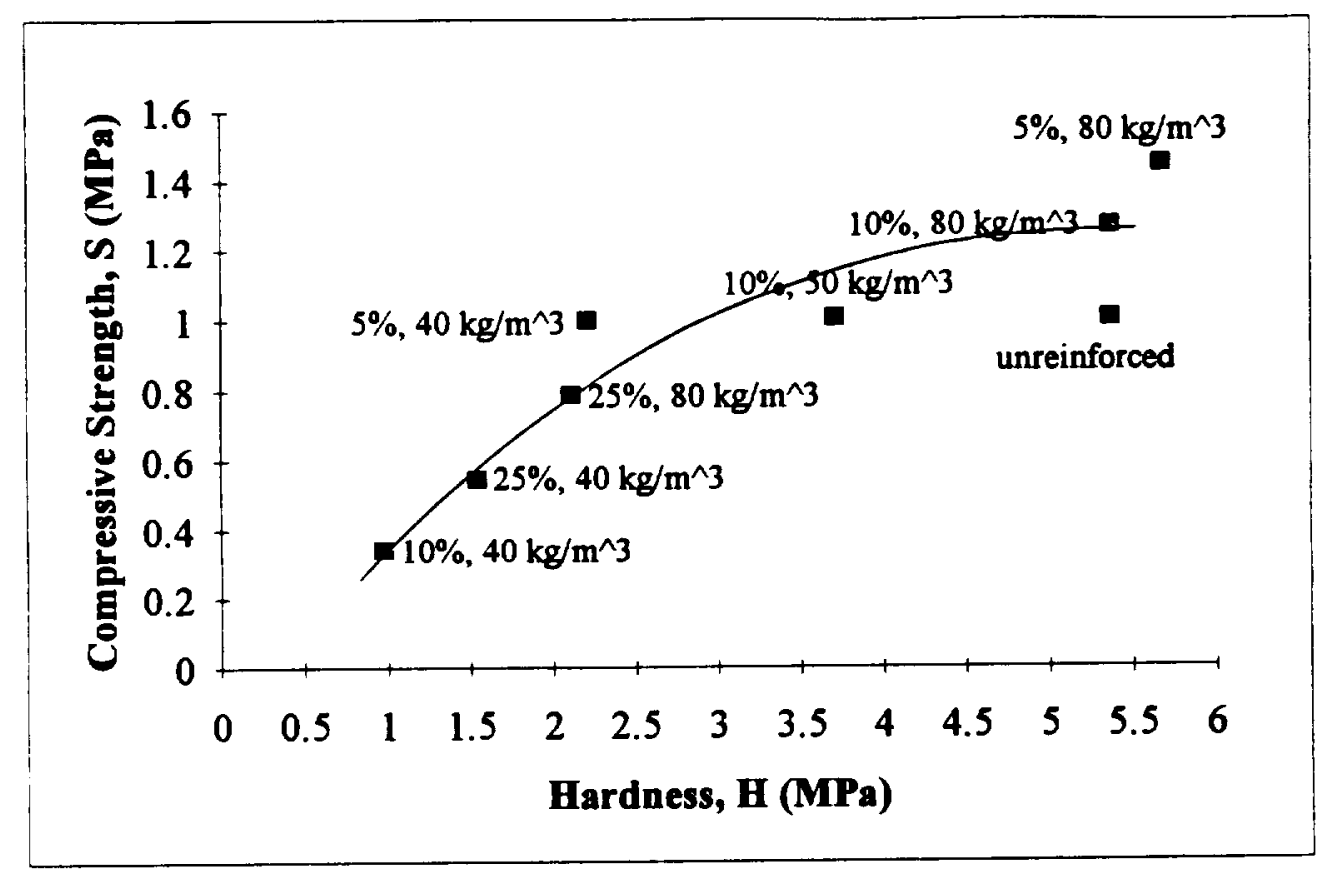

Figure 3.16

Compressive Strength vs. Hardness 


\subsection{Tensile Tests}

The tensile tests proved to be very challenging due to practical difficulties machining and handling specimens with such small cross-sectional areas within the gage length. In addition, there was only a limited amount of bulk aerogel material to work with of sufficient size and quality. As a result, only three of ten specimens machined remained intack up to the point of load application. The majority of specimens broke in the process of mounting them into the test fixture. Two of the specimens tested consisted of $25 \%$ fibers, and had a target density of $80 \mathrm{~kg} / \mathrm{m}^{3}$; one specimen consisted of $5 \%$ fibers and had a target density of $80 \mathrm{~kg} / \mathrm{m}^{3}$. The results of the three experiments are summarized in Table 3.5, and their stress-strain curves are provided in Figures 3.17 and 3.18.

The results show a significant discrepancy between the stress-strain responses of the two specimens manufactured with $25 \%$ fibers and a target density of $80 \mathrm{~kg} / \mathrm{m}^{3}$. Their initial slopes (i.e., Young's moduli) agree well, with values approximately equal to 13 $\mathrm{MPa}$, but then diverge at a strain of approximately $0.005 \mathrm{~mm} / \mathrm{mm}$. Furthermore, the ultimate tensile strength of the weaker specimen is $44 \%$ less than that of the stronger specimen. The Young's modulus of the $5 \%, 80 \mathrm{~kg} / \mathrm{m}^{3}$ specimen is significantly larger, with a value of approximately $23 \mathrm{MPa}$. However, since the ultimate tensile strength of this specimen falls between that of the previous two specimens, no conclusions about the relative strengths of the two types of material can be made on the basis of these tests.

Table 3.5

Summary of Tensile Results

\begin{tabular}{|ccccccc|}
\hline $\begin{array}{c}\text { Fiber } \\
\begin{array}{c}\text { Percentage } \\
(\%)\end{array}\end{array}$ & $\begin{array}{c}\text { Target } \\
\text { Density } \\
\left(\mathbf{k g} / \mathbf{m}^{\mathbf{3}}\right)\end{array}$ & $\begin{array}{c}\text { Final } \\
\text { Density } \\
\left(\mathbf{k g} / \mathbf{m}^{\mathbf{3}}\right)\end{array}$ & $\begin{array}{c}\text { Block } \\
\#\end{array}$ & $\begin{array}{c}\text { Ultimate Tensile } \\
\text { Strength } \\
(\mathbf{M P a})\end{array}$ & $\begin{array}{c}\text { Strain at } \\
\text { Fracture, } \boldsymbol{\varepsilon}_{\mathbf{f}} \\
(\mathbf{m m} / \mathbf{m m})\end{array}$ & $\begin{array}{c}\text { Young's } \\
\text { Modulus } \\
(\mathbf{M P a})\end{array}$ \\
\hline 5 & $\mathbf{8 0}$ & 320 & 38 & 0.25 & 0.012 & 23.2 \\
25 & 80 & 240 & 33 & 0.32 & 0.017 & $13.5^{*}$ \\
25 & $\mathbf{8 0}$ & 240 & 34 & 0.18 & 0.016 & $13.1^{*}$ \\
\hline
\end{tabular}

* Initial Young's Modulus 


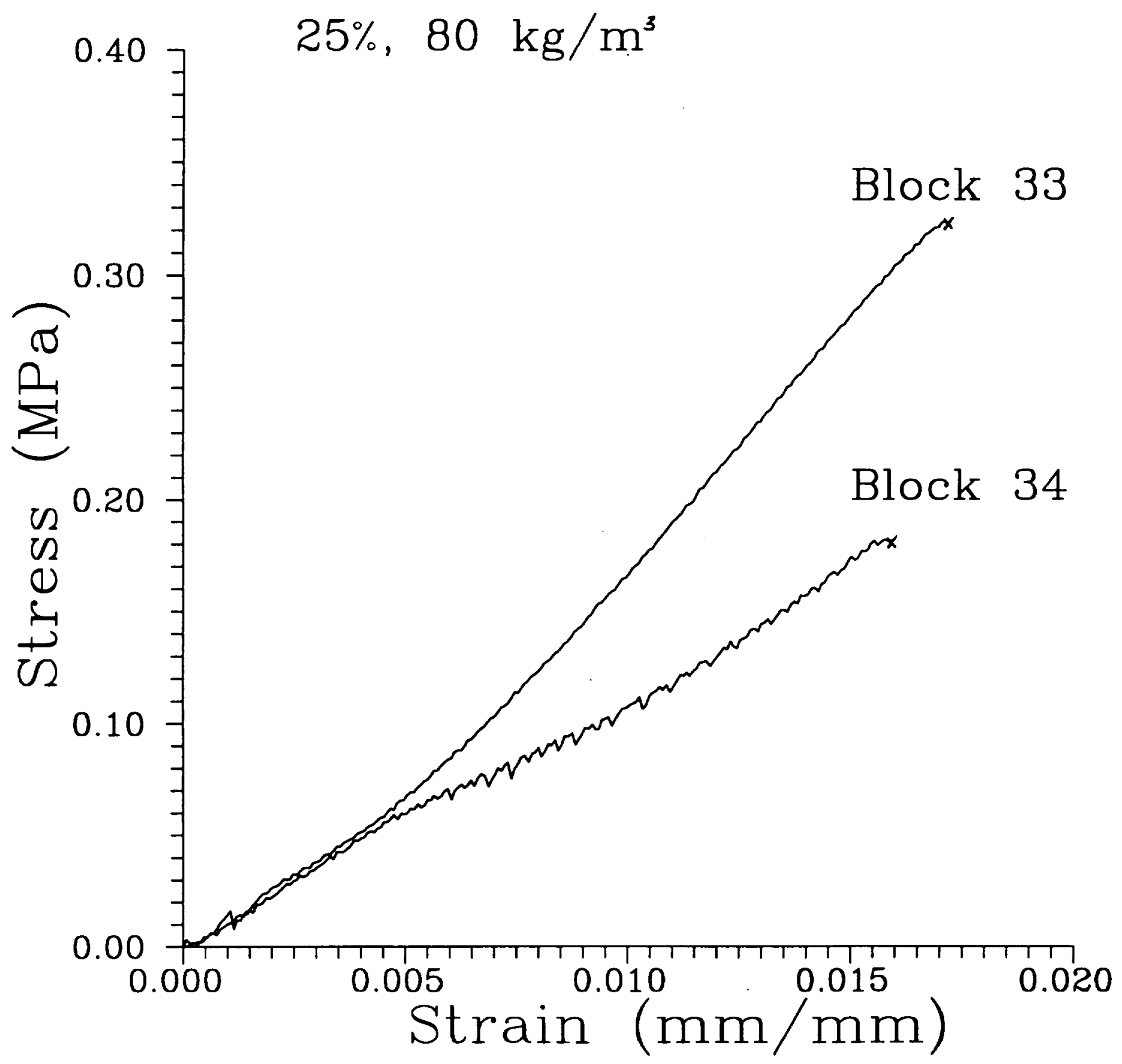

Figure 3.17

Stress-Strain Curve for Tensile Specimens.

Target Density $=80 \mathrm{~kg} / \mathrm{m}^{3}$, Fiber Percentage $=25 \%$ 


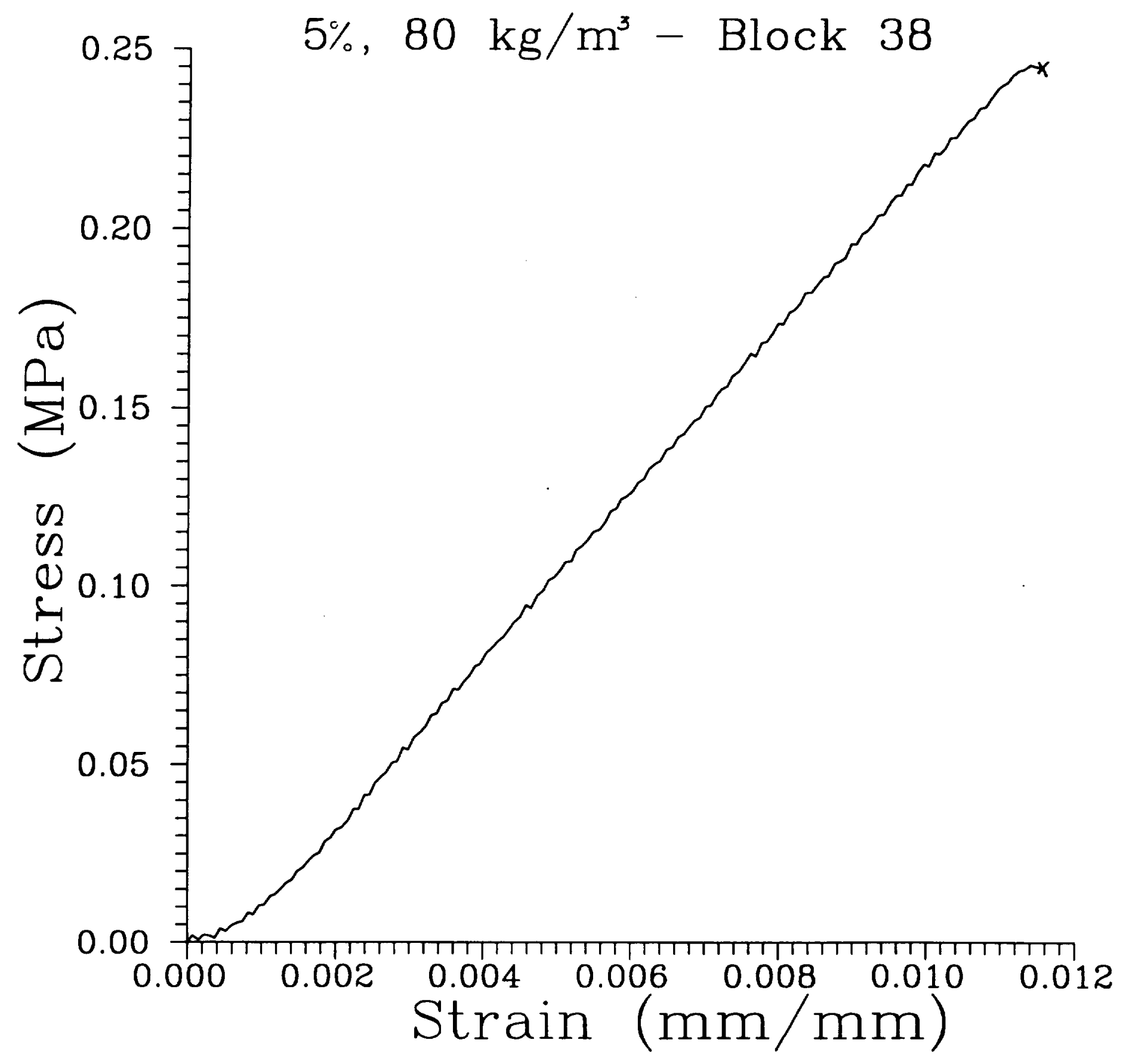

Figure 3.18

Stress-Strain Curve for Tensile Specimen.

Target Density $=80 \mathrm{~kg} / \mathrm{m}^{3}$, Fiber Percentage $=5 \%$ 


\subsection{Shear Tests}

Shear tests were attempted on six Iosipescu specimens. Five specimens had a target density of $80 \mathrm{~kg} / \mathrm{m}^{3}$ and $10 \%$ fibers, and one specimen had a target density of $80 \mathrm{~kg} / \mathrm{m}^{3}$ and $25 \%$ fibers. Tests were limited to these six specimens because of insufficient quality and quantity of material to machine a larger amount and variety of specimens. All but one specimen failed in tension rather than in shear. The exception to this trend failed under mixed-mode conditions. These findings are consistent with brittle material behavior. Brittle materials are stronger in shear than they are in tension, and thus preferentially fail by tension. As a result, only the lower bound of shear strength, equal to approximately $0.1 \mathrm{MPa}$ for both types of material, could be obtained from these tests. Diagrams depicting Iosipescu specimens failing by pure shear and by tension are provided in Figure 3.19.

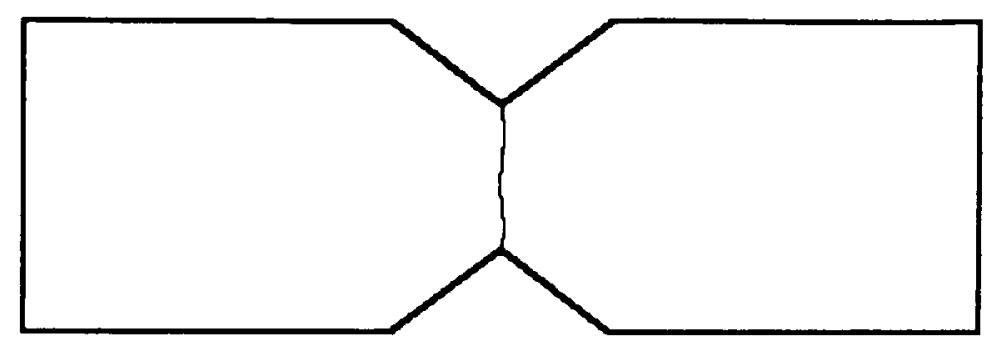

(a)

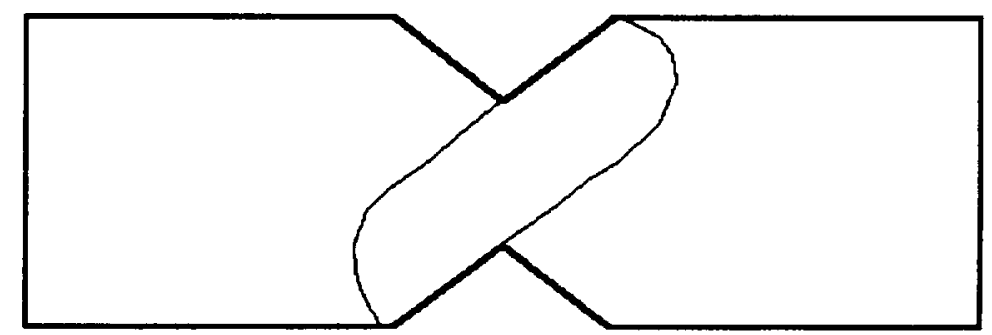

(b)

Figure 3.19

Diagrams of a) an Iosipescu specimen failing by pure shear, and b) and Iosipescu specimen failing by tension. 


\section{SUMMARY \& CONCLUSIONS}

Mechanical tests of unreinforced and fiber-reinforced silica aerogels have yielded several interesting findings. Most significantly, the aerogels generally exhibited lower compressive strengths, increased softness, and decreased elastic moduli when reinforced with fibers. This is partly due to the larger final densities observed for unreinforced and slightly reinforced aerogels relative to highly reinforced aerogels. During the supercritical drying process, the fibers support the matrix, reducing the amount of overall shrinkage. Without the fibers, or with smaller numbers of fibers, the matrix more readily shrinks resulting in a larger density. However, it is likely that density is not the only factor contributing to the lower strengths observed in reinforced aerogels. It is also possible that the fiber arrangement and the fiber-matrix bonding play a role in weakening the composite. The fibers do, nevertheless, offer at least one benefit: they seem to improve the aerogels' toughness.

The results of various qualitative tests indicate that the aerogels are: 1) sensitive to moisture absorption from handling and storage, 2) exhibit birefringence, and 3) may exhibit stress relaxation (or creep) under certain conditions. In addition, good correlation between hardness and compressive strength was found over a wide range of processing parameters. Finally, initial tensile and shear test results suggest that the aerogels have low tensile strengths relative to their compressive and shear strengths. This behavior is typical of brittle materials.

Future experiments should focus on detailed room temperature tensile tests, as well as on compression, hardness, and tensile tests at cryogenic temperatures. Cryogenic compression tests have been made in a gaseous helium environment by Arvidson and Scull [1986]. Modification of their technique may be applicable to other mecahnical testing on reinforced aerogels, as well. Moreover, before the mechanical response of reinforced aerogels can be fully understood, more tests of unreinforced aerogels are necessary. Unreinforced aerogels are of particular use because their birefringent nature allows for visual determination of stress fields during mechanical testing. In addition, the creep response of aerogels should be investigated in detail by the use of traditional techniques 
along with acoustic emission tests to record the sound of the composites cracking. Also of interest would be scanning electron microscope visualization of aerogel microstructure, cracks, and fiber pullout. Finally, fatigue, bending and load cycling tests should be initiated. 


\section{REFERENCES}

Arvidson, J. M., and L. L. Scull, "Compressive Properties of Silica Aerogel at 295, 76, and $20 \mathrm{~K}$," Advances in Cryogenic Engineering Materials, R. P. Reed and A. F. Clark (eds.), vol. 32, National Bureau of Standards, Boulder Colorado, 1986.

Cross, J., R Goswin, R. Gerlach, and J. Fricke, "Mechanical Properties of $\mathrm{SiO}_{2}$ Aerogels," Revue de Physique Appliquee, C4-4, 24, 185-190, 1989.

Fricke, J., "Aerogels and their Applications," Journal of Non-Crystalline Solids, 147\&148, 356-362, 1992.

Gronauer, M., A. Kadur, and J. Fricke, "Mechanical and Acoustic Properties of Silica Aerogel," Aerogels, J. Fricke (ed.), Springer, Berlin, 1986.

Gross, J. and J. Fricke, "Ultrasonic Velocity Measurements in Silica, Carbon, and Organic Aerogels," Journal of Non-Crystalline Solids, 145, 217-222, 1992.

Gross, J., J. Fricke, R. W. Pekala, and L. W. Hrubesh, "Elastic Nonlinearity of Aerogels," Physical Review B, 45(22), 12774-12777, 1992.

Iosipescu, N., "Photoelastic Investigations on an Accurate Procedure for the Pure Shear Testing of Materials," Rev. de Mec. Appl., 1, 147-164, 1963.

Teichner, S. J., G. A. Nicolaon, M. A. Vicarini, and G. E. E. Gardes, "Inorganic Oxide Aerogels," Advances in Colloid and Interface Science, 5, 245-273, 1976.

Woignier, T. and J. Phalippou, "Scaling Law Variation of the Mechanical Properties of Silica Aerogels," Revue de Physique Appliquee, C4-4, 24, 179-184, 1989. 


\section{APPENDIX A}

Specimen Dimensions 


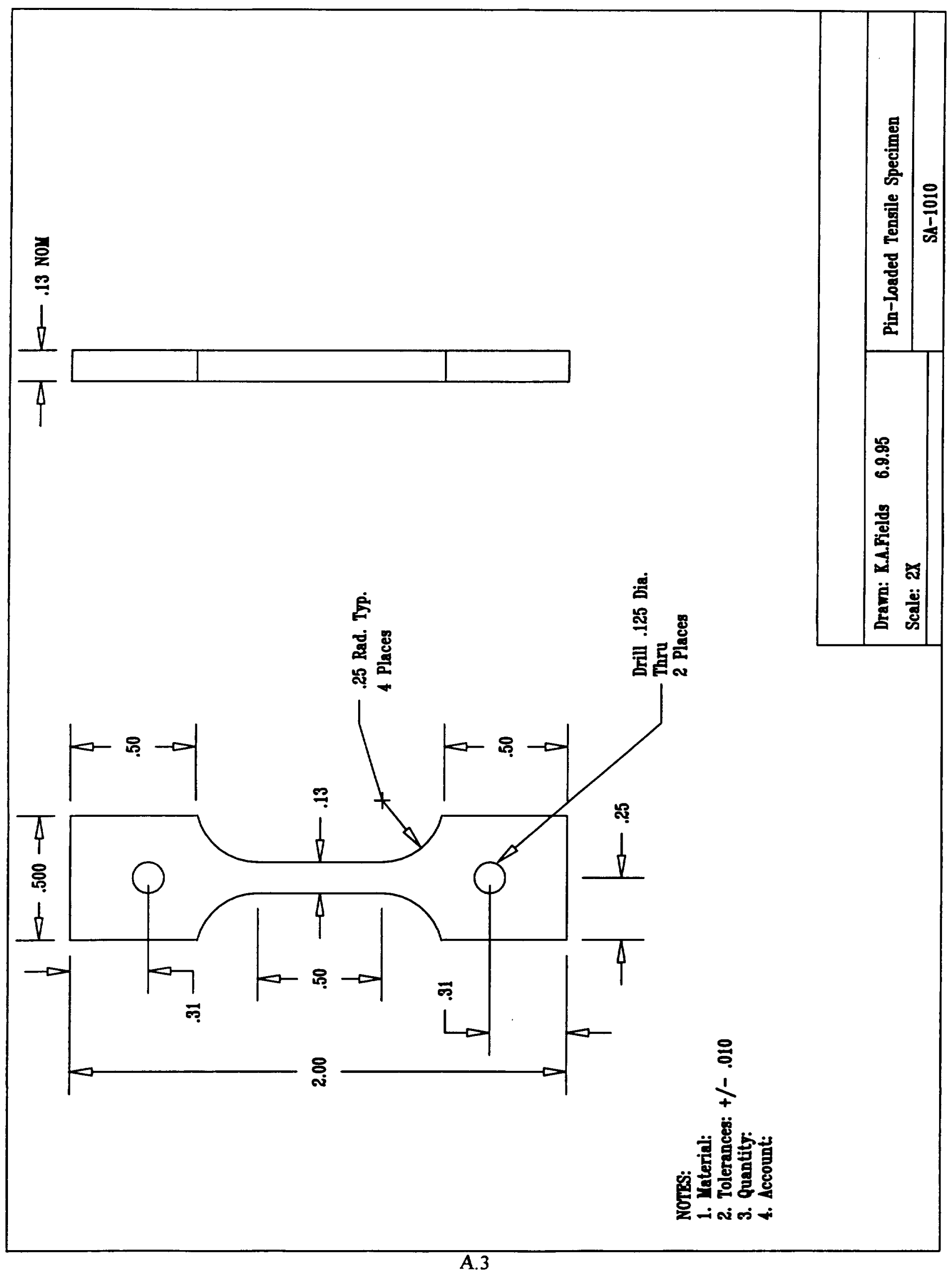



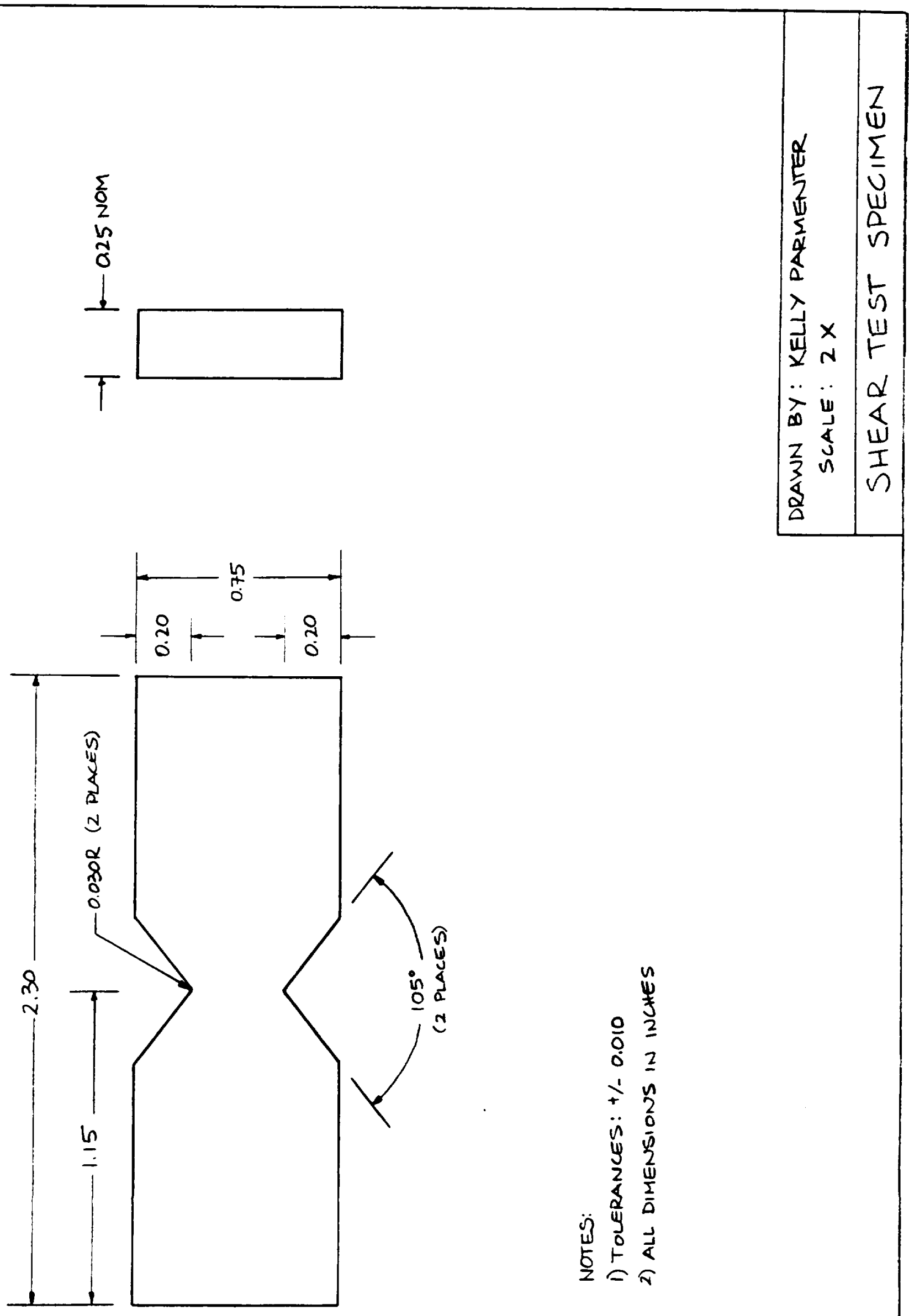
APPENDDX B

Hardness Results 


\section{Hardness \\ Block \#4, Unreinforced}

$3 / 21 / 95$

Avg. Density $=240 \mathrm{~kg} / \mathrm{m}^{\wedge} 3$

\begin{tabular}{ccc} 
Depth (mm) & Max. Load $(\mathbf{N})$ & Hardness $(\mathrm{MPa})$ \\
\hline 0.042 & 14.22 & 5.67 \\
0.041 & 14.24 & 5.78 \\
0.046 & 14.20 & 5.15 \\
0.054 & 14.21 & 4.38 \\
0.051 & 14.20 & 4.68 \\
0.043 & 14.25 & 5.50 \\
0.045 & 14.22 & 5.25 \\
0.042 & 14.23 & 5.63 \\
0.048 & 14.22 & 4.94 \\
0.041 & 14.22 & 5.76 \\
0.040 & 14.23 & 5.98 \\
0.042 & 14.22 & 5.68 \\
& \multicolumn{2}{c}{ Average } \\
\multicolumn{4}{c}{ Standard Deviation } \\
\end{tabular}

\section{Notes:}

Ball Diameter $=19.05 \mathrm{~mm}$

Hardness is based on depth at $2.02 \mathrm{~N}$ load

$\mathrm{H}=$ Max. Load/(pi * ball diam. * depth) 


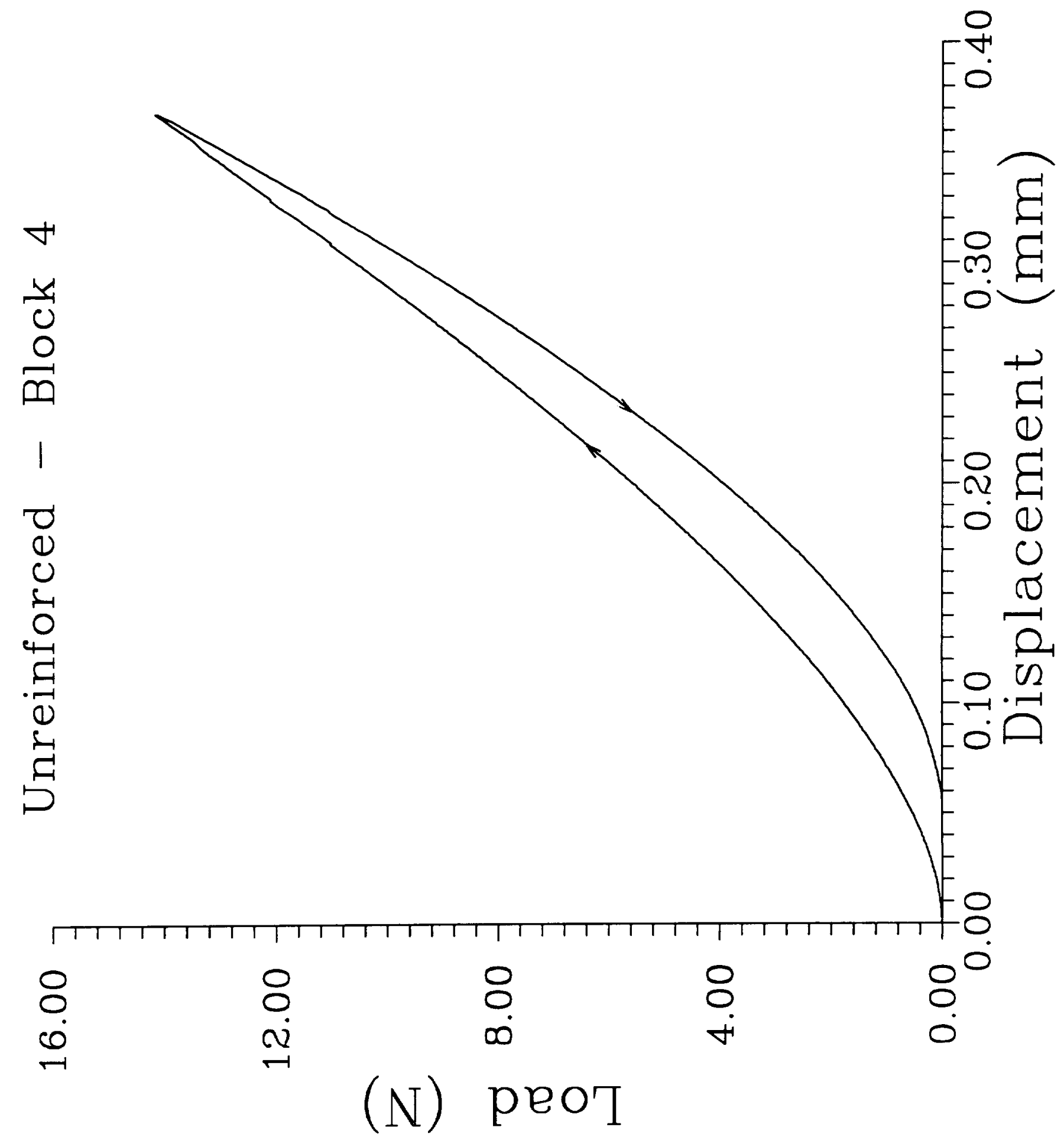

B. 3 


\section{Hardness}

Block \#12, $5 \%$ Fibers, Target Density $=40 \mathrm{~kg} / \mathrm{m}^{\wedge} 3$

$3 / 22 / 95$

Avg. Density $=260 \mathrm{~kg} / \mathrm{m}^{\wedge} 3$

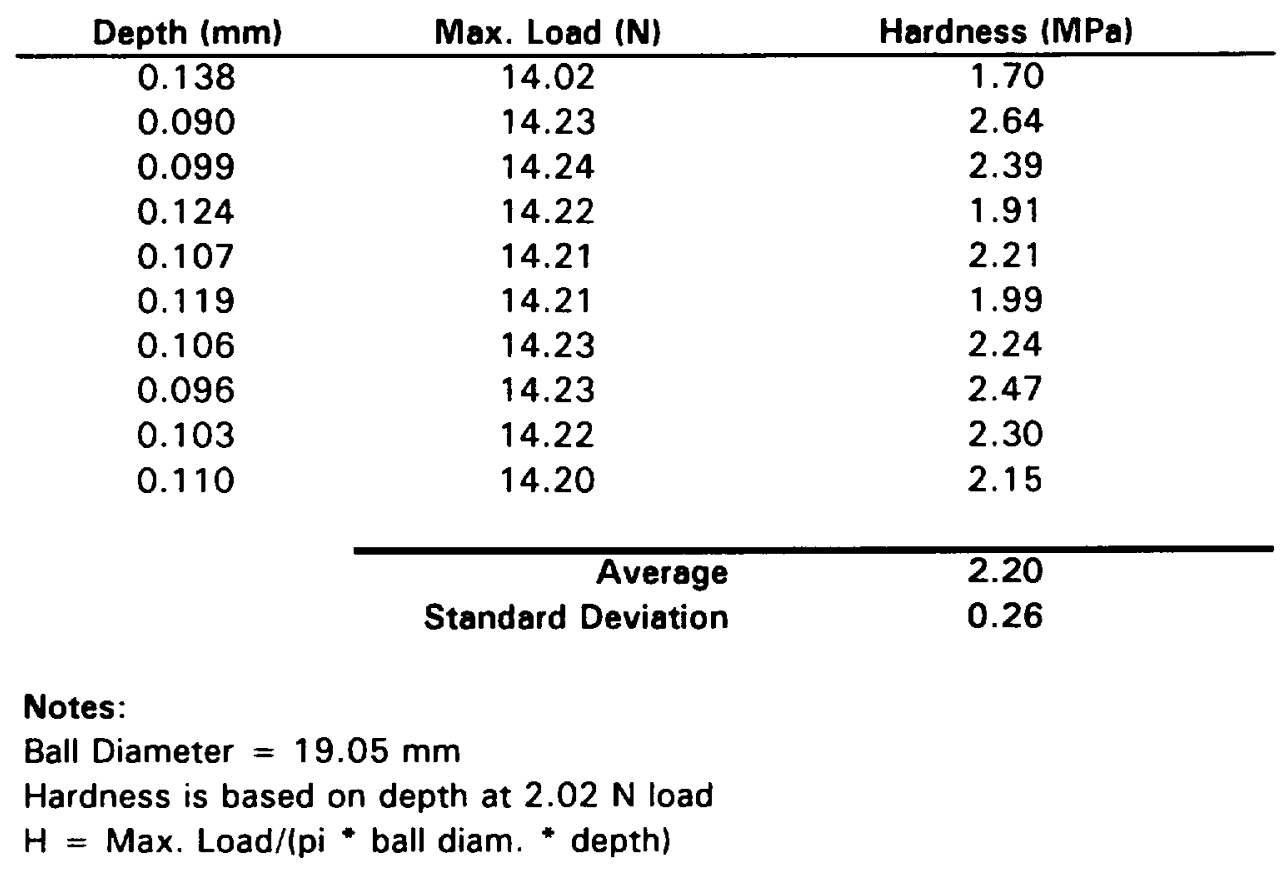

B.4 


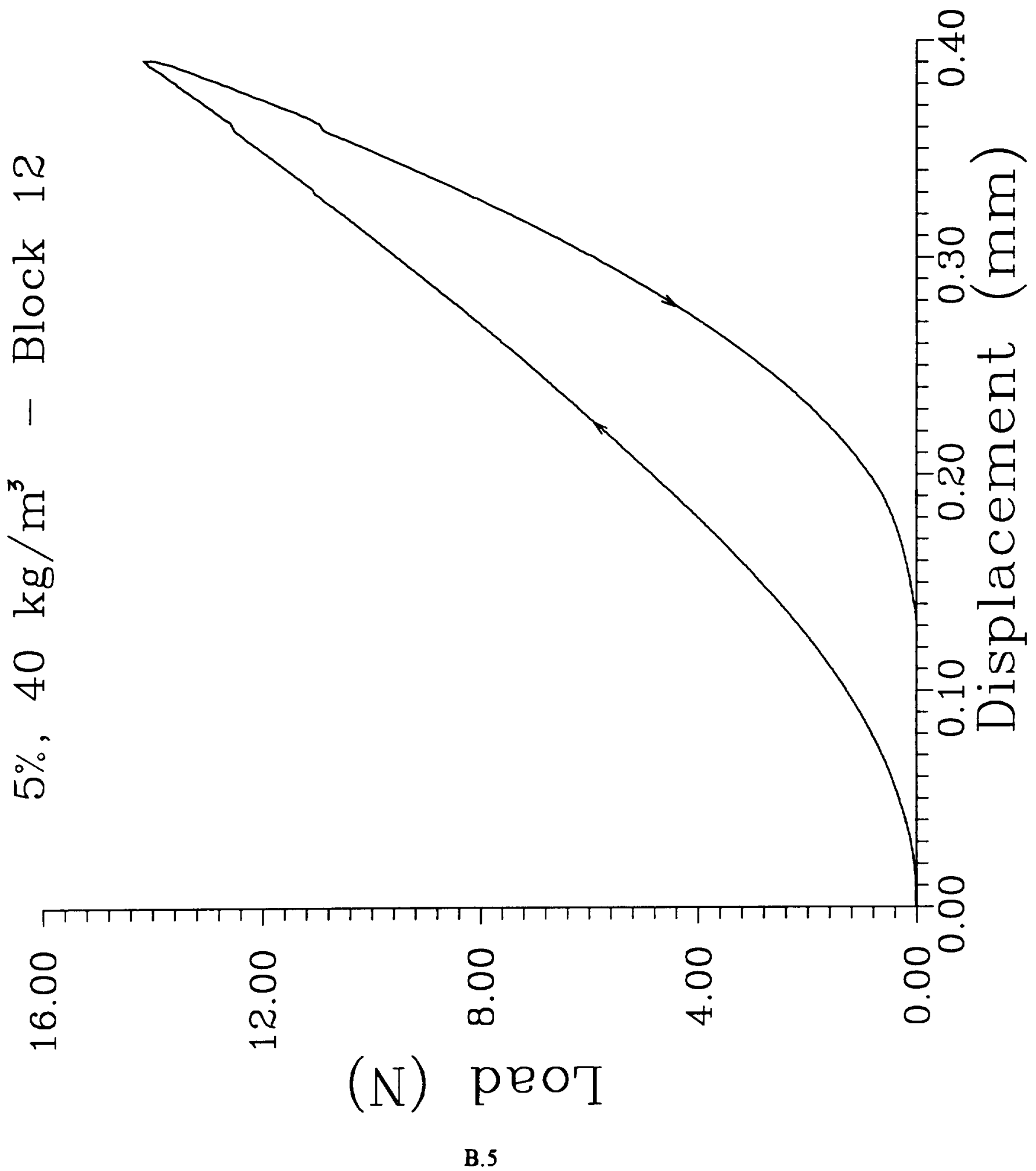




\section{Hardness}

Block \#35. 5\% Fibers, Target Density $=80 \mathrm{~kg} / \mathrm{m}^{\wedge} 3$

\section{$5 / 22 / 95$}

Avg. Density $=320 \mathrm{~kg} / \mathrm{m}^{\wedge} 3$

\begin{tabular}{ccc} 
Depth $(\mathrm{mm})$ & Max. Load $(\mathbf{N})$ & Hardness $(\mathrm{MPa})$ \\
\hline 0.052 & 14.25 & 4.55 \\
0.058 & 14.25 & 4.09 \\
0.047 & 14.27 & 5.05 \\
0.028 & 14.25 & 8.51 \\
0.030 & 14.26 & 7.91 \\
0.061 & 14.27 & 3.90 \\
& & 5.67 \\
& Sverage & 1.84
\end{tabular}

Notes:

Ball Diameter $=19.05 \mathrm{~mm}$

Hardness is based on depth at $2.02 \mathrm{~N}$ load

$H=$ Max. Load/(pi * ball diam. * depth) 


\section{Hardness}

Block \#14, 10\% Fibers. Target Density $=40 \mathrm{~kg} / \mathrm{m}^{\wedge} 3$

\section{$3 / 23 / 95$}

Avg. Density $=190 \mathrm{~kg} / \mathrm{m}^{\wedge} 3$

\begin{tabular}{ccc} 
Depth $(\mathrm{mm})$ & Max. Load $(\mathbf{N})$ & Hardness $(\mathrm{MPa})$ \\
\hline 0.174 & 10.12 & 0.97 \\
0.187 & 10.13 & 0.91 \\
0.176 & 10.14 & 0.96 \\
0.173 & 10.14 & 0.98 \\
0.185 & 10.15 & 0.92 \\
0.163 & 10.15 & 1.04 \\
0.167 & 10.13 & 1.01 \\
& & 0.97 \\
& Standard Deviation & 0.04
\end{tabular}

Notes:

Ball Diameter $=19.05 \mathrm{~mm}$

Hardness is based on depth at $2.02 \mathrm{~N}$ load

$H=$ Max. Load/(pi * ball diam. * depth) 


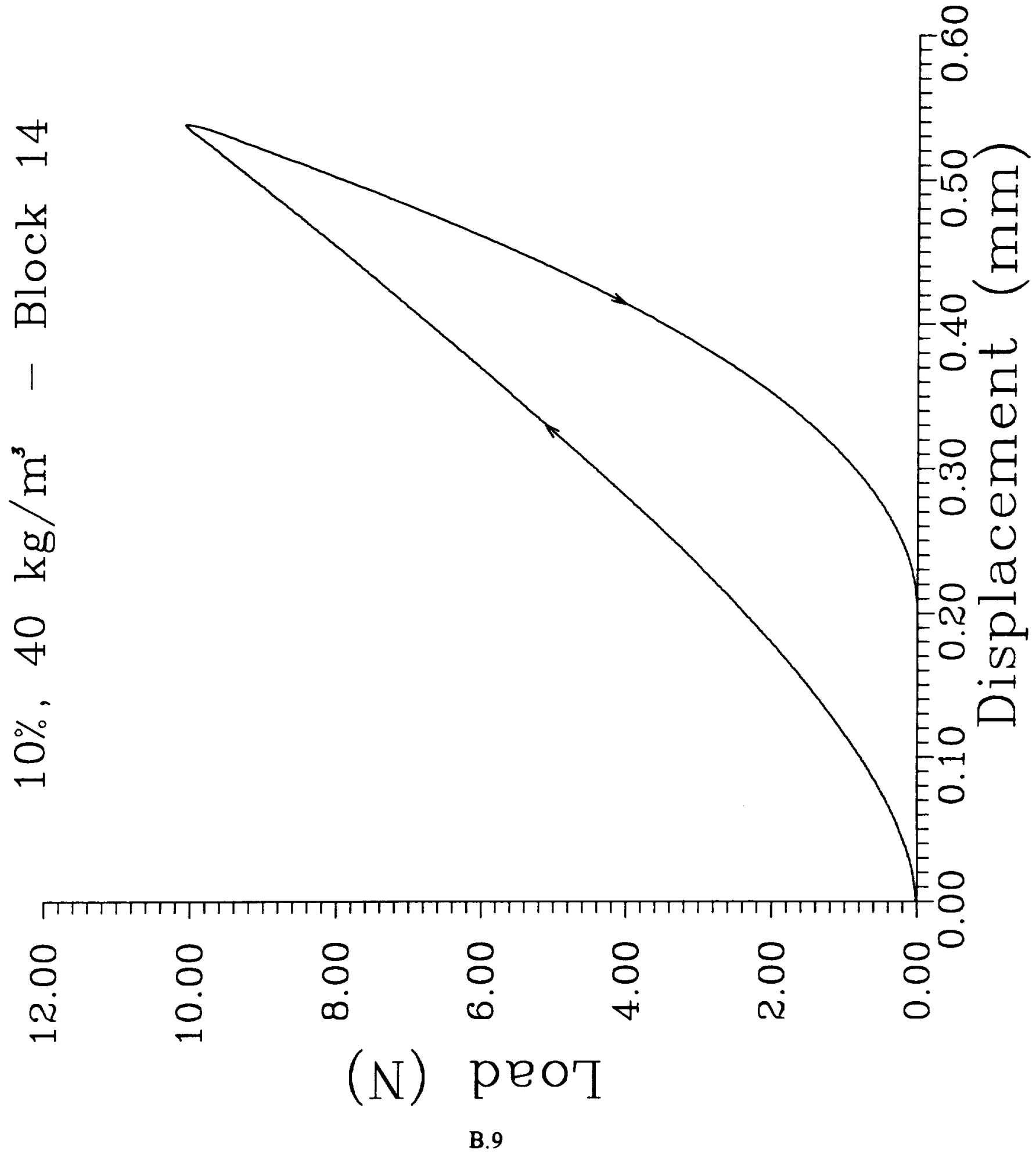




\section{Hardness}

Block \#2, $10 \%$ Fibers, Target Density $=50 \mathrm{~kg} / \mathrm{m}^{\wedge} 3$

\section{3/13/95}

Avg. Density $=230 \mathrm{~kg} / \mathrm{m}^{\wedge} 3$

\begin{tabular}{ccc} 
Depth $(\mathrm{mm})$ & Max. Load $(\mathbf{N})$ & Hardness $(\mathrm{MPa})$ \\
\hline 0.080 & 14.20 & 2.97 \\
0.053 & 14.43 & 4.54 \\
0.070 & 14.23 & 3.38 \\
0.073 & 14.20 & 3.25 \\
0.061 & 14.23 & 3.93 \\
0.057 & 14.20 & 4.17 \\
& \multicolumn{2}{c}{ Average } \\
\cline { 2 - 3 } & Standard Deviation & 0.71
\end{tabular}

Notes:

Ball Diameter $=19.05 \mathrm{~mm}$

Hardness is based on depth at $2.02 \mathrm{~N}$ load

$\mathrm{H}=$ Max. Load/(pi * ball diam. * depth) 


\section{Hardness}

Blocks\#16 \& 17, 10\% Fibers, Target Density $=80 \mathrm{~kg} / \mathrm{m}^{\wedge} 3$

\section{$5 / 22 / 95$}

Avg. Density $=330 \mathrm{~kg} / \mathrm{m}^{\wedge} 3$

\begin{tabular}{cccc} 
Depth $(\mathrm{mm})$ & Max. Load $(\mathbf{N})$ & Hardness $(\mathrm{MPa})$ & Block \# \\
\hline 0.116 & 14.29 & 2.06 & 17 \\
0.114 & 14.24 & 2.08 & 17 \\
0.121 & 14.26 & 1.97 & 17 \\
0.121 & 14.27 & 1.96 & 17 \\
0.025 & 14.27 & 9.37 & 17 \\
0.039 & 14.24 & 6.05 & 16 \\
0.040 & 14.34 & 5.99 & 16 \\
0.035 & 14.26 & 6.82 & 16 \\
0.050 & 15.00 & 5.03 & 16 \\
0.024 & 14.27 & 9.87 & 16 \\
0.039 & 14.26 & 6.15 & 16 \\
0.034 & 14.26 & 7.11 & 16 \\
& & &
\end{tabular}

Notes:

Ball Diameter $=19.05 \mathrm{~mm}$

Hardness is based on depth at $2.02 \mathrm{~N}$ load

$H=$ Max. Load/(pi * ball diam. * depth) 


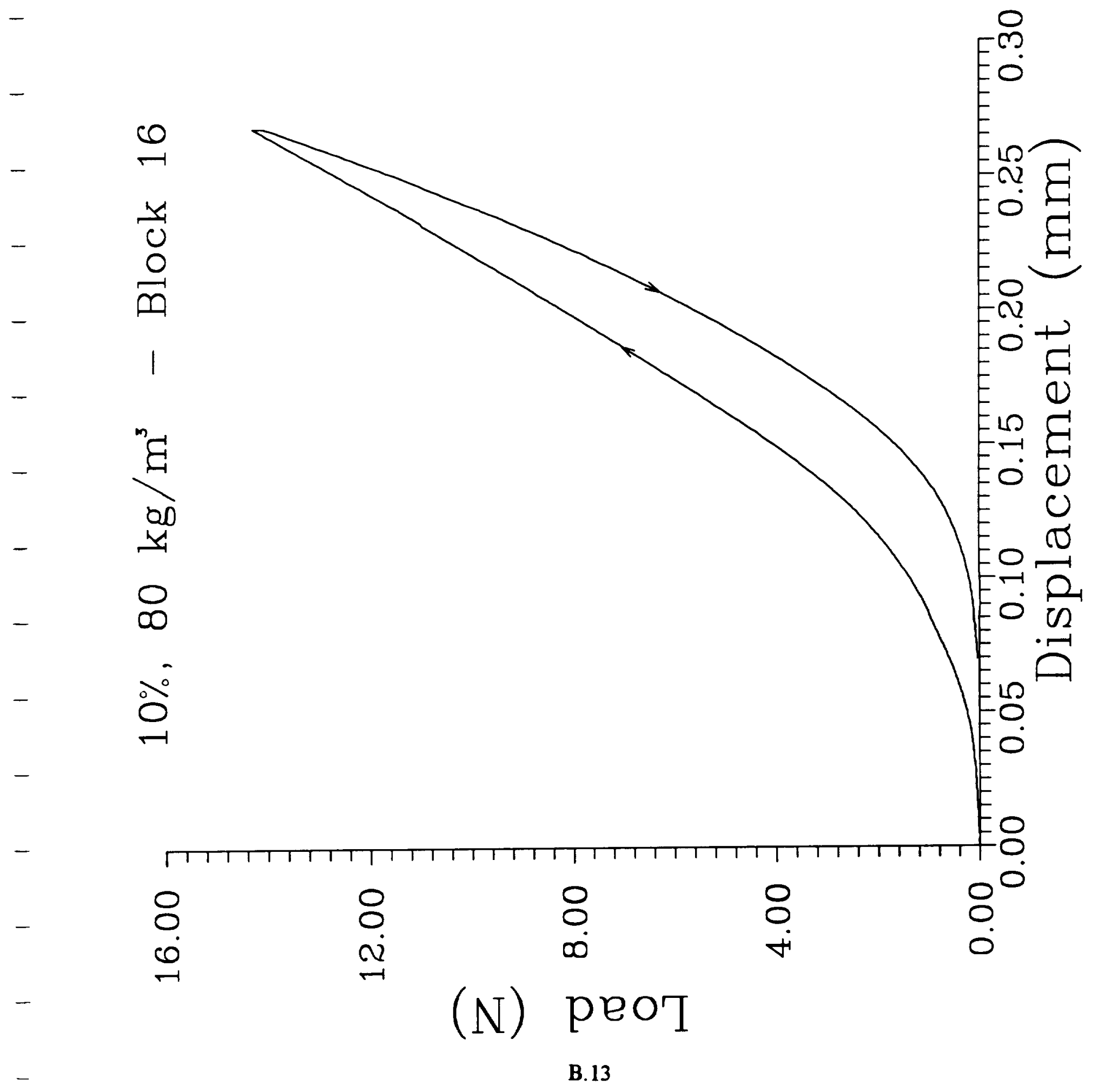




\section{Hardness}

Blocks \#5, 6 \& 7, 25\% Fibers, Target Density $=40 \mathrm{~kg} / \mathrm{m}^{\wedge} 3$

$$
5 / 18 / 95-5 / 19 / 95
$$

Avg. Density $=190 \mathrm{~kg} / \mathrm{m}^{\wedge} 3$

\begin{tabular}{cccc} 
Depth $(\mathrm{mm})$ & Max. Load $(\mathrm{N})$ & Hardness $(\mathrm{MPa})$ & Block \# \\
\hline 0.165 & 14.19 & 1.44 & 5 \\
0.164 & 14.19 & 1.45 & 5 \\
0.152 & 14.33 & 1.58 & 5 \\
0.148 & 14.20 & 1.61 & 5 \\
0.155 & 14.20 & 1.53 & 6 \\
0.155 & 14.23 & 1.53 & 6 \\
0.157 & 14.20 & 1.51 & 6 \\
0.159 & 14.19 & 1.50 & 6 \\
0.159 & 14.20 & 1.49 & 6 \\
0.146 & 14.21 & 1.63 & 7 \\
0.153 & 14.21 & 1.56 & 7 \\
0.147 & 14.20 & 1.62 & 7 \\
0.150 & 14.19 & 1.58 & 7 \\
0.158 & 14.20 & 1.51 & 7 \\
& & &
\end{tabular}

Notes:

Ball Diameter $=19.05 \mathrm{~mm}$

Hardness is based on depth at $2.02 \mathrm{~N}$ load

$\mathrm{H}=\operatorname{Max}$. Load/(pi * ball diam. * depth) 


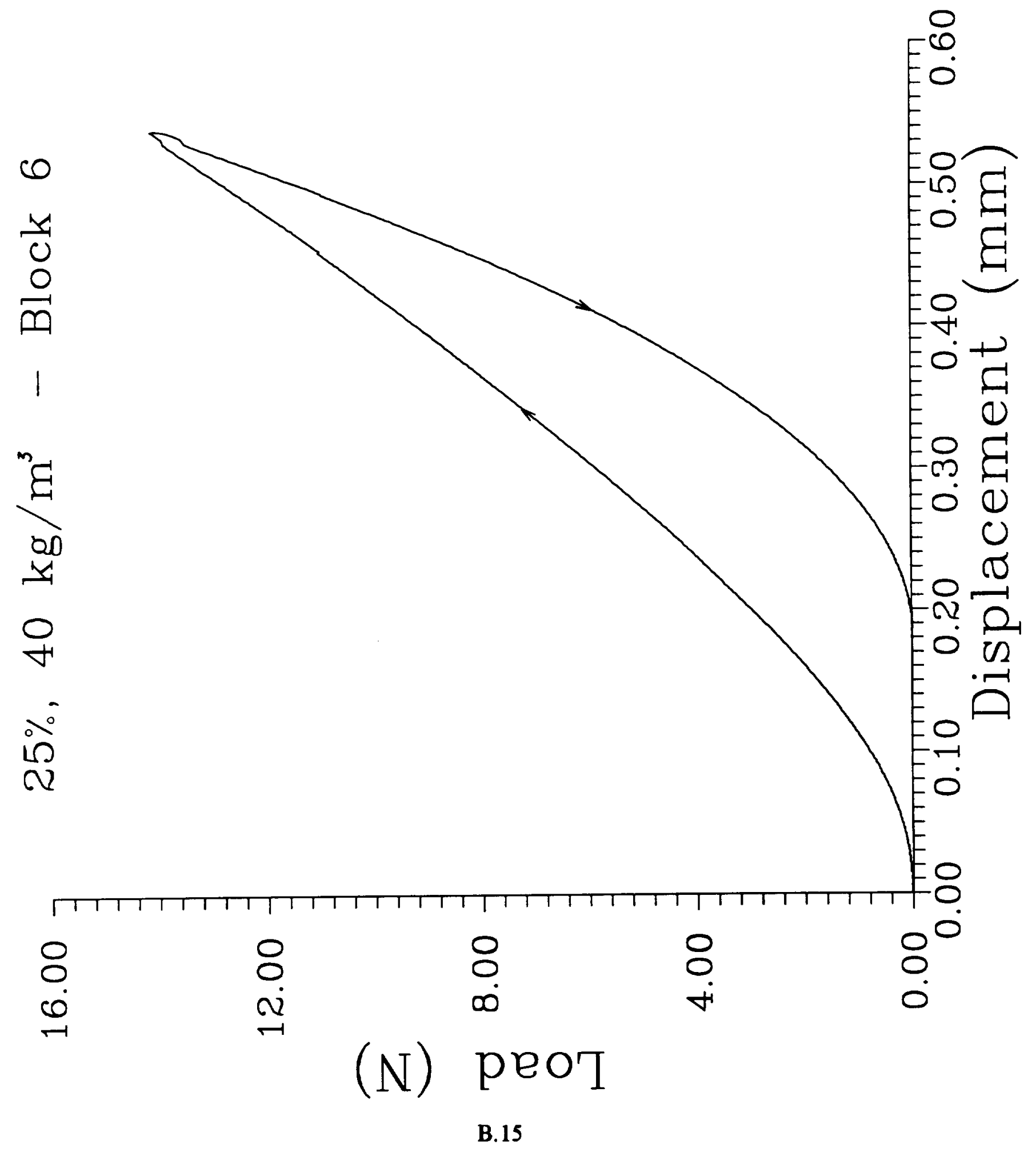




\section{Hardness}

Block A, 25\% Fibers, Target Density $=50 \mathrm{~kg} / \mathrm{m}^{\wedge} 3$

Avg. Density $=200 \mathrm{~kg} / \mathrm{m}^{\wedge} 3$

\begin{tabular}{ccc} 
Depth (mm) & Max. Load (N) & Hardness (MPa) \\
\hline 0.133 & 14.19 & 1.78 \\
0.101 & 14.18 & 2.34 \\
0.113 & 14.19 & 2.10 \\
0.115 & 14.20 & 2.07 \\
0.104 & 14.21 & 2.29 \\
0.112 & 14.21 & 2.13 \\
0.118 & 14.18 & 2.00 \\
0.107 & 14.21 & 2.22 \\
0.105 & 14.20 & 2.26 \\
0.099 & 14.20 & 2.39 \\
0.109 & 14.19 & 2.17 \\
0.128 & 13.99 & 1.83 \\
0.150 & 14.25 & 1.59 \\
0.119 & 14.23 & 2.00 \\
0.122 & 14.23 & 1.95 \\
0.104 & 14.21 & 2.28 \\
0.103 & 14.22 & 2.31 \\
0.120 & 14.19 & 1.98 \\
0.158 & 14.20 & 1.50 \\
0.118 & 14.23 & 2.01 \\
0.117 & 14.24 & 2.03 \\
0.130 & 14.18 & 1.83 \\
0.142 & 14.20 & 1.68 \\
0.135 & 14.19 & 1.75 \\
& & \\
\hline & Atandard Deviation & 0.24 \\
& &
\end{tabular}

Notes:

Ball Diameter $=19.05 \mathrm{~mm}$

Hardness is based on depth at $2.02 \mathrm{~N}$ load

$\mathrm{H}=$ Max. Load/(pi * ball diam. * depth) 


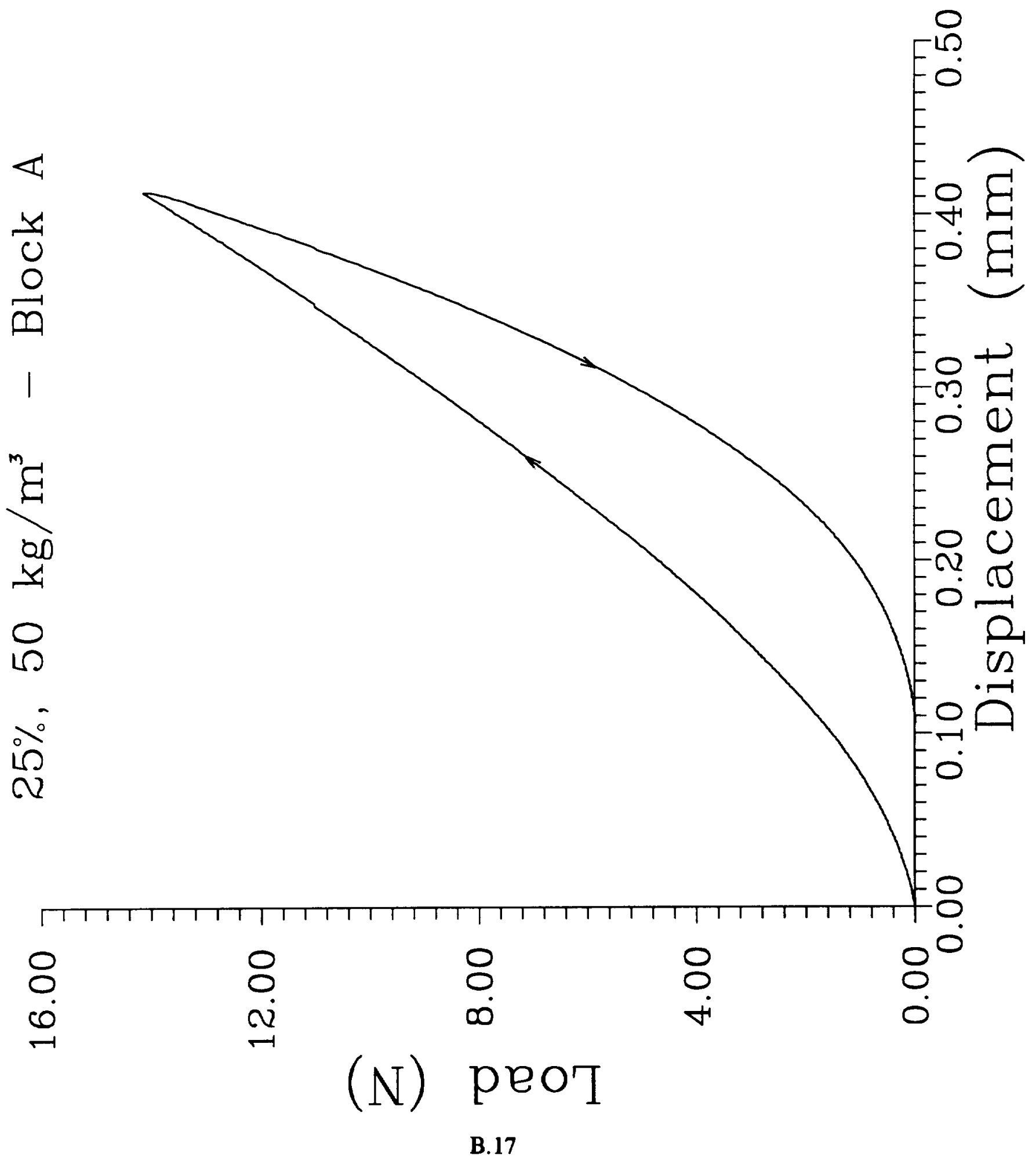




\section{Hardness}

Blocks \#2 and 3, 25\% Fibers, Target Density $=80 \mathrm{~kg} / \mathrm{m}^{\wedge} 3$

$3 / 9 / 95 \& 3 / 13 / 95$

Avg. Density $=240 \mathrm{~kg} / \mathrm{m}^{\wedge} 3$

\begin{tabular}{cccc} 
Depth $(\mathbf{m m})$ & Max. Load $(\mathbf{N})$ & Hardness $(\mathrm{MPa})$ & Block \# \\
\hline 0.130 & 14.19 & 1.82 & 2 \\
0.115 & 14.21 & 2.07 & 2 \\
0.143 & 14.61 & 1.71 & 2 \\
0.111 & 14.01 & 2.10 & 2 \\
0.110 & 14.24 & 2.17 & 2 \\
0.115 & 14.18 & 2.05 & 3 \\
0.110 & 14.21 & 2.16 & 3 \\
0.100 & 14.22 & 2.37 & 3 \\
0.097 & 14.22 & 2.46 & 3 \\
0.107 & 14.20 & 2.21 & 3 \\
& & & \\
& Average & 2.11 &
\end{tabular}

Notes:

Ball Diameter $=19.05 \mathrm{~mm}$

Hardness is based on depth at $2.02 \mathrm{~N}$ load

$\mathrm{H}=$ Max. Load/(pi * ball diam. * depth) 
APPENDIX C

Hardness Trend Data 


\section{Relaxation Test}

Avg. Density $=250 \mathrm{~kg} / \mathrm{m}^{\wedge} 3$

\section{$1 / 5 / 95$}

\begin{tabular}{ccccc} 
Max. Load (N) & Depth $(\mathrm{mm})$ & Time & $\begin{array}{c}\text { Hardness } \\
\text { (MPa) }\end{array}$ & Load Drop (N) \\
\hline 14.28 & 0.032 & 0 & 7.40 & 0.00 \\
14.30 & 0.038 & 1 & 6.31 & 0.51 \\
14.30 & 0.045 & 10 & 5.27 & 1.19 \\
14.27 & 0.053 & 30 & 4.49 & 1.67 \\
14.26 & 0.055 & 60 & 4.36 & 2.04
\end{tabular}

Notes:

Ball Diameter $=19.05 \mathrm{~mm}$

Hardness is based on depth at $2.02 \mathrm{~N}$ load

$\mathrm{H}=$ Max. Load/(pi * ball diam. * depth) 
Hardness vs. Maximum Load Test

Avg. Density $=300 \mathrm{~kg} / \mathrm{m}^{\wedge} 3$

$1 / 4 / 95$

\begin{tabular}{ccc} 
Depth (mm) & Max. Load (N) & Hardness (MPa) \\
\hline 0.020 & 10.23 & 8.48 \\
0.034 & 12.28 & 6.05 \\
0.036 & 14.28 & 6.60 \\
0.042 & 16.30 & 6.45 \\
0.033 & 18.35 & 9.33 \\
0.020 & 10.21 & 8.72 \\
0.024 & 12.27 & 8.38 \\
0.037 & 14.31 & 6.51 \\
0.033 & 16.32 & 8.23 \\
0.033 & 18.37 & 9.34
\end{tabular}

Notes:

Ball Diameter $=19.05 \mathrm{~mm}$

Hardness is based on depth at $2.02 \mathrm{~N}$ load

$\mathrm{H}=$ Max. Load/(pi * ball diam. * depth) 


\section{Hardness vs. Crosshead Speed}

Avg. Density $=210 \mathrm{~kg} / \mathrm{m}^{\wedge} 3$

\section{$12 / 28 / 95$}

\begin{tabular}{cccc} 
Max. Load (N) & Depth $(\mathbf{m m})$ & $\begin{array}{c}\text { Crosshead Speed } \\
(\mathrm{mm} / \mathrm{min})\end{array}$ & $\begin{array}{c}\text { Hardness } \\
(\mathrm{MPa})\end{array}$ \\
\hline 14.19 & 0.062 & 0.025 & 3.82 \\
14.21 & 0.051 & 0.051 & 4.65 \\
14.23 & 0.053 & 0.076 & 4.53 \\
14.25 & 0.050 & 0.102 & 4.74 \\
14.25 & 0.049 & 0.127 & 4.87 \\
14.25 & 0.048 & 0.152 & 4.96 \\
14.33 & 0.051 & 0.203 & 4.70
\end{tabular}

\section{Notes:}

Ball Diameter $=19.05 \mathrm{~mm}$

Hardness is based on depth at $2.02 \mathrm{~N}$ load

$\mathrm{H}=$ Max. Load/(pi * ball diam. * depth) 
APPENDDX D

Compression Results: Tests in Air 


\section{Summary of Compression Results \\ Unreinforced - 5th block \\ 4/17/95 - Tests in Air \\ Avg Density $=240 \mathrm{~kg} / \mathrm{m}^{\wedge} 3$}

\begin{tabular}{ccccc} 
Expt. \# & $\begin{array}{c}\text { Compressive } \\
\text { Strength } \\
(\mathrm{MPa})\end{array}$ & $\begin{array}{c}\text { Compressive Strain } \\
\text { at Fracture } \\
(\mathbf{m m} / \mathbf{m m})\end{array}$ & $\begin{array}{c}\text { E(50\%) } \\
(\mathrm{MPa})\end{array}$ & $\begin{array}{c}\text { E(90\%) } \\
(\mathrm{MPa})\end{array}$ \\
\hline 1 & 0.97 & 0.093 & 16.7 & 13.4 \\
2 & 1.01 & 0.113 & 18.5 & 14.9 \\
3 & 1.04 & 0.093 & 14.1 & 14.1 \\
Average & 1.01 & 0.100 & 16.4 & 14.1 \\
Std. Dev. & $\mathbf{0 . 0 3}$ & 0.009 & 1.8 & 0.6
\end{tabular}

Notes:

1) The crosshead speed was $0.1016 \mathrm{~mm} / \mathrm{min}$

2) $E(50 \%)$ is the secant modulus between the point $A$, of stress $=0.04 \mathrm{MPa}$, and point $B$, of stress $=50 \%$ of the compressive strength

3) $E(90 \%)$ is the secant modulus between the point $A$, of stress $=0.04 \mathrm{MPa}$, and point $C$, of stress $=90 \%$ of the compressive strength

4) The specimens were unreinforced

5) Tests were done at room temperature in air, with no prior desiccation 


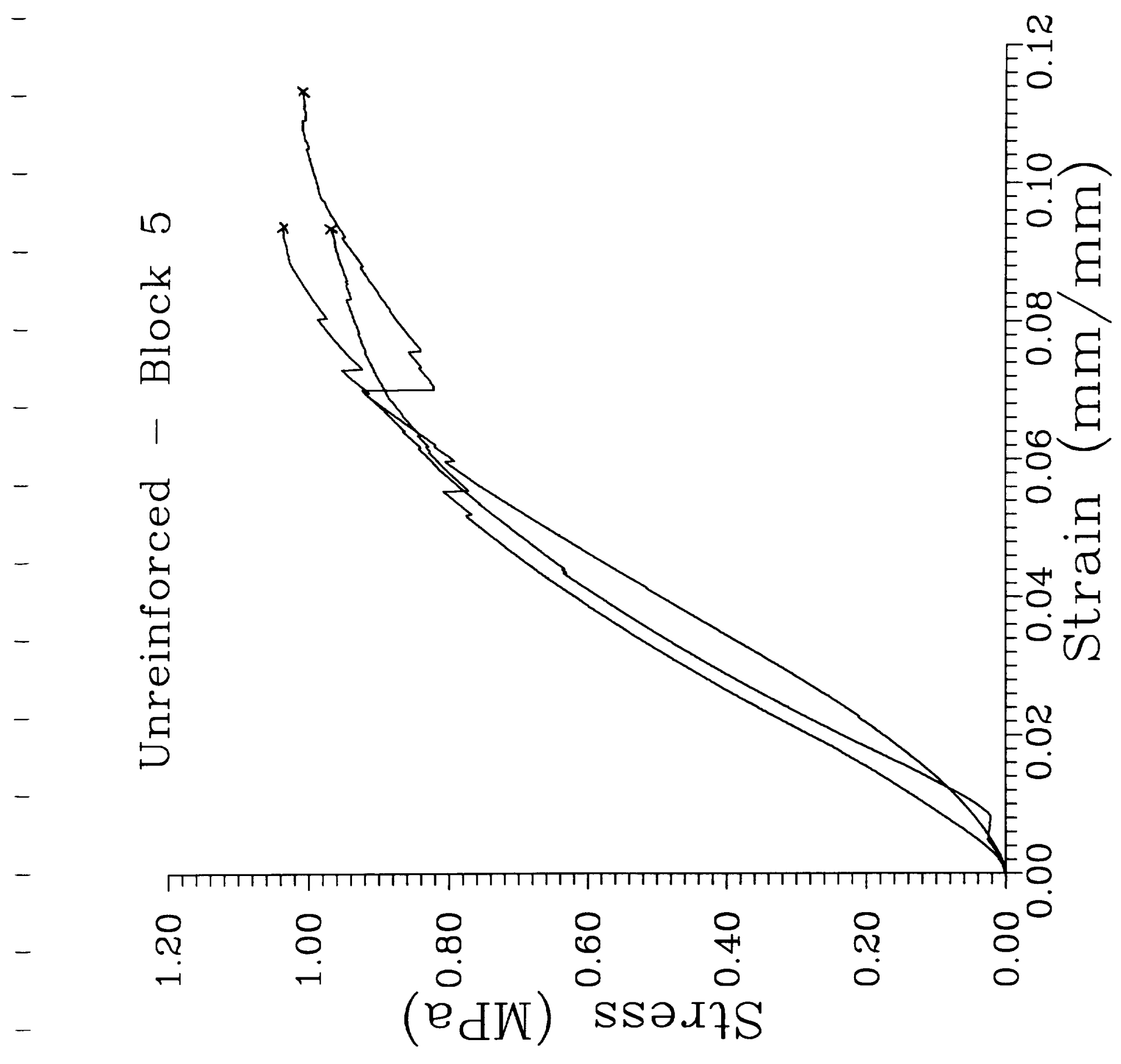




\section{Summary of Compression Results}

$5 \%, 40 \mathrm{~kg} / \mathrm{m}^{\wedge} 3$ - 9 th block

3/31/95 - Tests in Air

Avg Density $=260 \mathrm{~kg} / \mathrm{m}^{\wedge} 3$

\begin{tabular}{ccccc} 
Expt. \# & $\begin{array}{c}\text { Compressive } \\
\text { Strength } \\
\text { (MPa) }\end{array}$ & $\begin{array}{c}\text { Compressive Strain } \\
\text { at Fracture } \\
(\mathbf{m m} / \mathbf{m m})\end{array}$ & $\begin{array}{c}\mathrm{E} \text { (50\%) } \\
\text { (MPa) }\end{array}$ & $\begin{array}{c}\text { E(90\%) } \\
\text { (MPa) }\end{array}$ \\
\hline 1 & 1.09 & 0.058 & 21.4 & 22.7 \\
2 & 0.89 & 0.082 & 23.7 & 17.2 \\
3 & 1.02 & 0.074 & 16.1 & 15.0 \\
Average & 1.00 & & & \\
Std. Dev. & 0.08 & 0.071 & 20.4 & 18.3 \\
& & 0.010 & 3.2 & 3.2
\end{tabular}

Notes:

1) The crosshead speed was $0.1016 \mathrm{~mm} / \mathrm{min}$

2) $E(50 \%)$ is the secant modulus between the point $A$, of stress $=0.04 \mathrm{MPa}$, and point $B$, of stress $=50 \%$ of the compressive strength

3) $\mathrm{E}(90 \%)$ is the secant modulus between the point $\mathrm{A}$, of stress $=0.04 \mathrm{MPa}$, and point $C$, of stress $=90 \%$ of the compressive strength

4) The specimens were $5 \%$ fiber loaded, target density $=40 \mathrm{~kg} / \mathrm{m}^{\wedge} 3$

5) Tests were done at room temperature in air, with no prior desiccation 


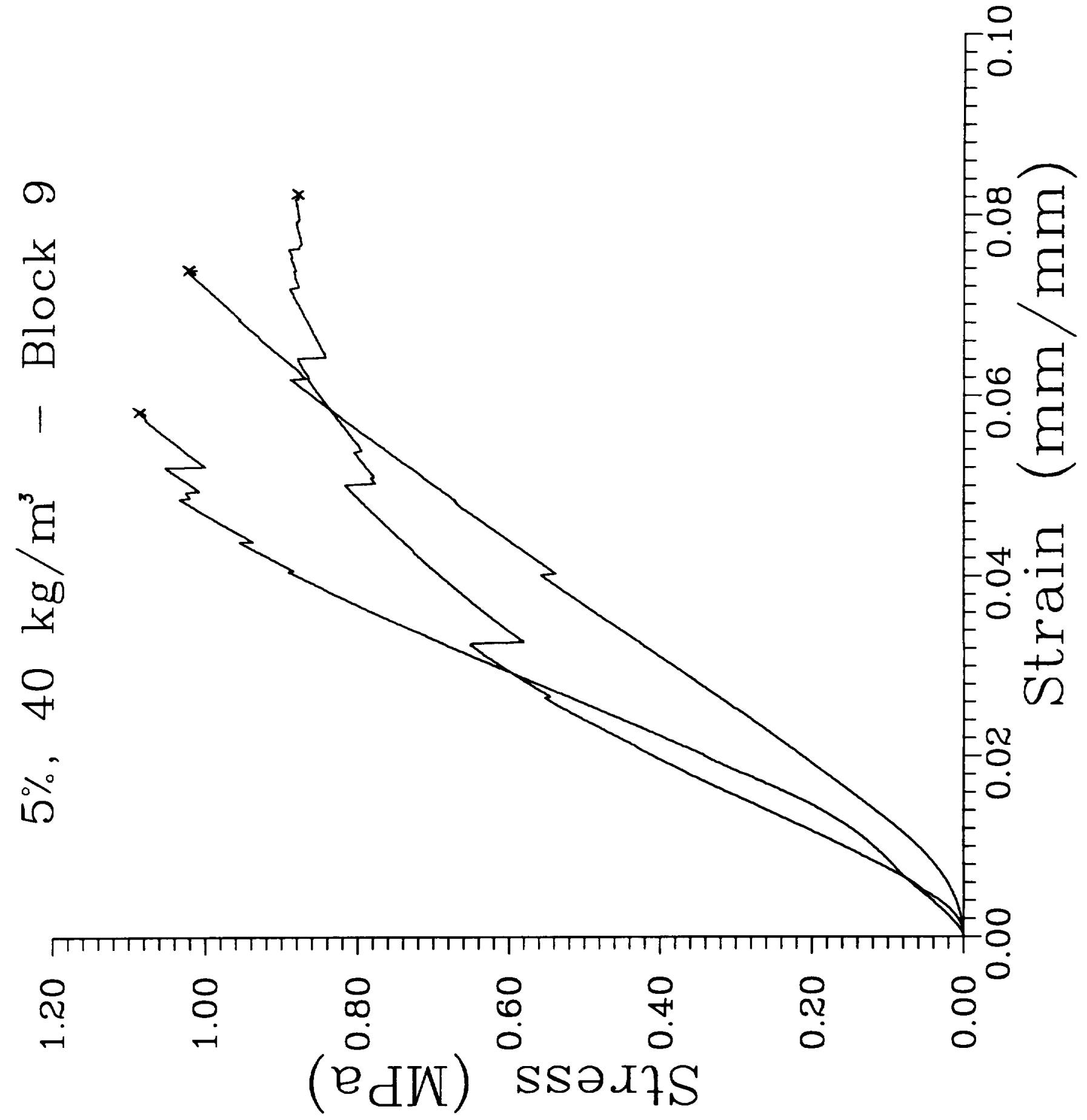

D.5 


\begin{tabular}{|c|c|c|c|c|}
\hline \multicolumn{5}{|c|}{$\begin{array}{c}\text { Summary of Compression Results } \\
5 \%, 80 \mathrm{~kg} / \mathrm{m}^{\wedge} 3-35 \text { th block } \\
6 / 2 / 95-\text { Tests in Air } \\
\text { Avg Density }=320 \mathrm{~kg} / \mathrm{m}^{\wedge} 3\end{array}$} \\
\hline Expt. \# & $\begin{array}{l}\text { Compressive } \\
\text { Strength } \\
\text { (MPa) }\end{array}$ & $\begin{array}{l}\text { Compressive Strain } \\
\text { at Fracture } \\
\text { (mm/mm) }\end{array}$ & $\begin{array}{c}E(50 \%) \\
(\mathrm{MPa})\end{array}$ & $\begin{array}{c}E(90 \%) \\
(\mathrm{MPa})\end{array}$ \\
\hline 1 & 1.21 & 0.046 & 30.3 & 29.9 \\
\hline 2 & - & - & - & - \\
\hline 3 & 1.37 & 0.058 & 37.4 & 35.8 \\
\hline 4 & 1.54 & 0.053 & 36.6 & 33.8 \\
\hline 5 & 1.68 & 0.053 & 39.5 & 36.2 \\
\hline Average & 1.45 & 0.053 & 36.0 & 33.9 \\
\hline Std. Dev. & 0.18 & 0.004 & 3.4 & 2.5 \\
\hline
\end{tabular}

Notes:

1) The crosshead speed was $0.1016 \mathrm{~mm} / \mathrm{min}$

2) $E(50 \%)$ is the secant modulus between the point $A$, of stress $=0.04 \mathrm{MPa}$, and point $B$, of stress $=50 \%$ of the compressive strength

3) $\mathrm{E}(90 \%)$ is the secant modulus between the point $A$, of stress $=0.04 \mathrm{MPa}$, and point $C$, of stress $=90 \%$ of the compressive strength

4) The specimens were $5 \%$ fiber loaded, target density $=80 \mathrm{~kg} / \mathrm{m}^{\wedge} 3$

5) Tests were done at room temperature in air, with no prior desiccation 


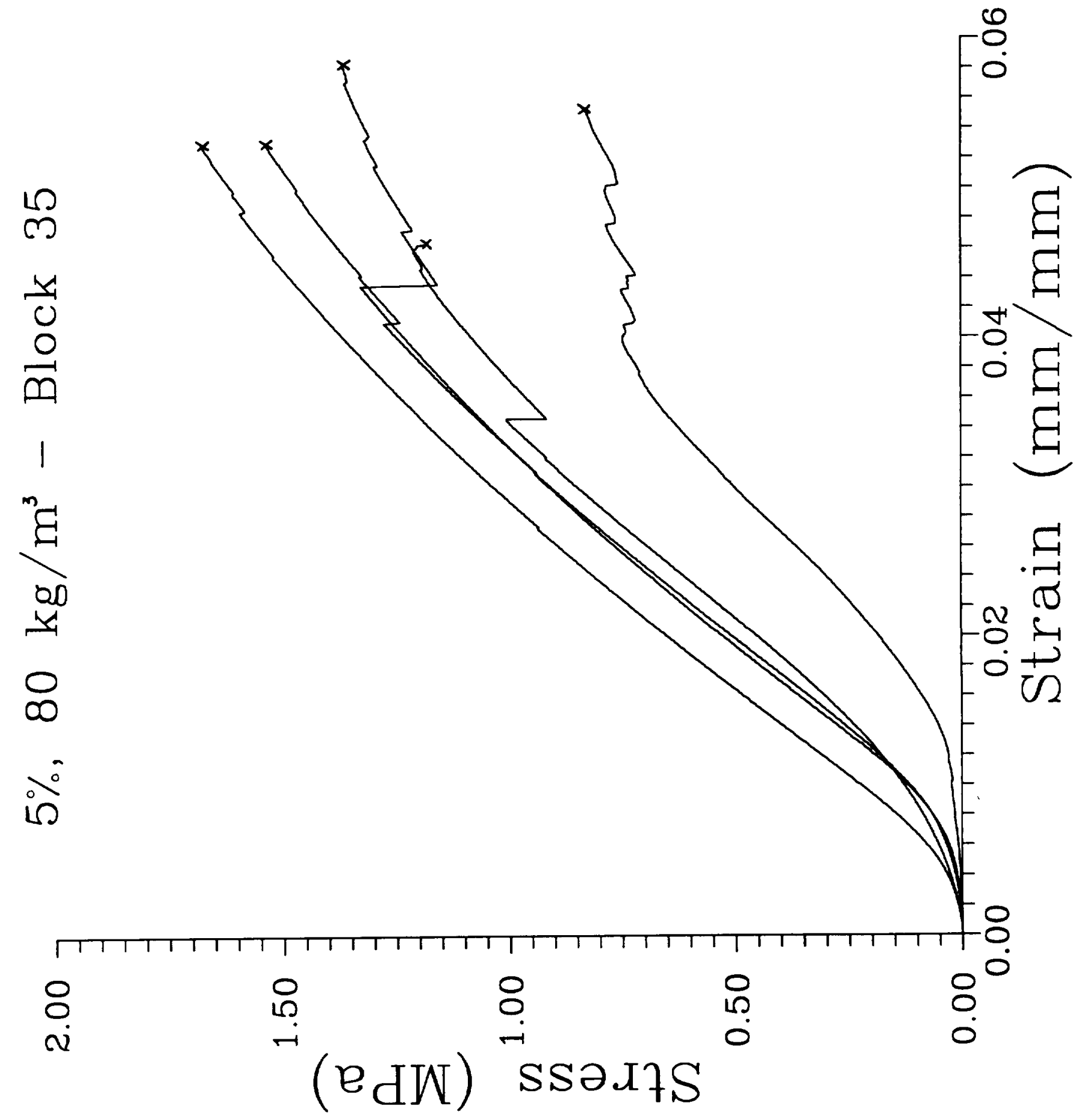

D. 7 


\begin{tabular}{|c|c|c|c|c|}
\hline \multicolumn{5}{|c|}{$\begin{array}{c}\text { Summary of Compression Results } \\
10 \%, 40 \mathrm{~kg} / \mathrm{m}^{\wedge} 3-15 \mathrm{th} \text { block } \\
3 / 31 / 95-\text { Tests in Air } \\
\text { Avg Density }=190 \mathrm{~kg} / \mathrm{m}^{\wedge} 3\end{array}$} \\
\hline Expt.\# & $\begin{array}{l}\text { Compressive } \\
\text { Strength } \\
\text { (MPa) }\end{array}$ & $\begin{array}{l}\text { Compressive Strain } \\
\text { at Fracture } \\
(\mathrm{mm} / \mathrm{mm})\end{array}$ & $\begin{array}{c}E(50 \%) \\
(\mathrm{MPa})\end{array}$ & $\begin{array}{c}E(90 \%) \\
(\mathrm{MPa})\end{array}$ \\
\hline 1 & 0.30 & 0.069 & 6.11 & 5.08 \\
\hline 2 & 0.38 & 0.064 & 10.14 & 7.24 \\
\hline 3 & 0.30 & 0.063 & 7.49 & 5.60 \\
\hline 4 & 0.36 & 0.061 & 9.97 & 7.34 \\
\hline 5 & 0.35 & 0.079 & 8.44 & 6.25 \\
\hline 6 & 0.35 & 0.078 & 6.45 & 5.32 \\
\hline Average & 0.34 & 0.069 & 8.10 & 6.14 \\
\hline Std. Dev. & 0.03 & 0.007 & 1.57 & 0.89 \\
\hline
\end{tabular}

Notes:

1) The crosshead speed was $0.1016 \mathrm{~mm} / \mathrm{min}$

2) $E(50 \%)$ is the secant modulus between the point $A$, of stress $=0.04 \mathrm{MPa}$, and point $B$, of stress $=50 \%$ of the compressive strength

3) $E(90 \%)$ is the secant modulus between the point $A$, of stress $=0.04 \mathrm{MPa}$, and point $C$, of stress $=90 \%$ of the compressive strength

4) The specimens were $10 \%$ fiber loaded, target density $=40 \mathrm{~kg} / \mathrm{m}^{\wedge} 3$

5) Tests were done at room temperature in air, with no prior desiccation 


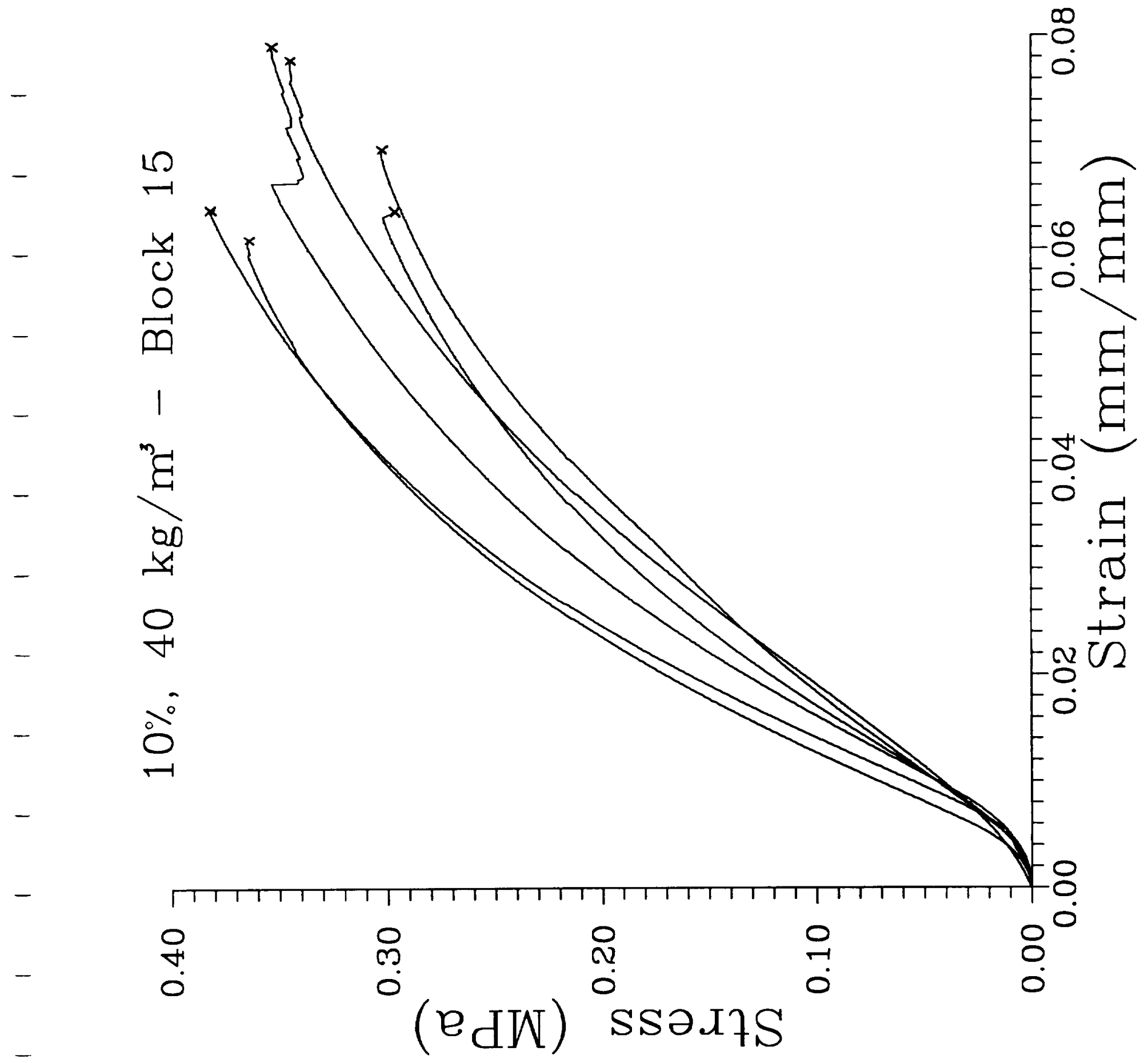

D. 9 


\section{Summary of Compression Results}

$10 \%, 50 \mathrm{~kg} / \mathrm{m}^{\wedge} 3$ - 2nd block

$3 / 14 / 95$ - Tests in Air

Avg Density $=230 \mathrm{~kg} / \mathrm{m}^{\wedge} 3$

\begin{tabular}{ccccc} 
Expt. \# & $\begin{array}{c}\text { Compressive } \\
\text { Strength } \\
\text { (MPa) }\end{array}$ & $\begin{array}{c}\text { Compressive Strain } \\
\text { at Fracture } \\
\text { (mm/mm) }\end{array}$ & $\begin{array}{c}\text { E(50\%) } \\
\text { (MPa) }\end{array}$ & $\begin{array}{c}\text { E(90\%) } \\
\text { (MPa) }\end{array}$ \\
\hline 1 & 1.05 & 0.066 & 24.7 & 18.9 \\
2 & 0.97 & 0.062 & 23.9 & 17.6 \\
3 & 0.99 & 0.069 & 23.5 & 17.7 \\
4 & 1.05 & 0.068 & 24.3 & 18.8 \\
5 & 1.05 & 0.070 & 23.9 & 18.3 \\
6 & 1.07 & 0.070 & 24.5 & 18.7 \\
7 & 1.02 & 0.073 & 23.1 & 16.9 \\
8 & 0.89 & 0.062 & 19.6 & 16.9 \\
9 & 0.97 & 0.064 & 23.3 & 18.1 \\
& & & & \\
Average & $\mathbf{1 . 0 1}$ & $\mathbf{0 . 0 6 7}$ & $\mathbf{2 3 . 4}$ & 18.0 \\
Std. Dev. & $\mathbf{0 . 0 5}$ & $\mathbf{0 . 0 0 4}$ & $\mathbf{1 . 4}$ & $\mathbf{0 . 7}$
\end{tabular}

Notes:

1) The crosshead speed was $0.1016 \mathrm{~mm} / \mathrm{min}$

2) $E(50 \%)$ is the secant modulus between the point $A$, of stress $=0.04 \mathrm{MPa}$, and point $B$, of stress $=50 \%$ of the compressive strength

3) $E(90 \%)$ is the secant modulus between the point $A$, of stress $=0.04 \mathrm{MPa}$, and point $C$, of stress $=90 \%$ of the compressive strength

4) The specimens were $10 \%$ fiber loaded, target density $=50 \mathrm{~kg} / \mathrm{m}^{\wedge} 3$

5) Tests were done at room temperature in air, with no prior desiccation 


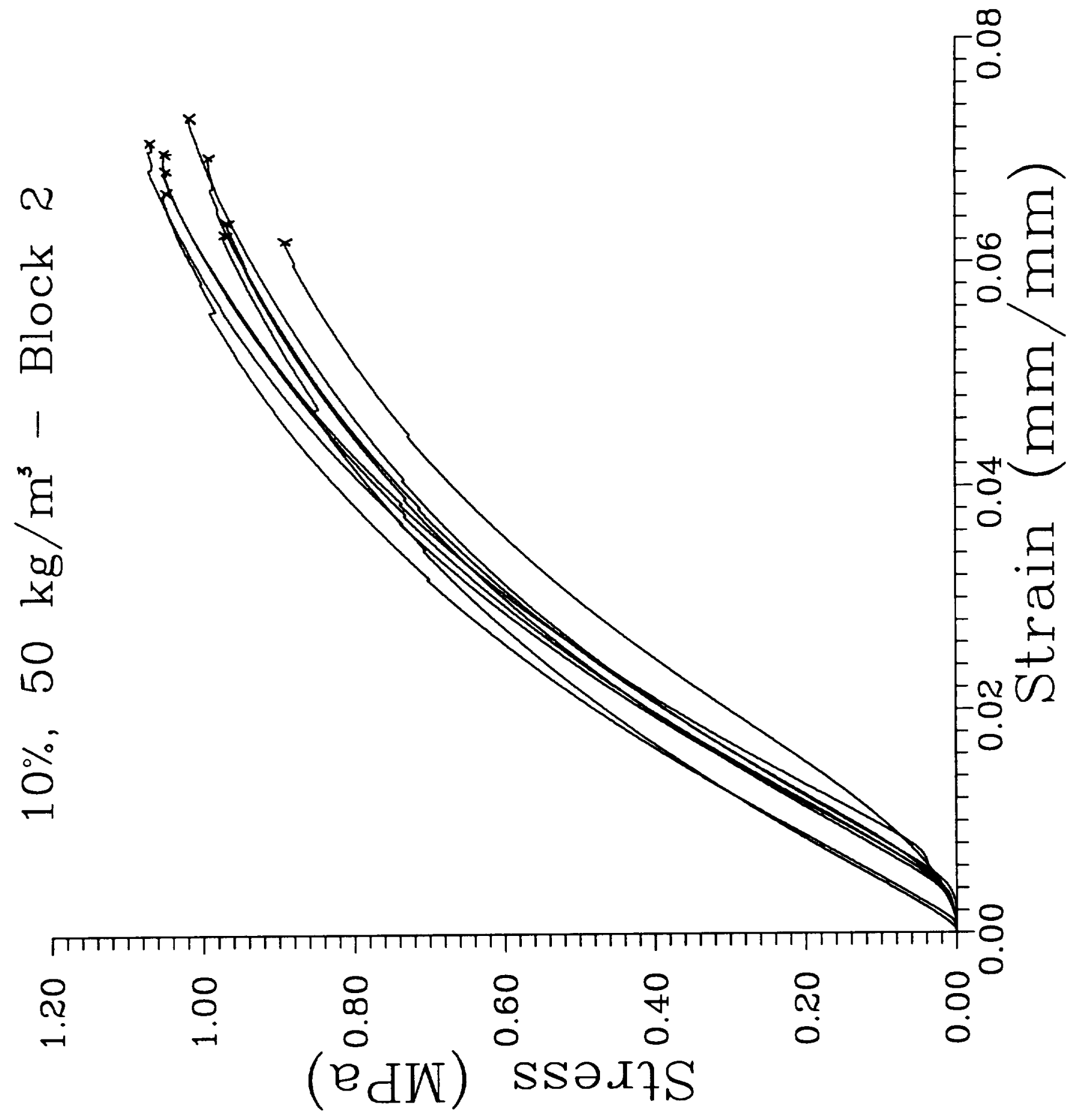

D. 11 


\begin{tabular}{|c|c|c|c|c|}
\hline \multicolumn{5}{|c|}{$\begin{array}{c}\text { Summary of Compression Results } \\
10 \%, 80 \mathrm{~kg} / \mathrm{m}^{\wedge} 3-16 \text { th \& } 17 \text { th block } \\
6 / 1 / 95-6 / 2 / 95-\text { Tests in Air } \\
\text { Avg Density }=330 \mathrm{~kg} / \mathrm{m}^{\wedge} 3\end{array}$} \\
\hline Expt. \# & $\begin{array}{l}\text { Compressive } \\
\text { Strength } \\
\text { (MPa) }\end{array}$ & $\begin{array}{l}\text { Compressive Strain } \\
\text { at Fracture } \\
\text { (mm/mm) }\end{array}$ & $\begin{array}{c}E(50 \%) \\
(\mathrm{MPa})\end{array}$ & $\begin{array}{c}E(90 \%) \\
(\mathrm{MPa})\end{array}$ \\
\hline $16-1$ & 1.05 & 0.051 & 26.5 & 29.1 \\
\hline $16-2$ & 1.18 & 0.057 & 22.9 & 25.9 \\
\hline $16-3$ & 1.23 & 0.054 & 26.3 & 28.7 \\
\hline $16-4$ & 1.19 & 0.051 & 26.3 & 28.9 \\
\hline $16-5$ & 1.52 & 0.052 & 34.8 & 37.8 \\
\hline $16 \cdot 6$ & 1.48 & 0.050 & 35.2 & 34.6 \\
\hline $16-7$ & 1.31 & 0.057 & 29.7 & 31.0 \\
\hline $16-8$ & 1.10 & 0.049 & 26.1 & 29.3 \\
\hline $16-9$ & 1.24 & 0.050 & 30.6 & 31.4 \\
\hline $17-1$ & 1.30 & 0.048 & 31.8 & 33.6 \\
\hline $17-2$ & 1.49 & 0.053 & 34.8 & 34.0 \\
\hline $17-3$ & 1.29 & 0.046 & 38.4 & 35.6 \\
\hline $17-4$ & 1.14 & 0.049 & 26.3 & 28.3 \\
\hline $17-5$ & 1.24 & 0.048 & 34.0 & 34.8 \\
\hline $17-6$ & 1.33 & 0.049 & 32.8 & 33.4 \\
\hline Average & 1.27 & 0.051 & 30.4 & 31.8 \\
\hline Std. Dev. & 0.14 & 0.003 & 4.4 & 3.2 \\
\hline
\end{tabular}

Notes:

1) The crosshead speed was $0.1016 \mathrm{~mm} / \mathrm{min}$

2) $E(50 \%)$ is the secant modulus between the point $A$, of stress $=0.04 \mathrm{MPa}$, and point $B$, of stress $=50 \%$ of the compressive strength

3) $E(90 \%)$ is the secant modulus between the point $A$, of stress $=0.04 \mathrm{MPa}$, and point $C$, of stress $=90 \%$ of the compressive strength

4) The specimens were $10 \%$ fiber loaded, target density $=80 \mathrm{~kg} / \mathrm{m}^{\wedge} 3$

5) Tests were done at room temperature in air, with no prior desiccation 


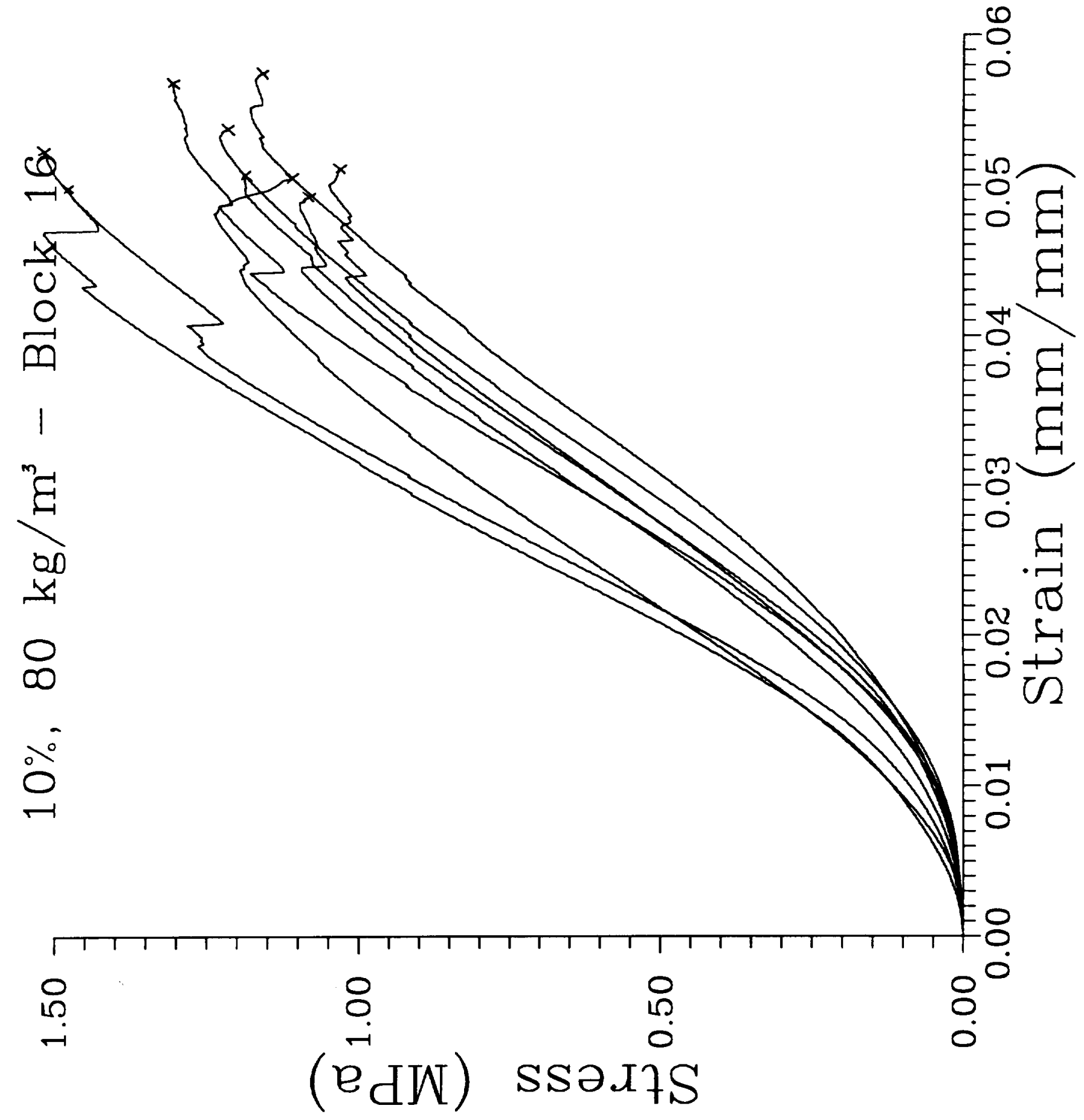

D. 13 


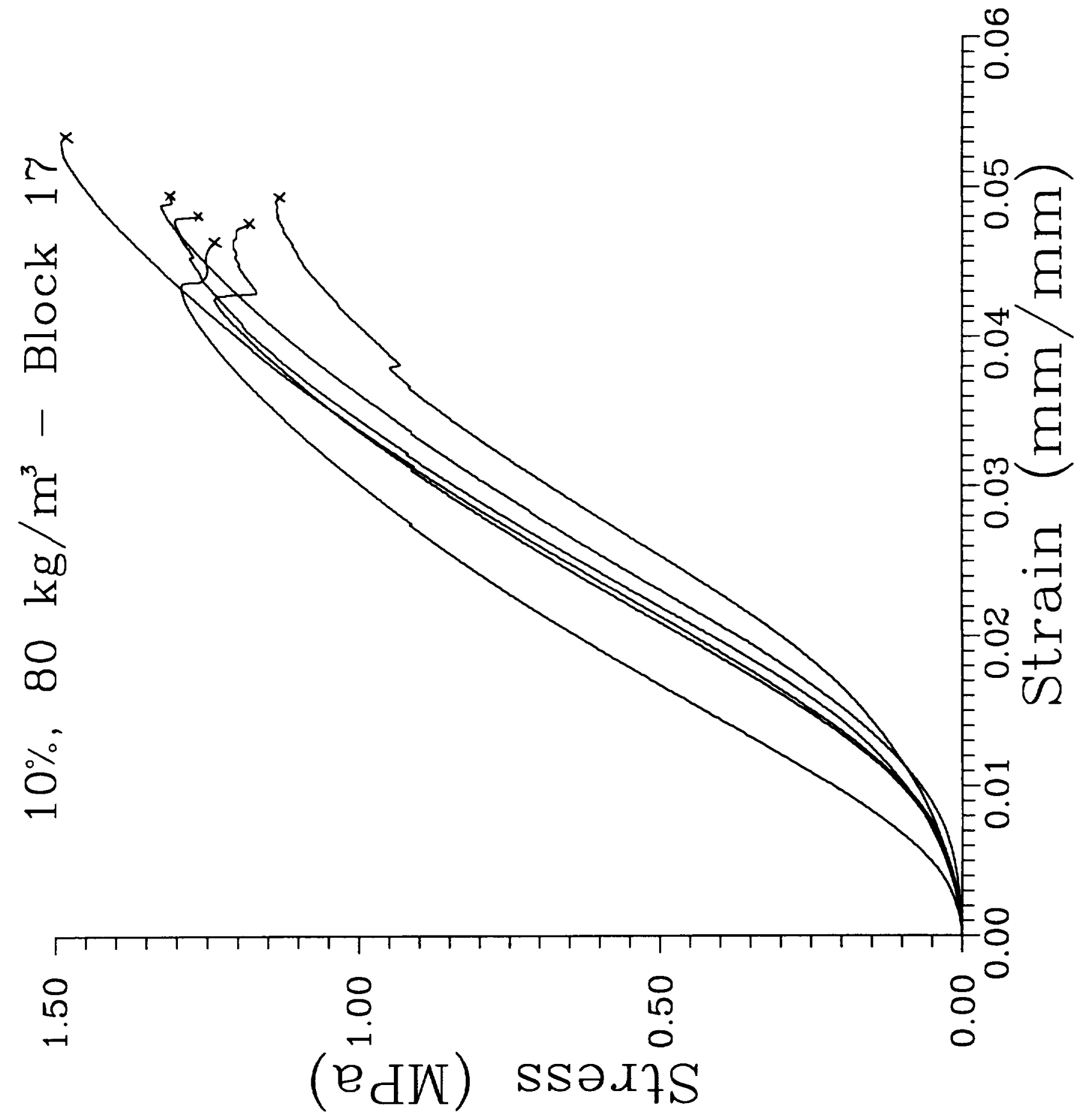

D. 14 


\section{Summary of Compression Results}

$25 \%, 40 \mathrm{~kg} / \mathrm{m}^{\wedge} 3 \cdot 5 \mathrm{th}, 6$ th \& 7 th block

$5 / 23 / 95-5 / 31 / 95 \cdot$ Tests in Air

Avg Density $=190 \mathrm{~kg} / \mathrm{m}^{\wedge} 3$

\begin{tabular}{ccccc} 
Expt. \# & $\begin{array}{c}\text { Compressive } \\
\text { Strength } \\
\text { (MPa) }\end{array}$ & $\begin{array}{c}\text { Compressive Strain } \\
\text { at Fracture } \\
\text { (mm/mm) }\end{array}$ & $\begin{array}{c}\text { E(50\%) } \\
\text { (MPa) }\end{array}$ & $\begin{array}{c}\text { E(90\%) } \\
\text { (MPs) }\end{array}$ \\
\hline $7-1$ & 0.59 & 0.154 & 8.4 & 5.0 \\
$7-2$ & 0.57 & 0.151 & 9.3 & 5.5 \\
$7-3$ & 0.57 & 0.134 & 9.2 & 5.6 \\
$7-4$ & 0.55 & 0.146 & 7.3 & 5.3 \\
$7-5$ & 0.50 & 0.106 & 9.6 & 6.4 \\
$6-1$ & 0.49 & 0.134 & 9.1 & 5.5 \\
$6-2$ & 0.57 & 0.164 & 8.4 & 4.7 \\
$6-3$ & 0.56 & 0.156 & 9.0 & 4.9 \\
$6-4$ & 0.49 & 0.125 & 9.4 & 6.0 \\
$6-5$ & 0.54 & 0.135 & 9.2 & 5.3 \\
$5-1$ & 0.58 & 0.156 & 8.0 & 4.6 \\
$5-2$ & 0.54 & 0.149 & 7.3 & 4.8 \\
$5-3$ & 0.58 & 0.155 & 7.7 & 4.7 \\
$5-4$ & 0.53 & 0.120 & 8.9 & 5.7 \\
$5-5$ & 0.54 & 0.148 & 8.6 & 5.2 \\
$5-6$ & 0.56 & 0.139 & 8.5 & 5.0 \\
& & & & \\
Average & 0.55 & 0.142 & 8.6 & 5.3 \\
Std. Dev. & 0.03 & 0.015 & 0.7 & 0.5
\end{tabular}

Notes:

1) The crosshead speed was $0.1016 \mathrm{~mm} / \mathrm{min}$

2) $E(50 \%)$ is the secant modulus between the point $A$, of stress $=0.04 \mathrm{MPa}$, and point $B$, of stress $=50 \%$ of the compressive strength

3) $E(90 \%)$ is the secant modulus between the point $A$, of stress $=0.04 \mathrm{MPa}$, and point $C$, of stress $=90 \%$ of the compressive strength

4) The specimens were $25 \%$ fiber loaded, target density $=40 \mathrm{~kg} / \mathrm{m}^{\wedge} 3$

5) Tests were done at room temperature in air, with no prior desiccation 


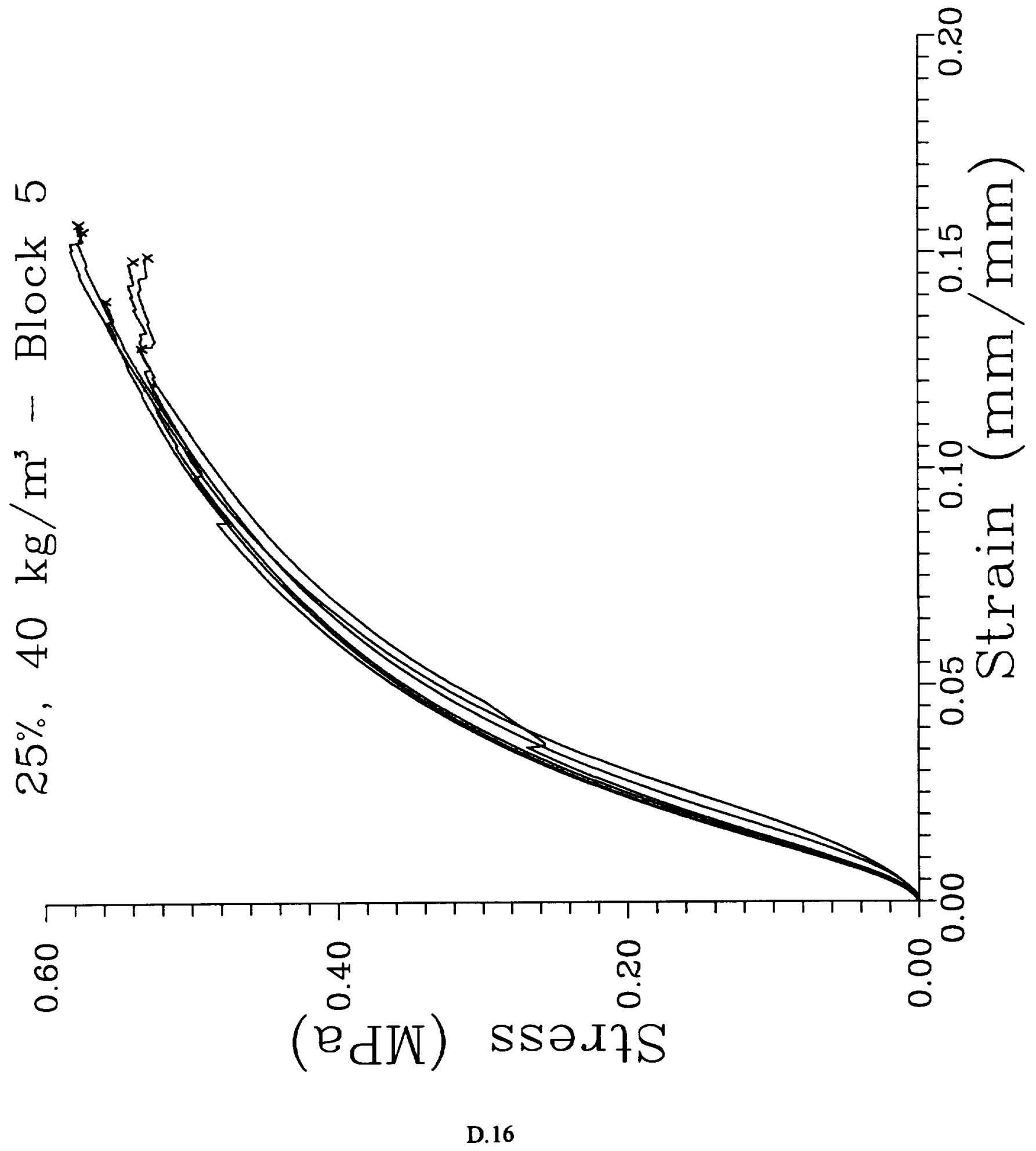




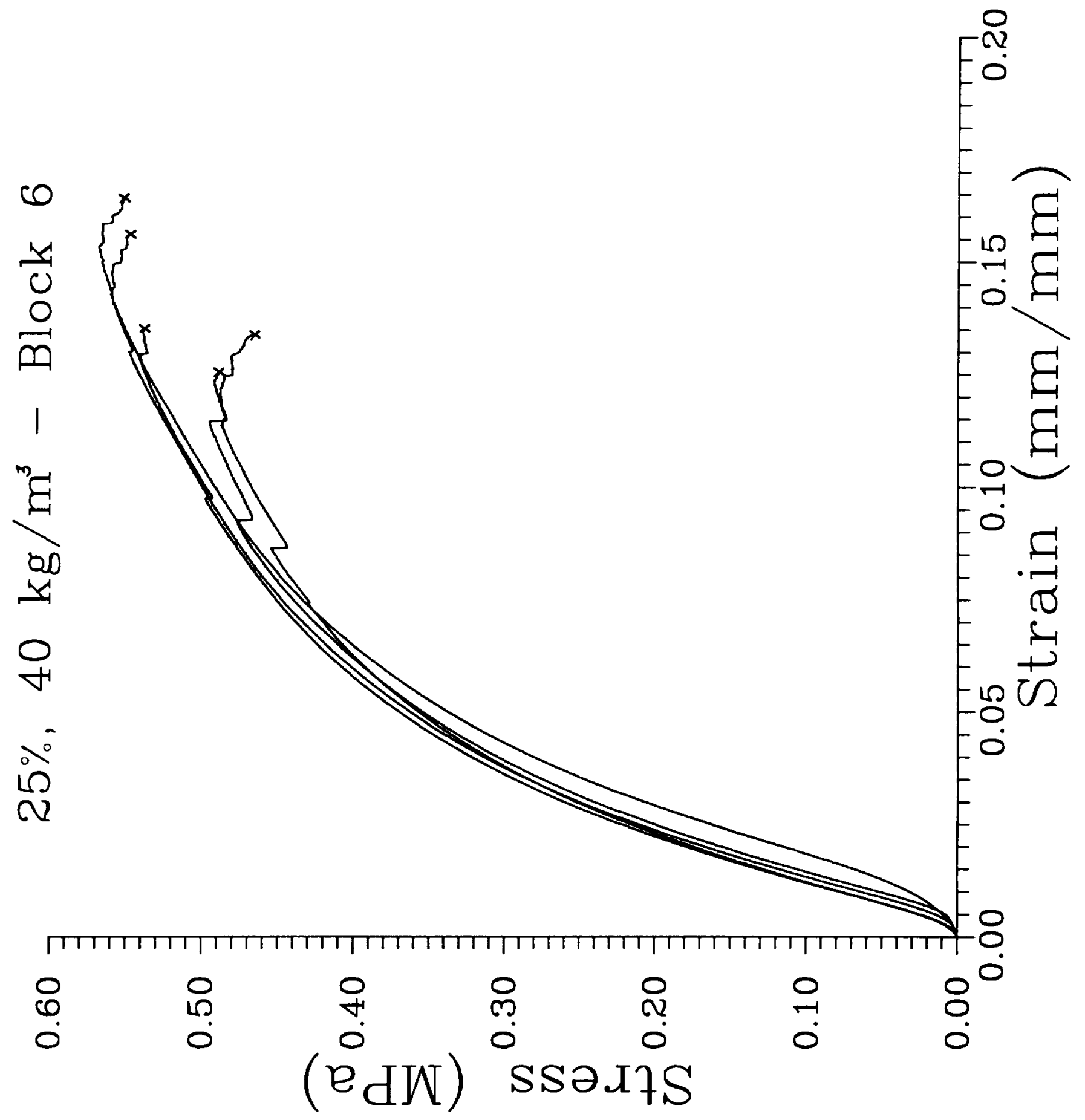

D. 17 


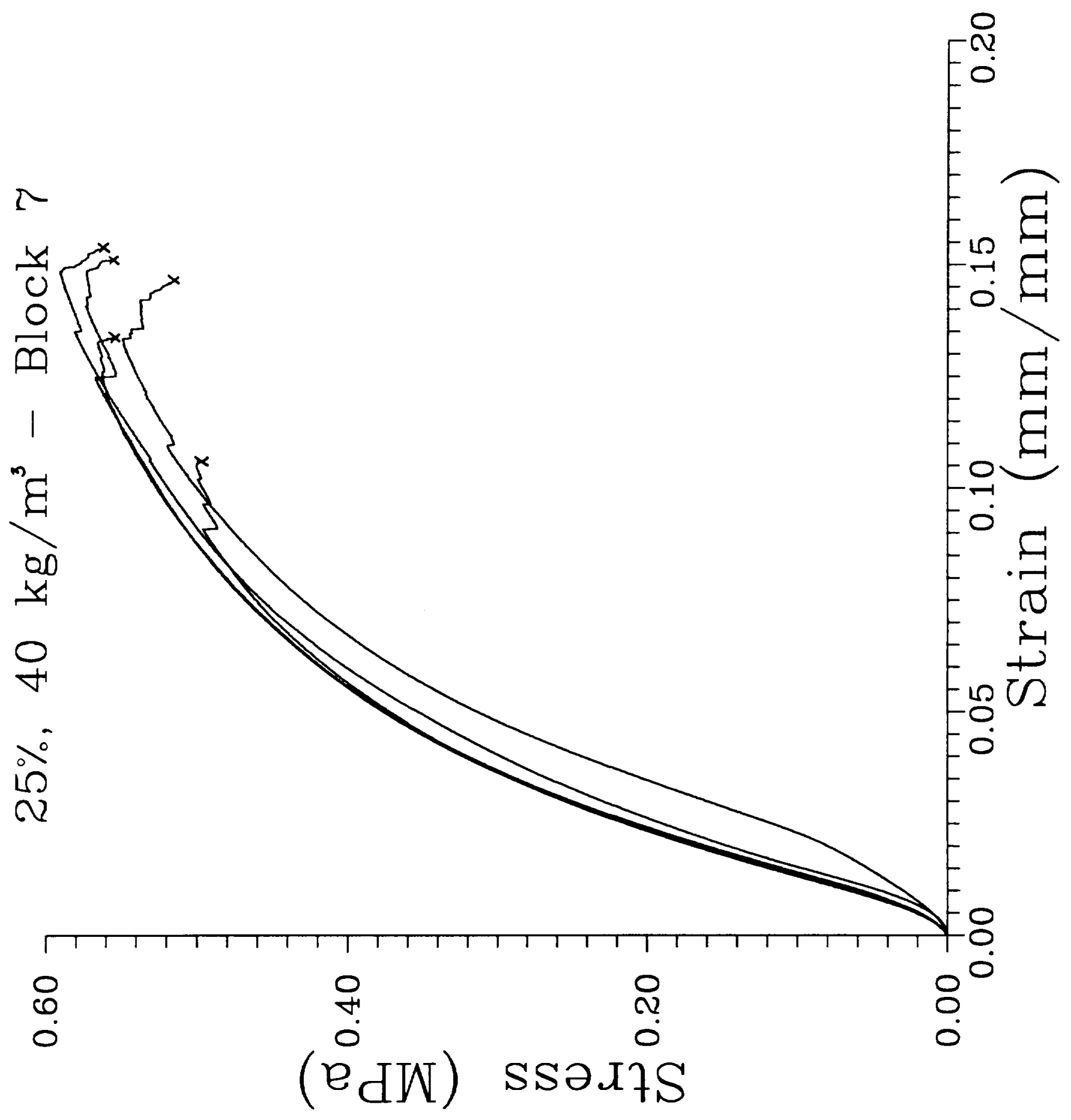

D. 18 


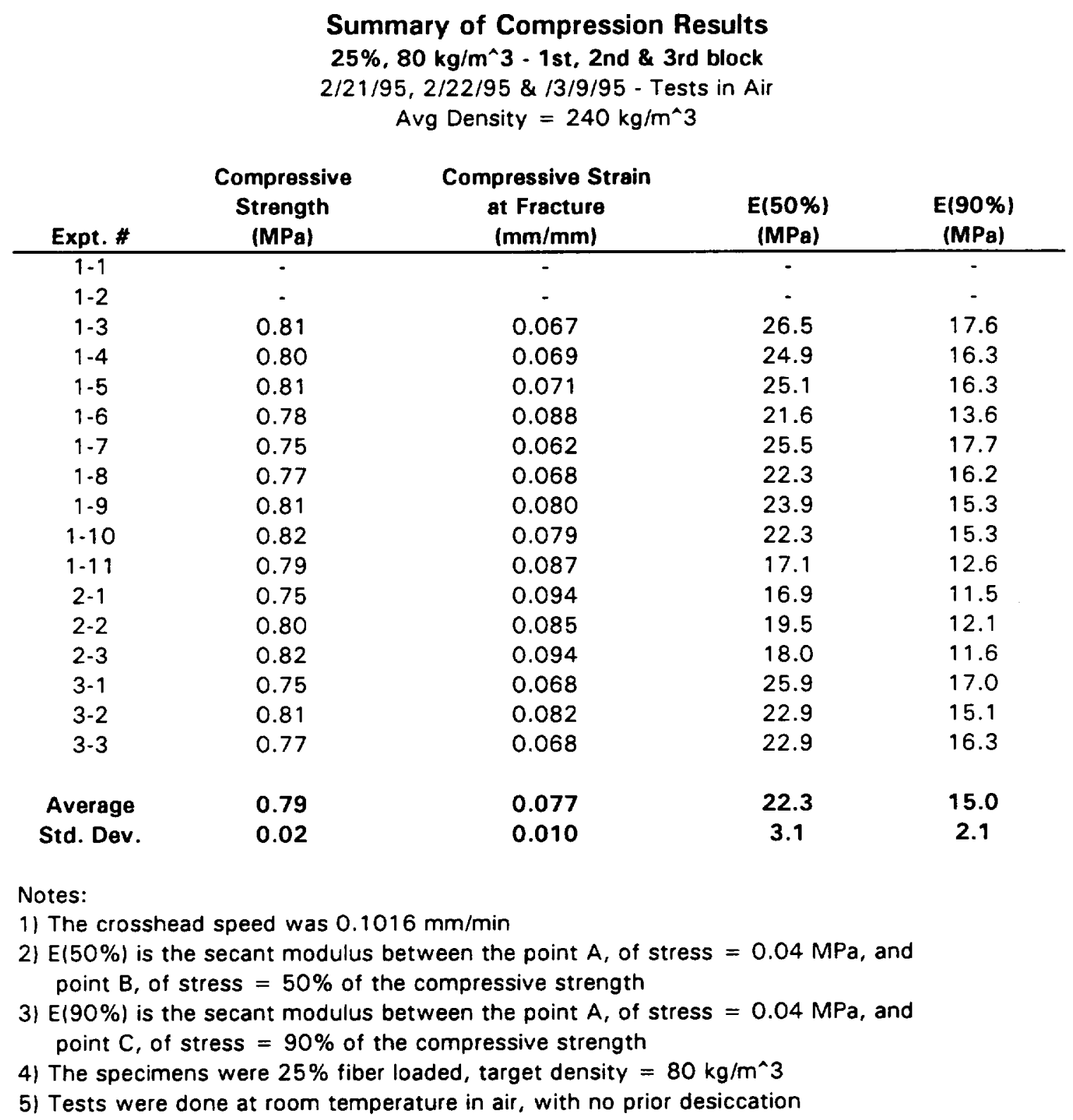

D. 19 


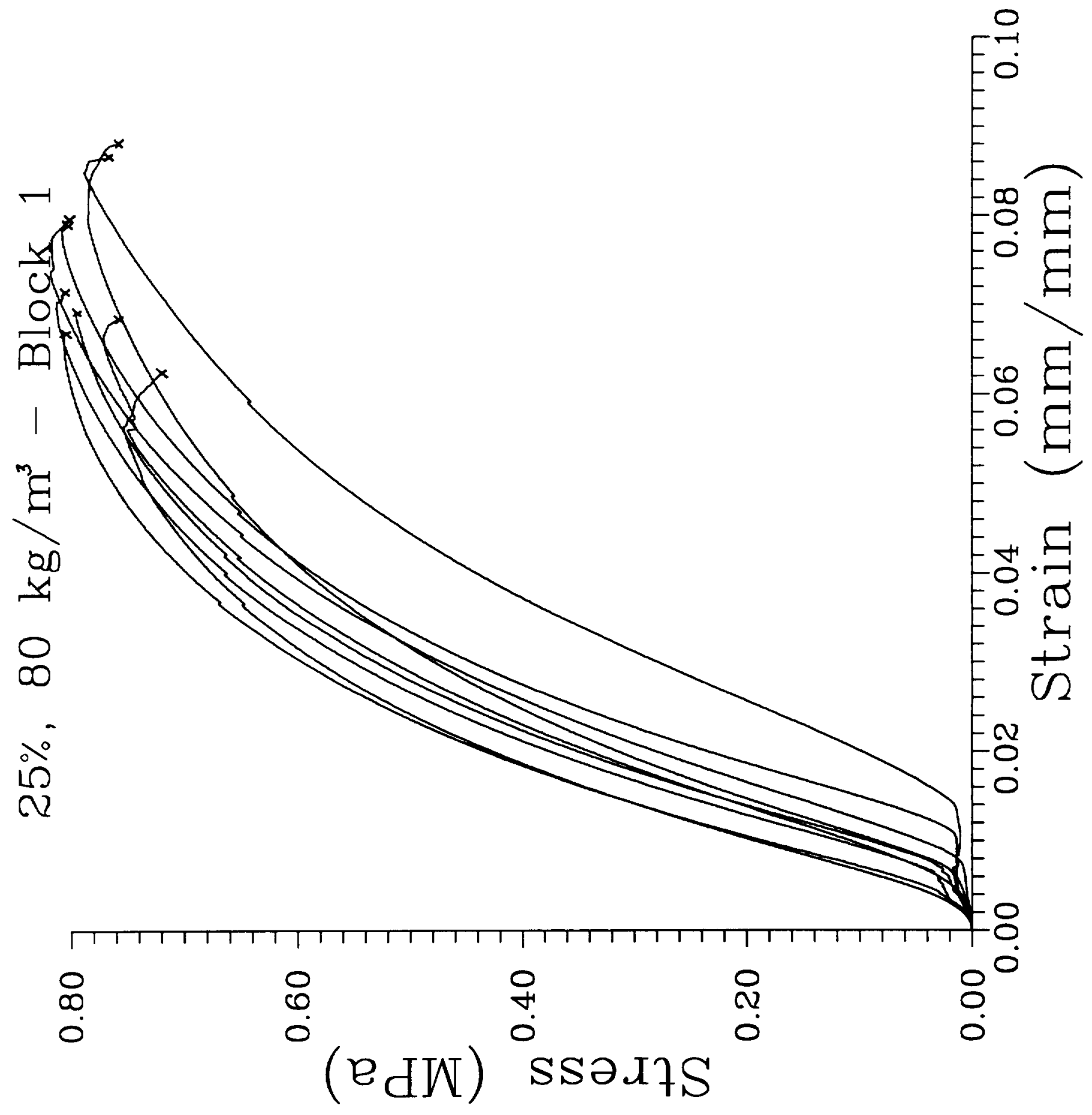

D. 20 


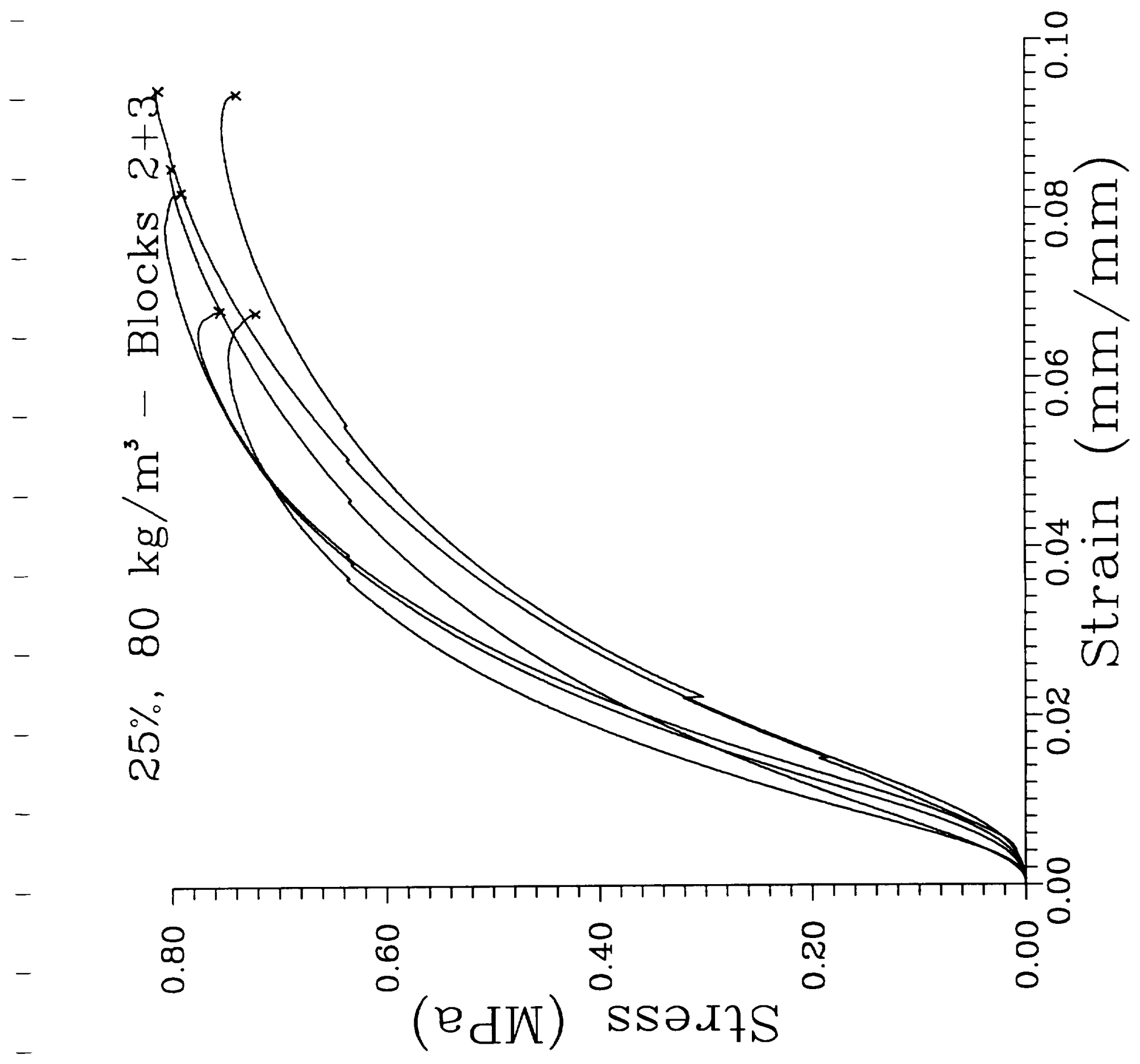




\section{APPENDDX E}

Compression Results: Tests in Ethanol 


\begin{tabular}{|c|c|c|c|c|}
\hline \multirow[b]{2}{*}{ Expt. \# } & \multicolumn{3}{|c|}{$\begin{array}{c}\text { Summary of Compression Results } \\
10 \%, 50 \mathrm{~kg} / \mathrm{m}^{\wedge} 3-1 \mathrm{st} \text { block } \\
5 / 3 / 95-\text { Tests in Ethanol } \\
\text { Avg Density }=250 \mathrm{~kg} / \mathrm{m}^{\wedge} 3\end{array}$} & \multirow[b]{2}{*}{$\begin{array}{c}E(90 \%) \\
(\mathrm{MPa})\end{array}$} \\
\hline & $\begin{array}{l}\text { Compressive } \\
\text { Strength } \\
\text { (MPa) }\end{array}$ & $\begin{array}{c}\text { Compressive Strain } \\
\text { at Fracture } \\
(\mathbf{m m} / \mathbf{m m})\end{array}$ & $\begin{array}{c}E(50 \%) \\
(\mathrm{MPa})\end{array}$ & \\
\hline 1 & 0.85 & 0.028 & - & - \\
\hline 2 & 0.33 & 0.048 & 14.0 & 11.2 \\
\hline 3 & 0.63 & 0.029 & 26.9 & 25.1 \\
\hline Average & 0.61 & 0.035 & 20.5 & 18.1 \\
\hline Std. Dev. & 0.21 & 0.009 & 6.4 & 6.9 \\
\hline
\end{tabular}

Notes:

1) The crosshead speed was $0.1016 \mathrm{~mm} / \mathrm{min}$

2) $E(50 \%)$ is the secant modulus between the point $A$, of stress $=0.04 \mathrm{MPa}$, and point $B$, of stress $=50 \%$ of the compressive strength

3) $E(90 \%)$ is the secant modulus between the point $A$, of stress $=0.04 \mathrm{MPa}$, and point $C$, of stress $=90 \%$ of the compressive strength

4) The specimens were $10 \%$ fiber loaded, target density $=50 \mathrm{~kg} / \mathrm{m}^{\wedge} 3$

5) Tests were done at room temperature in ethanol, with no prior desiccation 


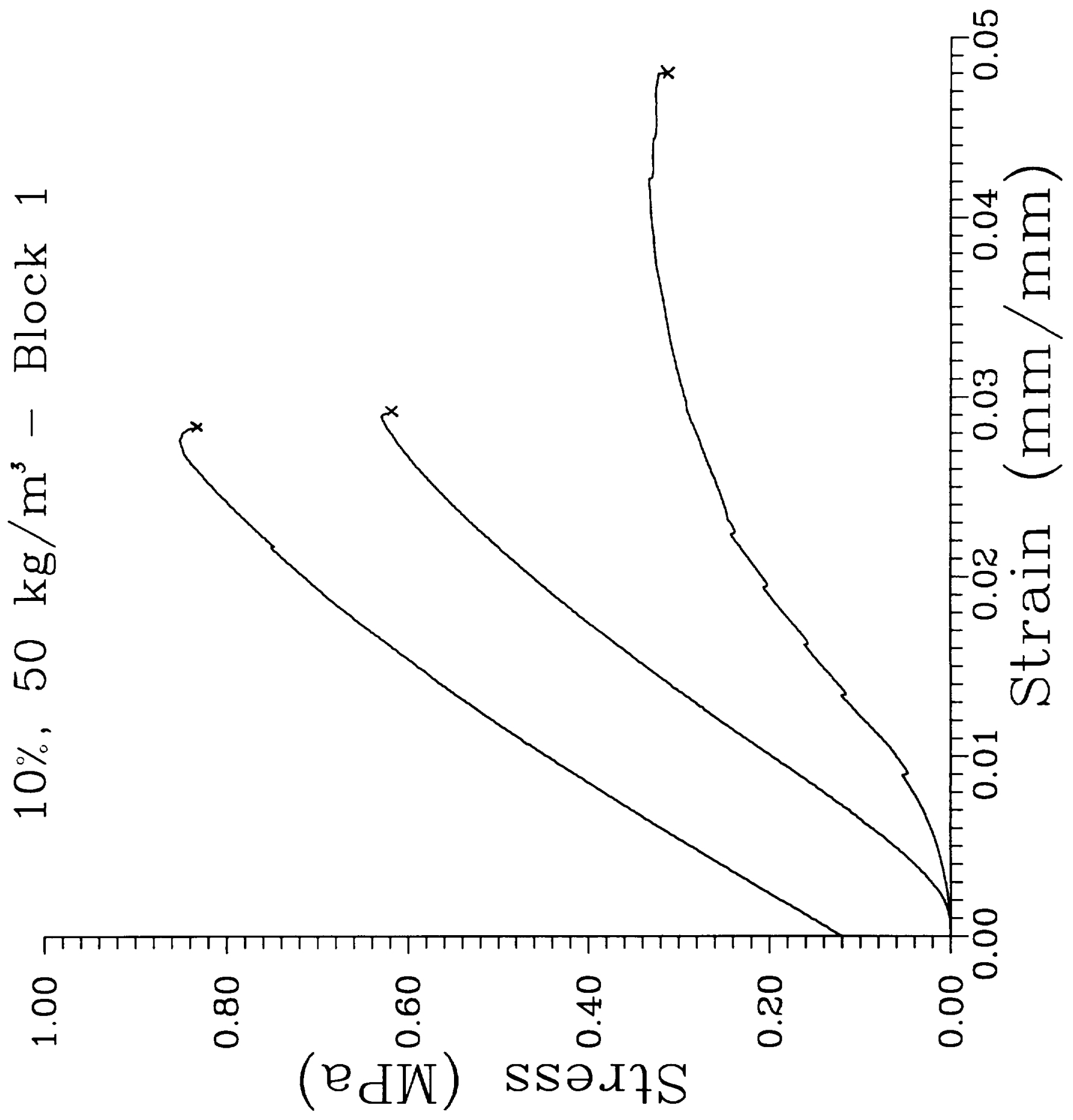




\begin{tabular}{ccccc}
\multicolumn{5}{c}{$\begin{array}{c}\text { Summary of Compression Results } \\
25 \%, 80 \mathrm{~kg} / \mathrm{m}^{\wedge} \text { 3 }- \text { 2nd block } \\
5 / 3 / 95-\text { Tests in Ethanol } \\
\text { Avg Density }=250 \mathrm{~kg} / \mathrm{m}^{\wedge} 3\end{array}$} \\
Expt. \# & $\begin{array}{c}\text { Compressive } \\
\text { Strength } \\
\text { (MPa) }\end{array}$ & $\begin{array}{c}\text { Compressive Strain } \\
\text { at Fracture } \\
\text { (mm/mm) }\end{array}$ & $\begin{array}{c}\text { E(50\%) } \\
\text { (MPa) }\end{array}$ & $\begin{array}{c}\text { E(90\%) } \\
\text { (MPa) }\end{array}$ \\
\hline 1 & 0.74 & 0.044 & 32.8 & 27.1 \\
2 & 0.55 & 0.053 & 20.6 & 18.7 \\
3 & 0.73 & 0.043 & 24.1 & 21.9 \\
4 & 0.60 & 0.052 & 19.8 & 15.9 \\
Average & 0.65 & 0.048 & 24.3 & 20.9 \\
Std. Dev. & 0.08 & 0.005 & 5.1 & 4.1
\end{tabular}

Notes:

1) The crosshead speed was $0.1016 \mathrm{~mm} / \mathrm{min}$

2) $E(50 \%)$ is the secant modulus between the point $A$, of stress $=0.04 \mathrm{MPa}$, and point $B$, of stress $=50 \%$ of the compressive strength

3) $E(90 \%)$ is the secant modulus between the point $A$, of stress $=0.04 \mathrm{MPa}$, and point $C$, of stress $=90 \%$ of the compressive strength

4) The specimens were $25 \%$ fiber loaded, target density $=80 \mathrm{~kg} / \mathrm{m}^{\wedge} 3$

5) Tests were done at room temperature in ethanol, with no prior desiccation 


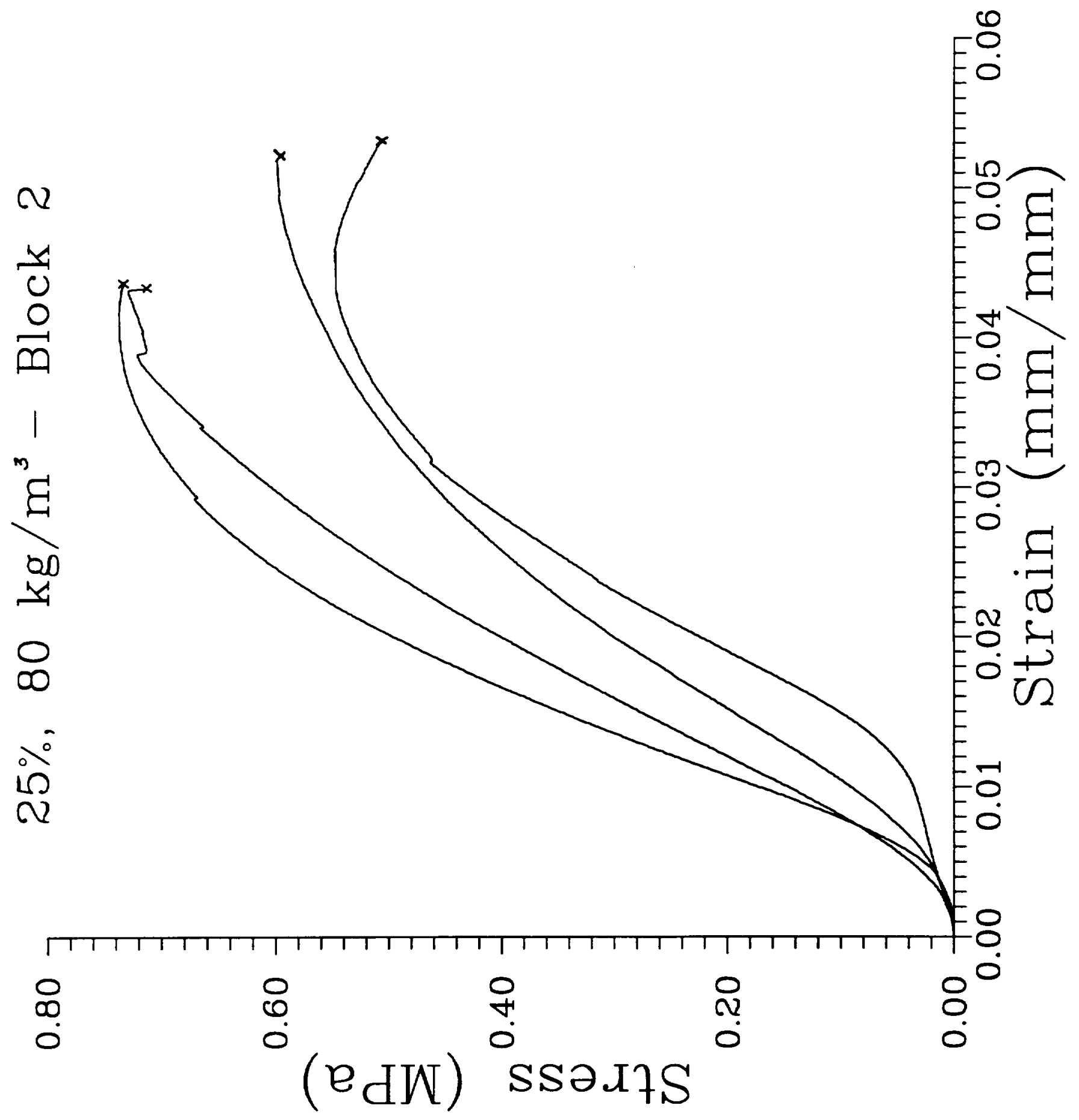




\section{APPENDIX $F$}

Compression Results: Specimens Aged in Air 


\section{Summary of Compression Results \\ $10 \%, 50 \mathrm{~kg} / \mathrm{m}^{\wedge} 3$ - 1 st block \\ $5 / 4 / 95$ - Tests in Air \\ Avg Density $=250 \mathrm{~kg} / \mathrm{m}^{\wedge} 3$}

\begin{tabular}{ccccc} 
Expt. \# & $\begin{array}{c}\text { Compressive } \\
\text { Strength } \\
(\mathbf{M P a})\end{array}$ & $\begin{array}{c}\text { Compressive Strain } \\
\text { at Fracture } \\
(\mathbf{m m} / \mathbf{m m})\end{array}$ & $\begin{array}{c}\text { E(50\%) } \\
(\mathbf{M P a})\end{array}$ & $\begin{array}{c}\text { E(90\%) } \\
(\mathbf{M P a})\end{array}$ \\
\hline 1 & 1.02 & 0.043 & 34.0 & 28.5 \\
2 & 1.12 & 0.047 & 34.4 & 28.3 \\
Average & 1.07 & 0.045 & 34.2 & 28.4 \\
Std. Dev. & 0.05 & 0.002 & 0.2 & 0.1
\end{tabular}

Notes:

1) The crosshead speed was $0.1016 \mathrm{~mm} / \mathrm{min}$

2) $E(50 \%)$ is the secant modulus between the point $A$, of stress $=0.04 \mathrm{MPa}$, and point $B$, of stress $=50 \%$ of the compressive strength

3) $E(90 \%)$ is the secant modulus between the point $A$, of stress $=0.04 \mathrm{MPa}$, and point $C$, of stress $=90 \%$ of the compressive strength

4) The specimens were $10 \%$ fiber loaded, target density $=50 \mathrm{~kg} / \mathrm{m}^{\wedge} 3$

5) Tests were done at room temperature in air, with no prior desiccation

6) The specimens were aged for 2 months 


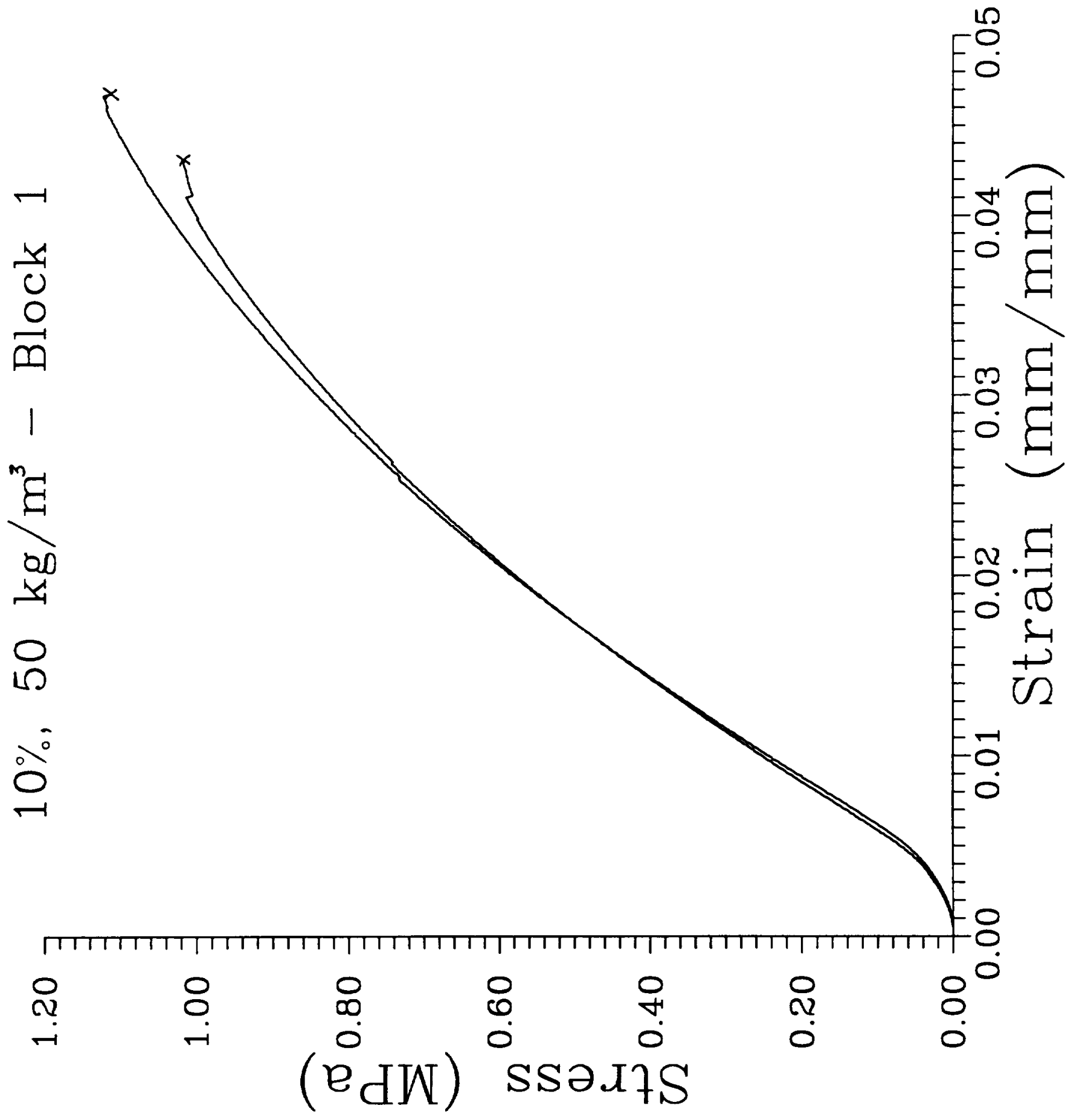




\begin{tabular}{|c|c|c|c|c|}
\hline \multicolumn{5}{|c|}{$\begin{array}{c}\text { Summary of Compression Results } \\
25 \%, 80 \mathrm{~kg} / \mathrm{m}^{\wedge} 3-2 \mathrm{nd} \& \text { 3rd blocks } \\
5 / 4 / 95-\text { Tests in Air } \\
\text { Avg Density }=250 \mathrm{~kg} / \mathrm{m}^{\wedge} 3\end{array}$} \\
\hline Expt. \# & $\begin{array}{l}\text { Compressive } \\
\text { Strength } \\
\text { (MPo) }\end{array}$ & $\begin{array}{l}\text { Compressive Strain } \\
\text { at Fracture } \\
(\mathbf{m m} / \mathbf{m m})\end{array}$ & $\begin{array}{c}E(50 \%) \\
(\mathrm{MPa})\end{array}$ & $\begin{array}{c}E(90 \%) \\
(\mathrm{MPa})\end{array}$ \\
\hline $2-1$ & 0.84 & 0.051 & 31.0 & 23.3 \\
\hline $2-2$ & 0.74 & 0.052 & 32.4 & 25.9 \\
\hline $2-3$ & 0.75 & 0.051 & 25.5 & 22.5 \\
\hline $3-1$ & 0.82 & 0.047 & 36.4 & 28.9 \\
\hline $3-2$ & 0.85 & 0.048 & 27.9 & 26.3 \\
\hline $3-3$ & 0.65 & 0.039 & 22.3 & 19.9 \\
\hline Average & 0.77 & 0.048 & 29.2 & 24.5 \\
\hline Std. Dev. & 0.07 & 0.004 & 4.6 & 2.9 \\
\hline
\end{tabular}

Notes:

1) The crosshead speed was $0.1016 \mathrm{~mm} / \mathrm{min}$

2) $E(50 \%)$ is the secant modulus between the point $A$, of stress $=0.04 \mathrm{MPa}$, and point $B$, of stress $=50 \%$ of the compressive strength

3) $E(90 \%)$ is the secant modulus between the point $A$, of stress $=0.04 \mathrm{MPa}$, and point $C$, of stress $=90 \%$ of the compressive strength

4) The specimens were $25 \%$ fiber loaded, target density $=80 \mathrm{~kg} / \mathrm{m}^{\wedge} 3$

5) Tests were done at room temperature in air, with no prior desiccation

6) The specimens were aged for 2 months 


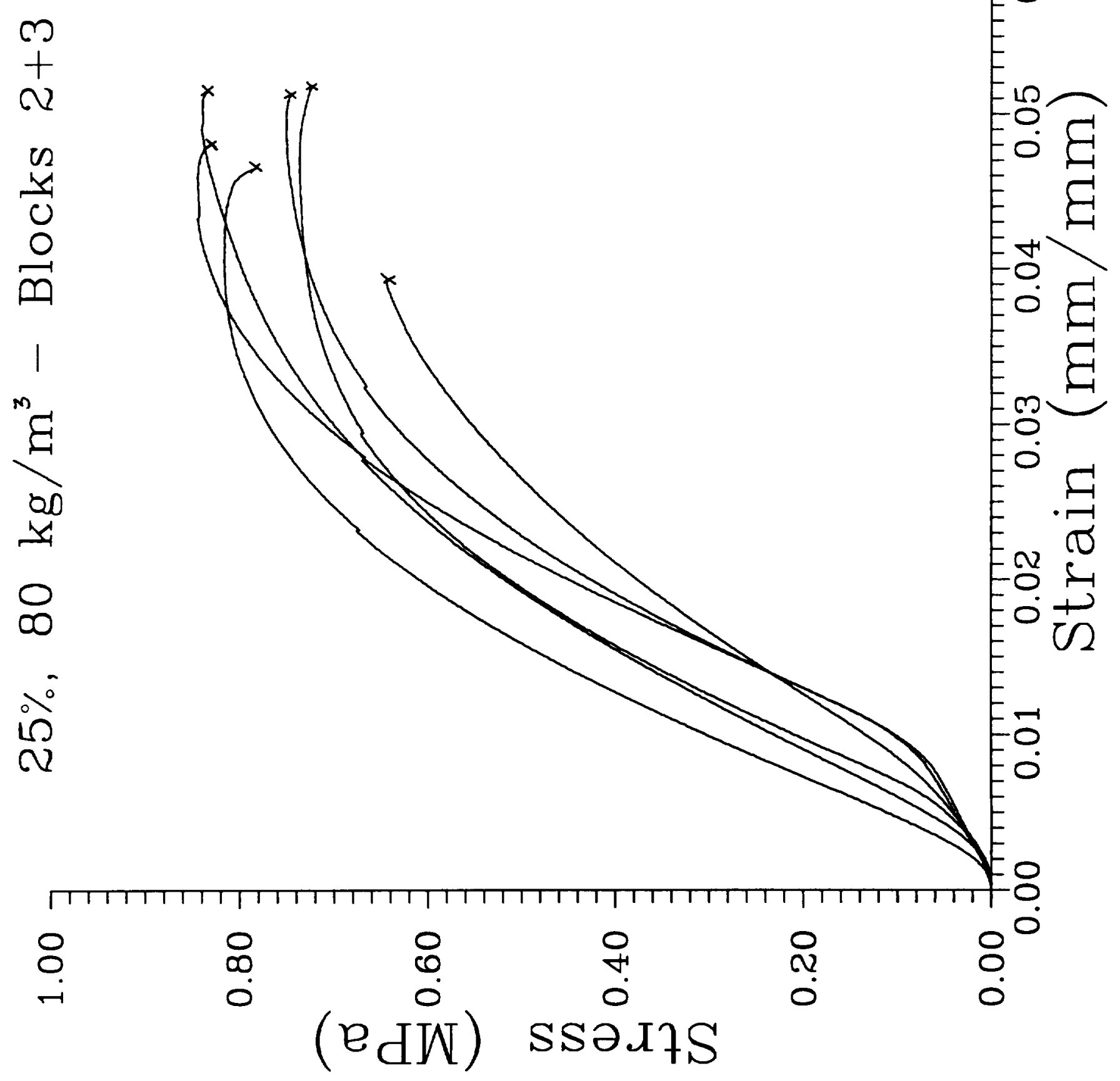




\section{APPENDIX G}

Compression Results: Specimens Aged in Air and Desiccated 


\begin{tabular}{|c|c|c|c|c|}
\hline \multirow[b]{2}{*}{ Expt. \# } & \multicolumn{3}{|c|}{$\begin{array}{l}\text { Summary of Compression Results } \\
25 \%, 80 \mathrm{~kg} / \mathrm{m}^{\wedge} 3-3 \text { rd block } \\
2 / 95 \text { - Tests in Air after Desiccation for } 10 \text { days } \\
\text { Avg Density }=240 \mathrm{~kg} / \mathrm{m}^{\wedge} 3\end{array}$} & \multirow[b]{2}{*}{$\begin{array}{c}E(90 \%) \\
(\mathrm{MPa})\end{array}$} \\
\hline & $\begin{array}{c}\text { Compressive } \\
\text { Strength } \\
\text { (MPa) }\end{array}$ & $\begin{array}{l}\text { Compressive Strain } \\
\text { at Fracture } \\
\text { (mm/mm) }\end{array}$ & $\begin{array}{c}E(50 \%) \\
(\mathrm{MPa})\end{array}$ & \\
\hline 1 & 0.87 & 0.040 & 31.6 & 28.7 \\
\hline 2 & 0.98 & 0.051 & 33.4 & 26.1 \\
\hline 3 & 0.86 & 0.049 & 27.9 & 24.9 \\
\hline 4 & 0.89 & 0.047 & 29.5 & 27.7 \\
\hline Average & 0.90 & 0.047 & 30.6 & 26.9 \\
\hline Std. Dev. & 0.05 & 0.004 & 2.1 & 1.5 \\
\hline
\end{tabular}

Notes:

1) The crosshead speed was $0.1016 \mathrm{~mm} / \mathrm{min}$

2) $E(50 \%)$ is the secant modulus between the point $A$, of stress $=0.04 \mathrm{MPa}$, and point $B$, of stress $=50 \%$ of the compressive strength

3) $E(90 \%)$ is the secant modulus between the point $A$, of stress $=0.04 \mathrm{MPa}$, and point $C$, of stress $=90 \%$ of the compressive strength

4) The specimens were $25 \%$ fiber loaded, target density $=80 \mathrm{~kg} / \mathrm{m}^{\wedge} 3$

5) Tests were done at room temperature in air, with 10 days of desiccation 


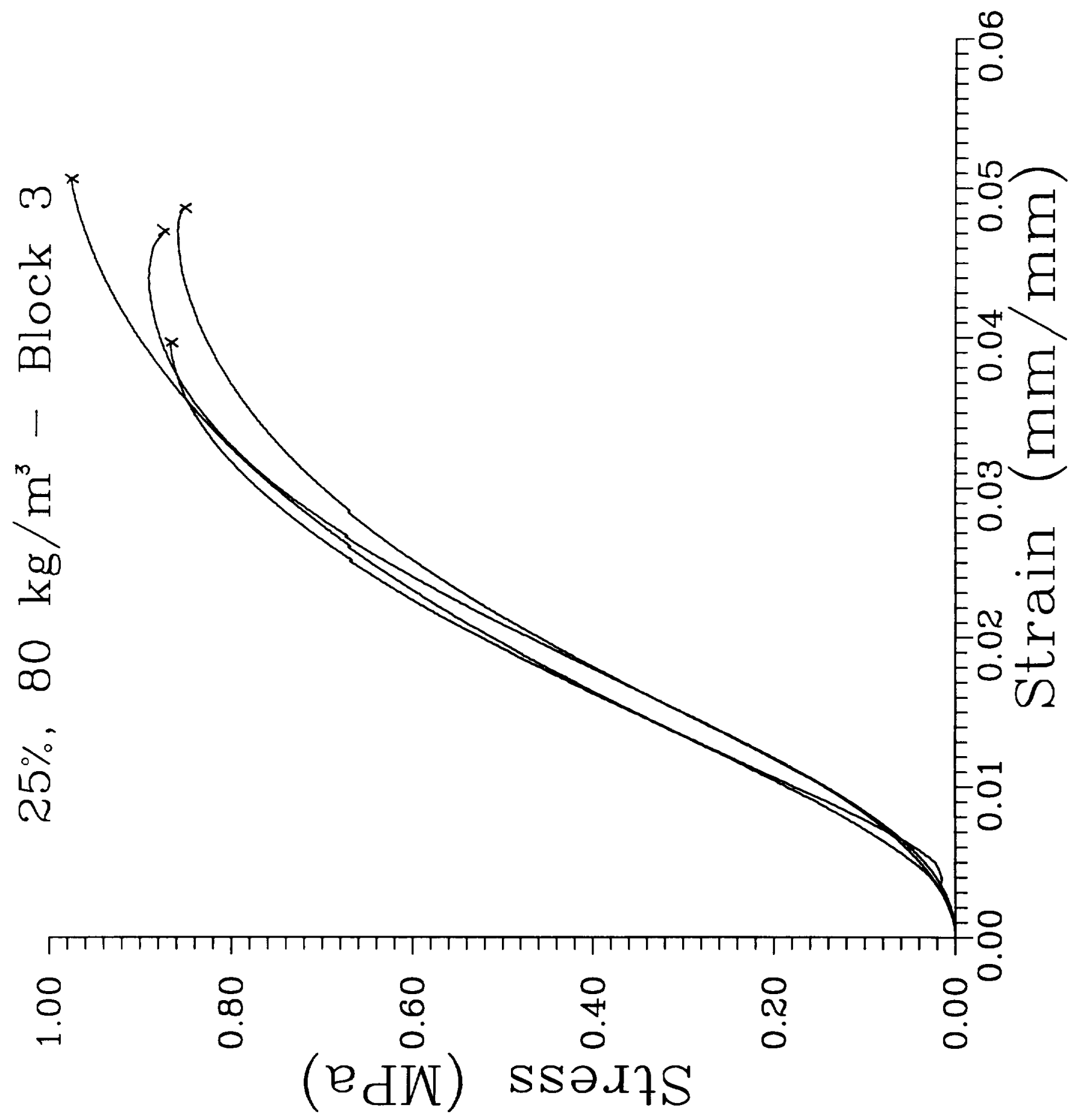

G.3 
-

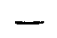

-

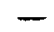

-

-

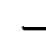

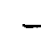

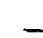

-

$-$

-

$-$

$-$

$-$

$-$ 